Prepared for the U.S. Department of Energy under Contract DE-AC05-76RL01830

\title{
Instrumentation for Monitoring around Marine Renewable Energy Converters: Workshop Final Report
}

\author{
B Polagye \\ A Copping \\ R Suryan \\ S Kramer \\ J Brown-Saracino \\ C Smith
}

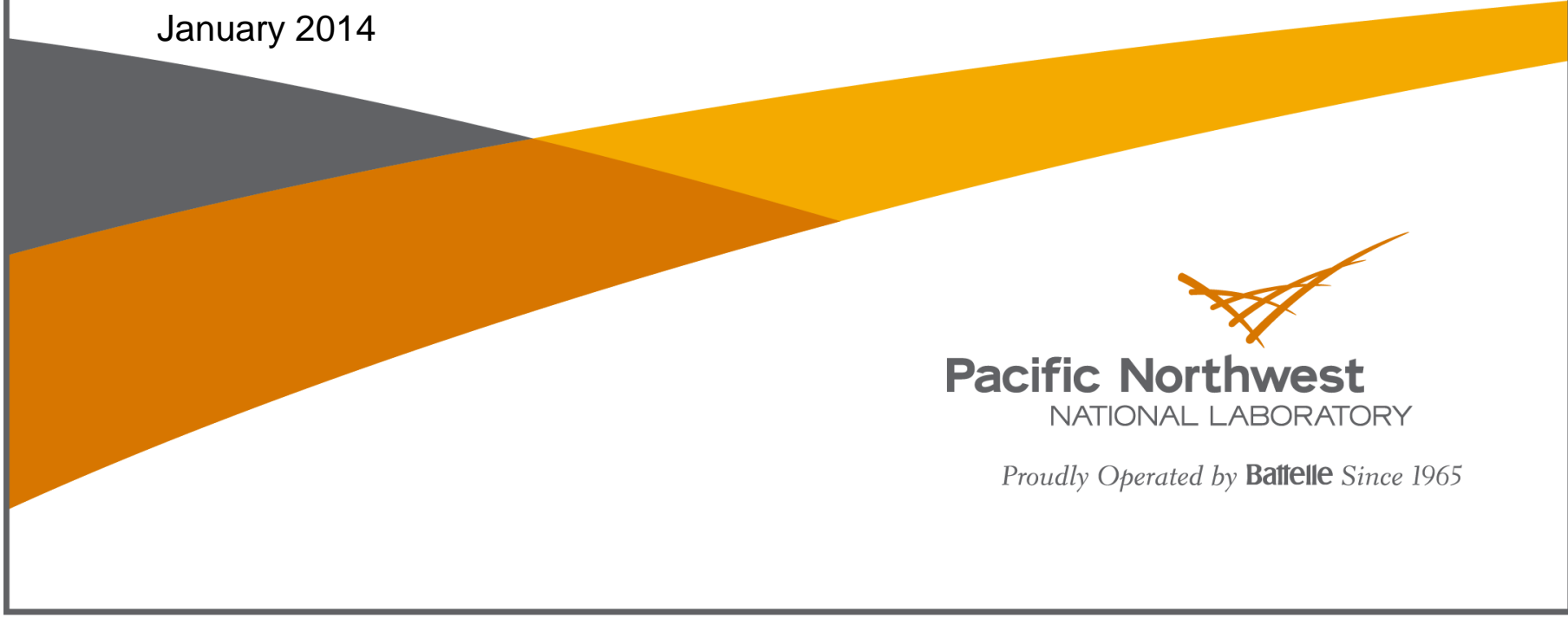




\title{
DISCLAIMER
}

This report was prepared as an account of work sponsored by an agency of the United States Government. Neither the United States Government nor any agency thereof, nor Battelle Memorial Institute, nor any of their employees, makes any warranty, express or implied, or assumes any legal liability or responsibility for the accuracy, completeness, or usefulness of any information, apparatus, product, or process disclosed, or represents that its use would not infringe privately owned rights. Reference herein to any specific commercial product, process, or service by trade name, trademark, manufacturer, or otherwise does not necessarily constitute or imply its endorsement, recommendation, or favoring by the United States Government or any agency thereof, or Battelle Memorial Institute. The views and opinions of authors expressed herein do not necessarily state or reflect those of the United States Government or any agency thereof.

\author{
PACIFIC NORTHWEST NATIONAL LABORATORY \\ operated by \\ BATTELLE \\ for the \\ UNITED STATES DEPARTMENT OF ENERGY \\ under Contract DE-AC05-76RL01830
}

Printed in the United States of America
Available to DOE and DOE contractors from the Office of Scientific and Technical Information, P.O. Box 62, Oak Ridge, TN 37831-0062; ph: (865) 576-8401 fax: $(865) 576-5728$
email: reports $a$ adonis.osti.gov
Available to the public from the National Technical Information Service 5301 Shawnee Rd., Alexandria, VA 22312 ph: (800) 553-NTIS (6847) email: orders@ntis.gov <http://www.ntis.gov/about/form.aspx> Online ordering: http://www.ntis.gov




\title{
Instrumentation for Monitoring around Marine Renewable Energy Converters: Workshop Final Report
}

\author{
B Polagye ${ }^{1}$ \\ A Copping \\ R Suryan ${ }^{2}$ \\ $\mathrm{S} \mathrm{Kramer}^{3}$ \\ J Brown-Saracino ${ }^{4}$ \\ C Smith ${ }^{4}$
}

January 2014

Prepared for

the U.S. Department of Energy

under Contract DE-AC05-76RL01830

Pacific Northwest National Laboratory

Richland, Washington 99352

\footnotetext{
${ }^{1}$ University of Washington, Northwest National Marine Renewable Energy Center, Seattle, Washington

${ }^{2}$ Oregon State University

${ }^{3}$ HT Harvey and Associates

${ }^{4}$ US Department of Energy, Wind and Waterpower Technologies Office
} 



\section{Recommended citation:}

Polagye, B., A. Copping, R. Suryan, S. Kramer, J. Brown-Saracino, and C. Smith. 2014. Instrumentation for Monitoring Around Marine Renewable Energy Converters: Workshop Final Report. PNNL-23110 Pacific Northwest National Laboratory, Seattle, Washington. 



\section{Summary}

As the marine energy industry explores the potential for generating significant power from waves and tidal currents, there is a need to ensure that energy converters do not cause harm to the marine environment, including marine animals that may interact with these new technologies in their native habitats. The challenge of deploying, operating, and maintaining marine energy converters in the ocean is coupled with the difficulty of monitoring for potentially deleterious outcomes between the converters, anchors, mooring lines, power cables and other gear, and marine mammals, sea turtles, fish, and seabirds. To better understand the state of instrumentation and capabilities for monitoring around marine energy converters, the U.S. Department of Energy directed Pacific Northwest National Laboratory and the Northwest National Marine Renewable Energy Center at the University of Washington to convene an invitation-only workshop of experts from around the world to address instrumentation needs for three key interactions of interest to the emerging industry:

- interactions between marine animals and marine renewable energy converters (MECs) near the converters ("nearfield")

- determining the distribution and habitat use of marine animals in the vicinity of MECs ("distribution and habitat use")

- characterizing the sounds produced by MECs ("sound").

The workshop participants were also asked to determine the capabilities of the following three instrumentation categories as they apply to monitoring around MECs:

- active acoustic instruments, including echosounders, imaging sonars, active tags, and radar

- passive acoustic instruments, including hydrophones and vector sensors

- optical technologies, focused on various camera deployment platforms.

Thirty-six scientists, engineers, and regulators from the United States, Canada, Europe, and Chile participated in the 2-day workshop, through a series of plenary presentations about the following:

- status of monitoring around MECs: purpose of monitoring, examples of success and limitations

- understanding the challenges of determining the distribution and habitat use of animals in the vicinity of MECs

- observing the effects of underwater sound on marine animals, and the regulatory context that drives these observations.

The bulk of the workshop was spent in breakout sessions that addressed the capabilities of the instrument systems of interest and the three situations around marine energy devices, where significant instrument needs, gaps, and solutions were identified (nearfield, distribution and habitat use, and sound).

For active acoustic instruments the discussion focused on the spatial and temporal limitations; data bandwidth and power requirements; data processing; seasonal, biological, atmospheric, environmental limitations; safety and permitting challenges; and mooring and platform challenges. 
Passive acoustic instrument discussions included the capabilities of hydrophones and vector sensors; the challenges of data collection in extreme energy environments; and data processing resulting from monitoring.

Optical technology discussions explored a range of deployment and data-gathering options including: underwater, surface, and airborne platforms.

The nearfield discussions stressed the importance of tailoring the monitoring around marine energy converters to the specific animals present at marine renewable energy sites, the animal life stages, and the protected status of the animals. The spatial scales over which each animal group ought to be monitored differs depending on the size and speed of the animal. While continuous temporal observations of converters is desirable, significant concern was expressed about the large data streams likely to be generated and the need for signal processing and software improvements in detection, tracking, localization, and classification of animals to enable automated data processing.

The distribution and habitat use group focused on the need to develop monitoring strategies for specific animal groups of interest that are peculiar to the high-energy areas in which marine energy converters are placed. The group focused on packages of instruments that could observe marine animals on temporal scales of months to years in order to understand how the presence of marine energy converters may alter animal use and behavior in their vicinity.

The sound group focused on how to measure sound from marine energy converters, how to determine if the measurements can adequately characterize the output of the converters, and how sound measurement techniques could be standardized.

Common themes that emerged from the aggregation of the breakout groups, informed by the plenary presentations and discussions, included the following:

- the importance of measuring risk as a key part of the initial plans for monitoring in order to focus programs appropriately, and to inform discussions that allow certain risks to be "retired" on a projectspecific basis

- the potential for huge data "mortgages" resulting from large streams of data that will flow from many of the instruments best suited for monitoring, and the need for automated data processing to optimize the data streams

- the need to integrate instruments into packages that can be deployed and operated as a single unit, and the need to integrate monitoring data streams with those generated from converter operation

- the lack of existing platforms and supporting technologies to allow otherwise capable monitoring instruments to realize their potential

- the importance of broad collaboration among the research community internationally, between researchers and developers, as well as between researchers and regulators to cost-effectively and efficiently use limited monitoring funds to understand interactions of marine energy converters with marine animals. 


\section{Acknowledgments}

The authors thank Robert Suryan, Oregon State University, Northwest National Marine Renewable Energy Center; Sharon Kramer, H.T. Harvey \& Associates; Jocelyn Brown-Saracino, New West Technologies, United States Department of Energy; and Courtney Smith, United States Department of Energy for their contributions at the workshop and to portions of this report. Hoyt Battey, Simon Geerlofs, and Jim Dawson served on the steering committee and guided workshop execution. We could not have completed this task without them.

We also gratefully acknowledge the financial support from the U.S. Department of Energy's Wind and Water Power Technologies Office that enabled us to organize, conduct, and report on the outcomes of this international workshop. We are also grateful for support from BioSonics, Inc. in making the workshop a success.

Rob Cavagnaro, Hayley Harguth, James Joslin, Danny Sale, and Brit Sojka from the University of Washington transcribed the notes from the plenary sessions and breakout groups. Their detailed notes formed the basis for the breakout session descriptions in this report.

Lara Aston of Pacific Northwest National Laboratory, Britta Timpane-Padgham of the University of Washington, and Nicole Faghin of the University of Washington provided exceptional logistical support and are the reason that everything associated with the workshop ran as smoothly as it did.

Finally, we thank all workshop participants for their contributions toward furthering our collective understanding of environmental monitoring of marine renewable energy. 



\section{Acronyms and Abbreviations}

\begin{tabular}{|c|c|}
\hline $2 \mathrm{D}$ & two-dimensional \\
\hline $3 \mathrm{D}$ & three-dimensional \\
\hline AUV & autonomous underwater vehicle \\
\hline $\mathrm{dB}$ & decibel(s) \\
\hline DIDSON & Dual frequency IDentification SONar \\
\hline DTLC & detection, tracking, localization, and classification \\
\hline DOE & United States Department of Energy \\
\hline EIMR & Environmental Interactions of Marine Renewable Energy Technologies \\
\hline EMEC & European Marine Energy Centre \\
\hline FLOWBEC & FLOW and BEnthic Ecology (project) \\
\hline FORCE & Fundy Ocean Research Centre for Energy \\
\hline GB & gigabyte(s)H \\
\hline GPS & $\mathrm{km}$ \\
\hline $\mathrm{kHz}$ & kilohertz \\
\hline $\mathrm{kW}$ & kilowatt(s)m \\
\hline $\mathrm{m}$ & meter(s) \\
\hline$m^{2}$ & square meter(s) \\
\hline $\mathrm{MB} / \mathrm{s}$ & megabytes per second \\
\hline MEC & marine renewable energy converter \\
\hline MHK & marine hydrokinetics \\
\hline MMO & marine mammal observer \\
\hline MRE & marine renewable energy \\
\hline MRED & marine renewable energy device \\
\hline $\mathrm{m} / \mathrm{s}$ & meter(s) per second \\
\hline NOAA & United States National Oceanic and Atmospheric Administration \\
\hline ORPC & Ocean Renewable Power Company \\
\hline$\mu \mathrm{Pa}$ & micropascal(s) \\
\hline PAM & passive acoustic monitoring \\
\hline ROV & remotely operated vehicle \\
\hline RPM & rotations per minute \\
\hline SNR & signal-to-noise ratio \\
\hline TEC & tidal (current) energy converter \\
\hline UAV & unmanned aerial vehicle \\
\hline WEC & wave energy converter \\
\hline wk & week $(\mathrm{s})$ \\
\hline
\end{tabular}





\section{Glossary}

demonstration arrays: first-generation arrays of marine renewable energy converter (MECs) intended to prove the commercial viability and environmental compatibility of a specific converter technology.

farfield: distances beyond the nearfield.

nearfield: a radius equivalent to several lengths of the MEC, which for most MECs will amount to a radius of less than $100 \mathrm{~m}$.

marine renewable energy: the energy available in marine resources. Here, taken to refer to either the energy in surface waves or tidal currents.

marine energy converter: a system for converting the energy in marine energy resources to electricity. Here, taken to refer to either a wave energy converter or tidal energy converter.

metocean conditions: a comprehensive term referring to both meteorological and oceanographic environmental conditions (e.g., winds, waves, and currents). 



\section{Contents}

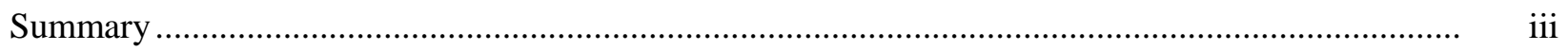

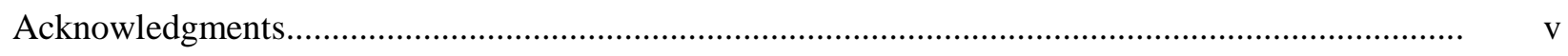

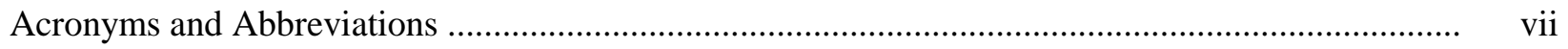

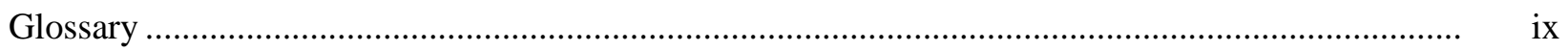

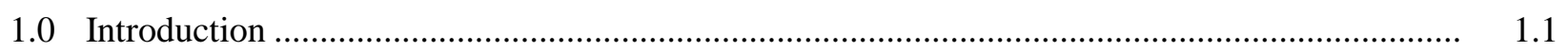

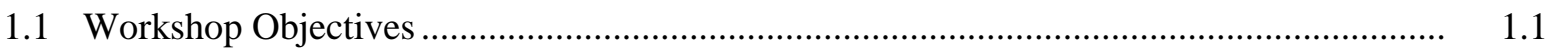

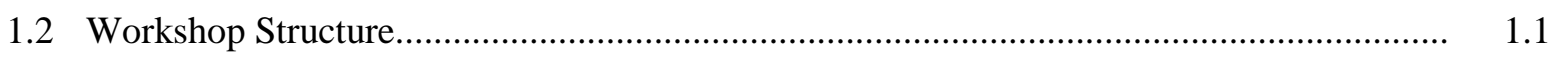

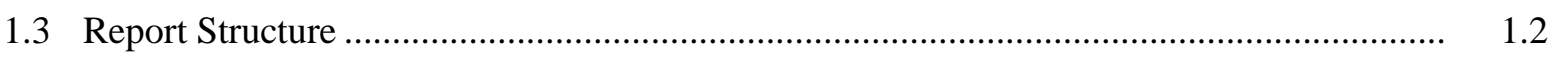

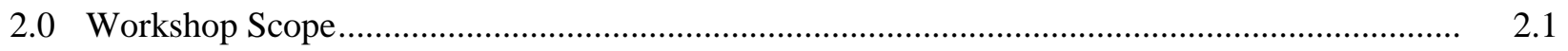

2.1 Marine Renewable Energy Technology .................................................................... 2.1

2.2 Geographic Extent and Environments of Interest ....................................................... 2.1

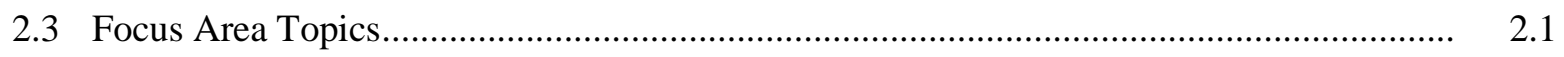

3.0 Plenary Sessions ..................................................................................................... 3.1

3.1 Status of Monitoring around Marine Renewable Energy Converters: Purpose of Monitoring, Examples of Success and Limitations ....................................................... 3.1

3.1.1 Lessons from Annex IV .......................................................................... 3.1

3.1.2 Fish Interactions with ORPC TidGen in Cobscook Bay ….................................. 3.2

3.1.3 Results from the SeaGen Monitoring Program ..................................................... 3.4

3.1.4 Results from Wave and Tidal Converter Monitoring at the European Marine Energy Centre.

3.2 Understanding the Challenges of Determining the Distribution and Habitat Use of Animals in the Vicinity of Marine Renewable Energy Converters................................. 3.6

3.2.1 Environmental Sensing at FORCE: Challenges and Opportunities ...................... 3.6

3.2.2 Characterizing Distributions and Habitats of Aquatic Organisms for Marine Renewable Energy....................................................................................... $\quad 3.8$

3.2.3 Hydrodynamics and Beastie Monitoring at United Kingdom Marine Renewable Energy Sites .................................................................................. 3.9

3.3 Observing the Effects of Underwater Sound on Marine Animals, and the Regulatory Context that Drives these Observations ......................................................................... 3.10

3.3.1 Probabilistic Models for Acoustic Changes ........................................................ 3.10

3.3.2 Lessons from Acoustic Monitoring in the United Kingdom ................................. 3.11

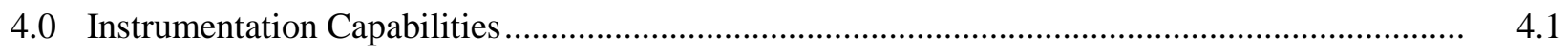

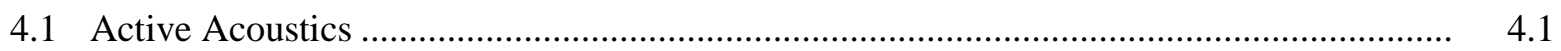

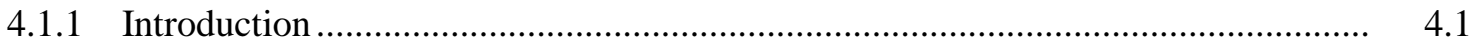

4.1.2 General Capabilities and Gaps for Imaging Sonars and Echosounders .................. 4.2

4.1.3 Single-Beam and Split-Beam Echosounders..................................................... 4.5

4.1.4 Multi-Beam Echosounder ......................................................................... 4.6

4.1.5 Two-Dimensional Imaging Sonar ................................................................ 4.6 
4.1.6 Three-Dimensional Scanning Sonar.............................................................. 4.6

4.1.7 Broadband Multi-Beam Echosounders ............................................................ 4.6

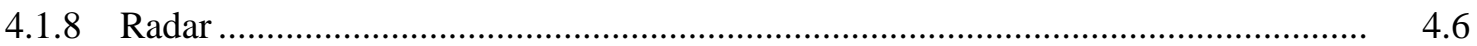

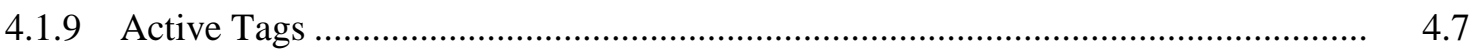

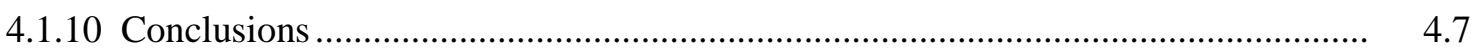

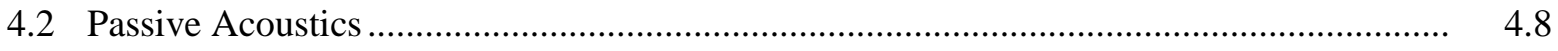

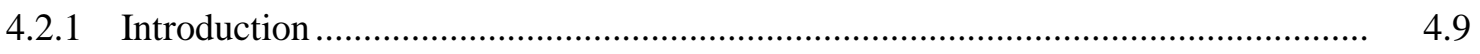

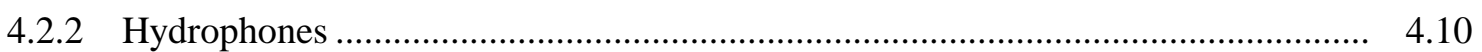

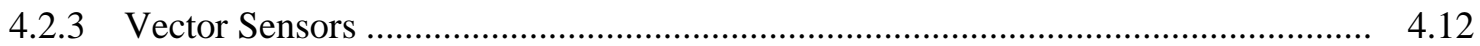

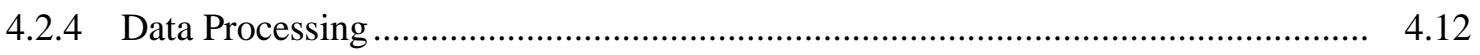

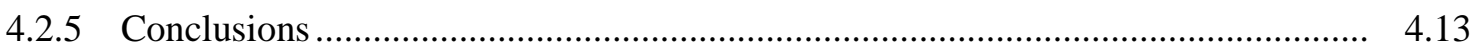

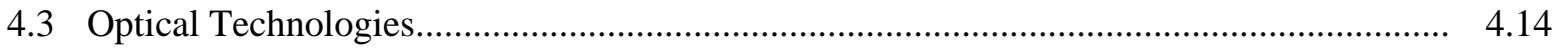

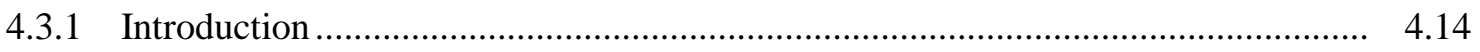

4.3.2 Remotely Operated Vehicles...................................................................... 4.16

4.3.3 Manned Submersibles ........................................................................................ 4.17

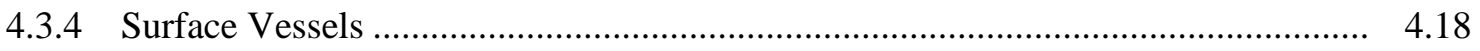

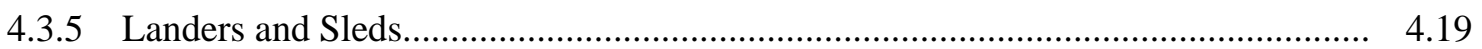

4.3.6 Autonomous Underwater Vehicles ......................................................................... 4.20

4.3.7 Animal-Borne Cameras................................................................................ 4.21

4.3.8 Fixed, Cabled Vantage Points above the Water Surface ........................................ 4.22

4.3.9 Fixed, Cabled Vantage Points below the Water Surface......................................... 4..23

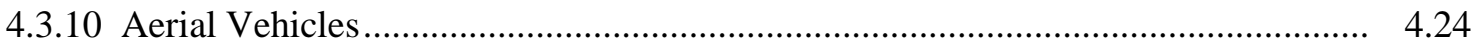

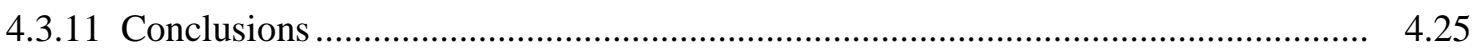

5.0 Instrumentation Needs, Gaps, and Solutions ….............................................................. 5.1

5.1 Marine Species near Marine Renewable Energy Converters .......................................... 5.1

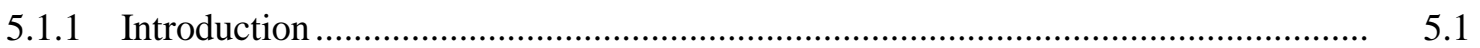

5.1.2 Setting Priorities for Nearfield Monitoring ......................................................... 5.3

5.1.3 Scales for Measuring Nearfield Interactions ................................................... 5.4

5.1.4 Nearfield Interactions of Interest.................................................................. 5.5

5.1.5 Priority Gaps and Solutions......................................................................... 5.12

5.2 Determining the Distribution and Habitat Use of Marine Species in the Vicinity of Marine Renewable Energy Converters........................................................................ 5.14

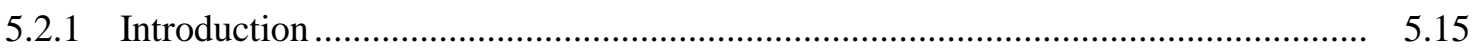

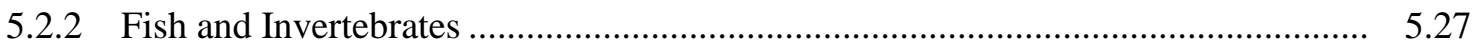

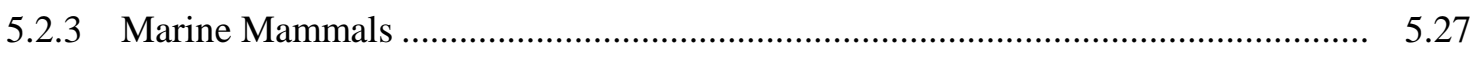

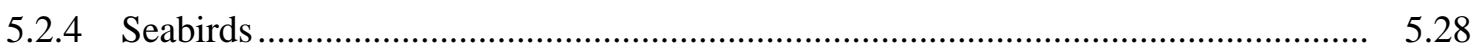

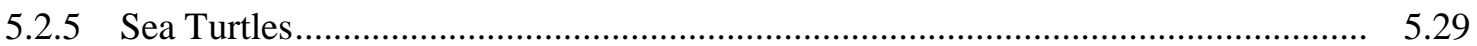

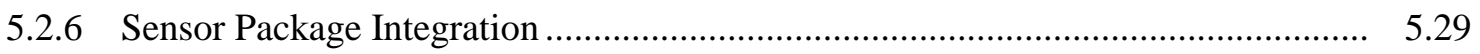

5.2.7 Priority Gaps and Solutions...................................................................... 5.30 
5.3 Sound Produced by Marine Renewable Energy Converters ......................................... 5.31

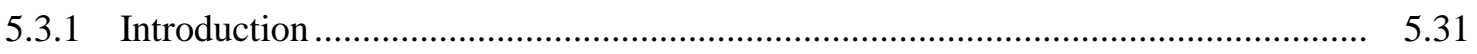

5.3.2 Measurements of Sound from Tidal Energy Converters ....................................... 5.33

5.3.3 Measurements of Sound from Wave Energy Converters ..................................... 5.35

5.3.4 Elements of an Acoustic Characterization Standard ........................................... 5.36

5.3.5 Priority Gaps and Solutions............................................................................. 5.37

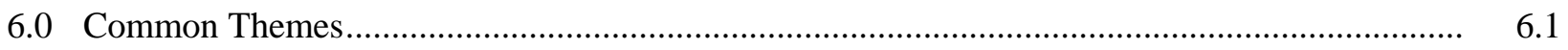

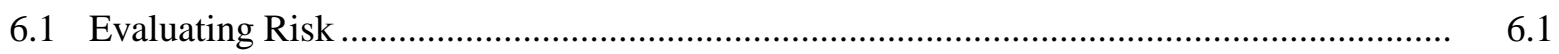

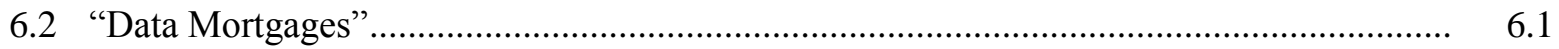

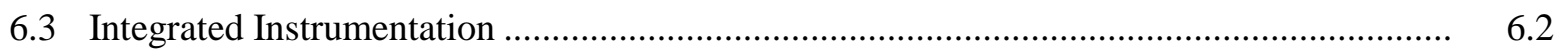

6.4 Platforms and Supporting Technologies ................................................................ 6.3

6.5 Collaborations between Developers and Researchers ...................................................... 6.4

7.0 Recommended Near-Term Next Steps .........................................................................

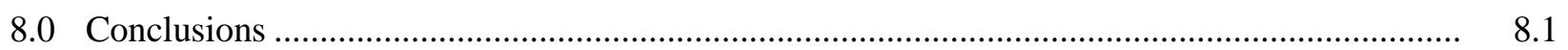

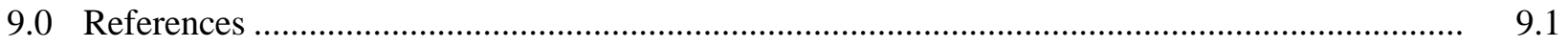

Appendix A - Workshop Participant List and Affiliations ......................................................... A.1

Appendix B - Workshop Evaluation Responses ........................................................................... B. B. 


\section{Tables}

4.1 Optical capability summary for remotely operated vehicles ................................................. 4.16

4.2 Optical capability summary for manned submersibles ....................................................... 4.17

4.3 Optical capability summary for surface vessels ............................................................... 4.18

4.4 Optical capability summary for landers and sleds ............................................................. 4.19

4.5 Optical capability summary for autonomous underwater vehicles ....................................... 4.20

4.6 Optical capability summary for animal-borne cameras ....................................................... 4.21

4.7 Optical capability summary for fixed, cabled platforms above the water surface .................... 4.22

4.8 Optical capability summary for fixed, cabled platforms below the water surface .................... 4.23

4.9 Optical capability summary for aerial vehicles................................................................. 4.24

5.1 Necessary spatial and temporal resolution for receptor monitoring of distribution and habitat use as a function of deployment platform ….......................................................... 5.15

5.2 Monitoring distribution and habitat use with split-beam and multi-beam active acoustics ....... 5.17

5.3 Monitoring distribution and habitat use with acoustic cameras ............................................ 5.18

5.4 Monitoring distribution and habitat use with tags.............................................................. 5.19

5.5 Monitoring distribution and habitat use with optical cameras ............................................ 5.20

5.6 Monitoring distribution and habitat use with human observers .......................................... 5.22

5.7 Monitoring of distribution and habitat use with passive acoustics ........................................ 5.23

5.8 Monitoring distribution and habitat use with trawls .......................................................... 5.24

5.9 Monitoring distribution and habitat use with LiDAR ....................................................... 5.25

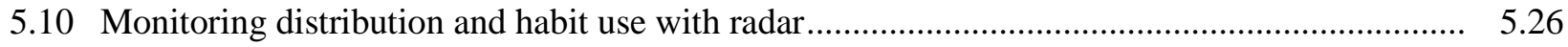

5.11 Sound measurement difficulty and regulatory interest ................................................. 5.33

5.12 Measurements of sound from tidal energy converters ..................................................... 5.34

5.13 Measurements of sound from wave energy converters ......................................................... 5.35 


\subsection{Introduction}

As the marine renewable energy (MRE) industry has developed, a set of challenges has emerged around the need to understand potential environmental effects of the devices. In general, environmental studies conducted to date have, at high cost, demonstrated that small pilot projects are unlikely to have biologically significant environmental effects. However, these studies have often not substantially reduced uncertainty around environmental effects, nor have they provided assurances that the experience derived from pilot projects will scale in a predictable manner to larger commercial installations. If environmental monitoring costs continue to scale linearly with project size, this could prove debilitating to the emergence of a MRE industry.

Advances in instrumentation hardware and use have the potential to help industry and regulatory agencies better understand and mitigate potential environmental effects. However, only limited financial resources are available to affect these advances, which demands a scheme for prioritizing and coordinating the development of instrumentation, methodologies, and (eventually) standards for their use. This process may occur in parallel, and in close association with, the first demonstration arrays. Marine renewable energy test facilities are also likely to play an important role in maturing instrumentation and methodologies to the point that they can be applied to demonstration arrays.

A workshop was convened by Pacific Northwest National Laboratory and the Northwest National Marine Renewable Energy Center, with funding from the U.S. Department of Energy, to evaluate gaps in available instrumentation for environmental monitoring and to identify possible solutions for how to fill those gaps. The 36 invited participants met for 2 days (June 25-26, 2013) on the University of Washington campus in Seattle, Washington. Participants included scientists and industry practitioners with established expertise in instrumentation that is, or could be, used to monitor MRE projects. Many of the participants have had practical experience working with these instruments in energetic wave and tidal environments.

\subsection{Workshop Objectives}

The workshop, reported herein, had three objectives:

- to enhance the understanding of the state of instrumentation readiness to answer important environmental questions for MRE development

- to develop a consensus among experts on methods for applying instrumentation to meet high-priority monitoring needs for MRE projects

- to provide a forum to foster new and continuing collaboration around monitoring the environmental effects of MRE.

\subsection{Workshop Structure}

To advance these objectives, the workshop did not revisit the underlying prioritization of environmental studies (Cada et al. 2007; Boehlert and Gill 2010; Polagye et al. 2011). Rather, given a set of identified priorities, attention was focused on instrumentation needs, capabilities, gaps, and solutions. 
While study methodologies, including well-defined hypotheses, are essential to the successful application of instrumentation, methodologies were not a primary workshop focus.

The workshop structure was chosen to promote dialogue about measurements of either stressors (e.g., sound) or receptors (e.g., marine mammals), which could then be combined in various ways to assess stressor-receptor interactions. The stressor and receptor studies chosen for discussion at the workshop addressed the following:

- direct interaction of fish, marine mammals, sea turtles, and birds with marine energy converters (including abrasion, collision, and strike)

- changes in the distribution and use of habitats by marine animals in response to MRE generation

- characteristics of the sound produced by marine energy converters.

Each expert participated in three breakout group discussions. The first breakout discussion was focused on instrumentation needs associated with a specific set of environmental uncertainties:

- observations of marine animals (fish, marine mammals, sea turtles, and birds) in the "nearfield" of marine energy converters. Nearfield is defined as being within a few characteristic length scales of the converter. Such studies are often intended to detect individual interactions with converters.

- observations of marine animal distribution and pelagic habitat use in high-energy environments. Such studies are often intended to detect changes at the population level.

- measurements of the sound produced by marine converters and the temporal and spatial characteristics of this sound in the vicinity of converters.

The second breakout discussion focused on instrumentation capabilities to address the needs identified by the first set of discussions and were broken down by instrumentation type, as follows:

- active acoustics: including echosounders, imaging sonars, active tags, and radar

- passive acoustics: including hydrophones and vector sensors

- optical technologies: focused on various camera deployment platforms.

Participants then returned to their first breakout groups and discussed instrumentation gaps and solutions in the context of the needs identified during the first breakout group, and the available instrument capabilities identified during the second breakout group.

The workshop concluded with a discussion among the participants about cross-cutting, high-priority gaps and solutions that could be pursued in a coordinated manner.

\subsection{Report Structure}

This report is structured around the plenary and breakout group discussions that took place during the workshop. Section 2.0 describes the scope of the workshop discussions and provides definitions for the remainder of the report. Section 3.0 includes brief narratives of each of the plenary talks given to frame the breakout discussions. Section 4.0 describes instrumentation capabilities for active acoustic, passive acoustic, and optical technologies. Section 5.0 describes instrumentation needs, gaps, and solutions for 
monitoring of marine species near marine renewable energy converters; determining the distribution and habitat use of marine species in the vicinity of converters; and characterizing sound produced by converters. Section 6.0 summarizes common themes noted between the breakout discussions and Section 7.0 recommends next steps in instrumentation development. Appendixes A and B, respectively, contain a list of workshop participants and the results of the workshop evaluation survey. 



\subsection{Workshop Scope}

The scope of the workshop included specific areas of focus and excluded others for reasons noted below.

\subsection{Marine Renewable Energy Technology}

For the purposes of this report, the definition of marine renewable energy converters (MECs) is restricted to conversion of two types of marine resources: wave energy and tidal energy. Similar considerations also apply to elements of offshore wind platforms and ocean current energy converters, but these are not explicitly discussed in this report. Wave energy converters (WECs) deployed in the nearshore and offshore are considered, as are the different classes of WECs, such as point absorbers, attenuators, surge devices, overtopping devices, and oscillating water columns.

Excluded from the report are onshore facilities that are not unique to MRE, such as electrical substations or pumping facilities (e.g., as used for near-shore hydraulic power take-off approaches).

\subsection{Geographic Extent and Environments of Interest}

While a number of specific examples from the United States are given in the following sections of this report, the intent is for a globally relevant narrative, with priority given to topics of universal importance, rather than those with only a national or regional importance.

Monitoring technologies are focused on the pelagic environment and air/sea interface, because they are the ecological strata that have proven most difficult to characterize.

\subsection{Focus Area Topics}

The list of topics in Section 1.2 are not an exhaustive list of either stressors or receptors around MECs. For example, the list excludes receptors such as benthic habitat, sediment transport, and invertebrates, as well as stressors such as electromagnetic fields, chemical effects, and energy removal. These topics are worthy of discussion and are the subject of active research programs by industry and research institutions. However, the focus of the workshop discussions that underpin this report was on topics for which cost-effective, efficient, and reproducible results have been elusive, despite significant field and laboratory efforts to better understand them.

The workshop emphasizes instrumentation (needs, capabilities, gaps, and solutions), rather than regulations or methods. However, the procedures for applying or deploying instruments are discussed when they present a barrier to effective use of the instrumentation. This relatively narrow focus is intended to move toward new capabilities for obtaining observations commonly needed across MRE technologies and geography, with a specific emphasis on those that are challenging for the industry to develop at an acceptable cost. 



\subsection{Plenary Sessions}

Plenary sessions focused on the status of monitoring around MECs, understanding the challenges of measuring the species distribution and habitat use near MECs, and observing the effects of underwater sound on marine animals. These sessions provided all participants with a representative sampling of leading-edge research in each topic area.

\subsection{Status of Monitoring around Marine Renewable Energy Converters: Purpose of Monitoring, Examples of Success and Limitations}

This session featured Annex IV lessons learned, fish interactions with the Ocean Renewable Power Company's TidGen tidal energy converter, and results from the MCT SeaGen monitoring program and wave converter monitoring at the European Marine Energy Center.

\subsubsection{Lessons from Annex IV}

\section{Presenter: Andrea Copping, Pacific Northwest National Laboratory}

The Annex IV initiative is based on the concept of sharing information and analyses internationally. It was created under the Ocean Energy Systems agreement for 2010-2012, and is led by the United States Department of Energy and other federal partners. Annex IV intends to share data on the environmental effects of marine energy through a publicly accessible database (Tethys) and to carry out initial analyses of the effects of marine energy devices on the environment. Two experts' workshops helped guide the effort, which involved three case studies.

The process for analysis of the three case studies was to collect data about the specific interactions from installed marine energy projects and from ongoing research projects; to evaluate the information to determine what we know about the interaction; and to identify key gaps in the data and studies. Two of those case studies are reported on here.

The Annex IV case studies evaluated 1) the interaction of marine animals with turbine blades and 2) the effects of acoustic output from tidal and wave devices on marine animals. Lines of evidence for each case study involved gathering data from field studies, laboratory experiments, and numerical modeling.

Case study 1 (interaction of marine animals with turbine blades) concluded that no evidence suggests that direct interaction of marine mammals, birds, or fish with tidal turbine blades is likely to be a significant problem; that attraction of animals to turbines could increase risk; that data collected from short deployments may not scale to large long-term deployments; and that monitoring around multiturbine arrays is needed. Key information gaps include the need for observations and measurements of animal movement around tidal turbines of varying designs and in specific waterbodies; studies of the interactions of indigenous animals with a broad array of tidal turbine designs; laboratory experiments that expose fish and other species to turbines so that fish can avoid the turbine if they so choose; models that 
describe physical and biological interactions to determine the outcomes of animal encounters with turbine blades; and field measurements of animal encounters with arrays.

Case study 2 (effects of acoustic output from tidal and wave devices on marine animals) concluded that field deployments are needed to measure ambient noise and sound propagation prior to deployment, to accurately measure the sound of the converter under different regimes; laboratory or controlled exposure experiments are needed to determine dose/response relationships for animals and sound to understand potential responses of animals; we need to determine how sound from multiple converters combines; and acoustic outputs and effects are needed for a range of converters, as well as the anchors, moorings, and foundations under different operating regimes.

Annex IV has been renewed for another 3 years (2013-2016), based on input from the experts' workshop held in September 2012, and through discussions with other nations. The United States is committed to continuing the effort. The scope of Annex IV Phase 2 will be continued collection and analysis of project monitoring data and research information; creation of Tethys/Annex IV as a commons for collaboration for researchers, developers, regulators, and stakeholders; engagement of more direct hands-on participation by scientists from other nations; and provision of support for international conferences and workshops on environmental effects of marine energy.

\subsubsection{Fish Interactions with ORPC TidGen in Cobscook Bay}

\section{Presenter: Gayle Zydlewski, University of Maine}

Prior to MEC development, the University of Maine Fish Assessment Study Team of the Maine Tidal Power Initiative studied the behavior of fishes of Cobscook Bay in related to the Ocean Renewable Power Company's (ORPC's) TidGen tidal energy converter. ORPC's project site is in the eastern-most bay of the United States at the entrance to the Bay of Fundy. The project was initiated in 2009 to determine 1) how fish behave around a tidal turbine (rotating and not) in the nearfield of the TidGen converter; 2) at what distance fish respond to a tidal turbine, near or farfield; and 3) what the "natural" vertical distributions of fishes in these tidal environments are and to ultimately determine how their distributions are affected by the introduction of a MEC.

Nearfield data collection using the Dual frequency IDentification SONar (DIDSON) acoustic imaging system on each side of a rotating (and non-rotating) turbine has resulted in a better understanding of small fish ( $<10 \mathrm{~cm}$ long) responses within $2 \mathrm{~m}$ of both sides of the ORPC converter. Most fish moved in the same direction as the water current. About $50 \%$ of individual fish and about $33 \%$ of schools interacted with the turbine in some way. Less than $1 \%$ of individuals and about $15 \%$ of schools showed avoidance behavior, $35 \%$ versus $14 \%$ entered or exited the turbine, and $16 \%$ versus $2 \%$ remained in its wake. The rest of the individuals and schools passed above or below or milled about during periods of slack water. Milling behavior only occurred when the turbine was not rotating (i.e., near slack water). Turbine rotation reduced the probability of entering the turbine by $35 \%$, and increased the probability of avoidance and passing by $120 \%$ and $97 \%$, respectively, but avoidance remained rare in absolute terms. Fewer schools entered the turbine than individuals ( $21 \%$ versus $48 \%$, respectively), more schools avoided the turbine (28\% versus $1 \%$ ), and about $50 \%$ of both groups passed through the turbine. Schools avoided the turbine from farther away than individuals (on average $2.5 \mathrm{~m}$ versus $1.7 \mathrm{~m}$ ). The DIDSON was a useful tool for monitoring fish interactions with the tidal turbine. It was especially well suited to 
sampling at night, when a video camera would not have been useful without artificial lighting that could alter the natural behavior of fish. Because tidal turbines are likely to be placed in deep (dark) or turbid water, DIDSON and other acoustics equipment may be the most appropriate monitoring tools. Shortcomings of using a DIDSON for this purpose included the limited boundaries of the viewing window and sampling a narrow slice of the water, which made it difficult to follow fish from upstream of the turbine to downstream and may have resulted in some fish being counted multiple times. Result from this work will soon be available in an article by Viehman and Zydlewski (accepted Estuaries and Coasts).

Limited data about animal interaction with the TidGen converter have been collected using a stationary side-looking split-beam echosounder. Data were recorded within $10 \mathrm{~m}$ of the bottom-mounted device. Temporal resolution was high, collecting data $24 \mathrm{~h} / \mathrm{d}, 7 \mathrm{~d} / \mathrm{wk}$ for several months. These data are being analyzed to determine fish behavior as they approached (during flood tide) and departed (during ebb tide) the TidGen converter. Data could not be collected while the turbine was generating power because of electrical interference between the data and power transmission cables (copper, rather than fiber-optic, communication link to shore). Therefore, hydroacoustic data were collected only for periods of time when the turbine was not rotating (either during slack tides when the current was too weak, or when the brake was applied), or when it was free-spinning (rotating but not generating power). These data include fish direction, aggregation, and target strength (for indication of size). Limitations of this approach include the inability to determine whether animals interacted with the device (because the acoustic return from the device precludes detections in that zone); the extensive data set likely requires subsampling; analyses are on one side of the device; there is no species identification; and deployment is expensive.

Several mobile acoustic transects over the TidGen converter indicated that nearfield animal responses may be discernible using a mobile approach. This will allow analysis of individual animal movement relative to the device slightly further afield (from $200 \mathrm{~m}$ to 2-3 m) than the DIDSON or stationary sidelooking acoustics, determination of upstream and downstream orientation to the converter, use of target strength to approximate fish size, and the ability to build a relationship between fish behavior and physical hydrodynamics. Limitations of this approach include low temporal resolution (minutes to move over the converter), low sample size, relatively high expense due to boat costs, and the inability to discriminate some species.

Twenty-four-hour stationary surveys have been conducted to determine fish vertical distribution relative to the TidGen deployment depth. Relative fish biomass density and vertical distribution were analyzed for variation with respect to site, year, month, and diel and tidal cycles. A seasonal pattern was apparent in both years at both the control and project sites, with maxima in spring and late fall. Fish biomass density was generally greatest near the sea floor, and diel changes in vertical distribution were frequently observed, but changes in distribution related to diel and tidal cycles were less apparent from survey to survey. The patterns at the project and control sites were very similar, demonstrating that the control site provides a reference for quantifying changes in fish density and vertical distribution related to the tidal device rather than natural variation. Challenges of this approach include limited temporal resolution (24-hour surveys), getting close enough to the converter to document responses, expense due to boat costs, inability to discriminate to the species level. 


\subsubsection{Results from the SeaGen Monitoring Program}

\section{Presenter: Beth Mackey, Royal Haskoning DHV}

Marine Current Turbines Ltd (MCT) operates the SeaGen tidal turbine in the Narrows of Strangford Lough, of Northern Ireland, converting energy from tidal flow into electricity. The Siemens/Marine Current Turbine (MCT) SeaGen is a pile-mounted dual-rotor tidal turbine that has operated since 2008. SeaGen generates power at currents $>1 \mathrm{~m} / \mathrm{s}$, has a 4-m cross-beam and a $16-\mathrm{m}$ rotor diameter, and rotates at a maximum speed of 14 RPM with a maximum tip speed of $12 \mathrm{~m} / \mathrm{s}$. The pile is $3 \mathrm{~m}$ in diameter and extends $10 \mathrm{~m}$ above the water surface.

The SeaGen environmental monitoring program has advanced through several stages pre-installation monitoring (2004), licensing and baseline studies (2005-2006), new licensing (2007-2008), a final environmental monitoring plan (2008), completion of various stages of operation of the turbine under restricted conditions to protect marine mammals and relicensing with the potential for unrestricted operation (2013).

The most important aspect of the SeaGen environmental assessment was concern about marine mammals, especially harbor seals, because Strangford Lough is a Special Area of Conservation. The SeaGen monitoring and assessment are organized as an adaptive management strategy. Key questions include:

- Will increased boat traffic during installation disturb marine mammals?

- Will there be a barrier effect from the noise during installation and operation?

- Will there be a loss of feeding habitat around the turbine?

- What are the risks of collision between marine mammals and the device?

Surveys for harbor seals take place as observations from shore, from boats, as carcass surveys, aerial surveys, and by tagging seals with GPS tags. Harbor porpoises were also studied in the vicinity of the turbine using T-PODs. The results show that harbor seals use the Lough at all tide states, with transits through the narrow channel with the turbine at slack tide generally, and animals tend to travel in the surface and deeper waters. Harbor seal populations have been historically declining in Northern Ireland, but there is no evidence that the SeaGen tidal turbine has any deleterious impact on the population, due to recent increases in the population within the Special Area of Conservation that includes Strangford Lough.

The sound from the tidal turbine is also monitored to determine whether it may mask marine mammal communication or have other negative impacts. The sound from the tidal turbine was characterized (broadband sound pressure level of $174 \mathrm{~dB}$ re $1 \mu \mathrm{Pa}$ ) and was determined to be able to mask harbour porpoise communication to $400 \mathrm{~m}$ potentially disturb marine mammals to $6.5 \mathrm{~km}$ (porpoise) and $610 \mathrm{~m}$ (harbour seals).

Mitigation for SeaGen has involved the presence of marine mammal observers (MMOs), and later active sonar, to trigger shutdown of the turbine to keep the marine mammals safe. Looking at avoidance rates and carcass surveys convinced consenters that SeaGen could be safely operated without shutdown by following an adaptive management strategy. 
Lessons learned from SeaGen and Strangford Lough indicate that there are various ways to minimize risk (to the developer, regulator, and to marine mammals), but remaining uncertainty and knowledge gaps could constrain operation and development of commercial scale tidal power. These gaps include the need to answer the following questions:

- What is the true potential for collision between the device and marine mammals?

- What are the near field avoidance rates?

- How can we be sure if a collision has (or more importantly has not) occurred?

These questions can be answered by ensuring the following:

- Monitoring methods (for baseline and impact monitoring) include a good temporal and spatial fit for (a clearly defined) purpose.

- The limitations of the monitoring are explicit.

- The approach is agreed to with the regulator.

- The developer and regulator are prepared to take an adaptive approach to management where uncertainty exists, because it may be the only way to move forward.

- There is good project communication.

\subsubsection{Results from Wave and Tidal Converter Monitoring at the European Marine Energy Centre}

\section{Presenter: Ian Hutchison, Aquatera Limited}

At a test facility like the European Marine Energy Centre (EMEC), deployments most often consist of single machines and their associated support structures/mooring systems. Therefore, the assumption is, that there will be no significant effects on the receiving environment (particularly for wave energy converters). However, each deployment still provides an opportunity to validate key assumptions made during the environmental assessment stage, but more often than not, the main focus for developers at this stage is on prototype testing and technology demonstration.

EMEC provides a comprehensive ongoing monitoring program that includes marine wildlife behavior and distribution monitoring across its test sites. Supplementary project-specific monitoring undertaken by developers most often then falls into two categories: 1) impact monitoring - monitoring any potentially significant impacts that may arise from the installation, operation, and removal of devices and supporting structures; and 2) research - investigating other potential interactions between wave and tidal energy development and the receiving environment that may become more important at demonstration/ commercial scale.

Each developer produces an Environmental Mitigation and Monitoring Plan that aims to validate/ challenge assumptions made during environmental assessments relating to any potential significant effects (where applicable), inform adaptive management protocols (where applicable), and become a core part of the technology development process. 
They also may produce a research plan to inform future planning, site selection, and environmental impact assessment activities; validate/challenge assumptions made during environmental assessments relating to any possible interactions; undertake hypothesis testing and investigative studies; and develop novel monitoring techniques and procedures, which are conducted in parallel with technology development.

Significant progress has been made at the test sites in recent years in a number of key areas, including the following:

- potential impacts on seabed communities. After an extensive review by the regulators and their advisors, there is no longer a standing requirement for environmental benthic reports at the full-scale wave and tidal test sites. ${ }^{1}$ This is a notable shift from the previous position where pre- and postinstallation and post-decommissioning environmental benthic reports were required from each developer.

- potential disturbance to marine wildlife from vessel operations. Until recently, MMOs have been required onboard Dynamic Positioning vessels during onsite operations. Now, provided that appropriate mitigation measures are implemented, there may be no requirement for MMOs to be onboard dynamic positioning vessels during onsite work. This is a direct result of years of operating experience and the development of appropriate protocols and mitigation measures.

Most developers are also actively engaged in wider research regarding the acoustic outputs of devices and possible wider interactions with marine wildlife.

\subsection{Understanding the Challenges of Determining the Distribution and Habitat Use of Animals in the Vicinity of Marine Renewable Energy Converters}

This session featured challenges and opportunities associated with environmental sensing at Fundy Ocean Research Centre for Energy, characterizing distributions and habitats of aquatic organisms for MRE, and hydrodynamics and beastie monitoring at United Kingdom MRE sites.

\subsubsection{Environmental Sensing at FORCE: Challenges and Opportunities}

Presenter: Anna Redden, Acadia University

The Fundy Ocean Research Centre for Energy (FORCE) test site is located in the Minas Passage, on the upper Bay of Fundy, where tidal range varies from 6 to $13 \mathrm{~m}$, maximum depth-averaged speed is 3 to $4 \mathrm{~m} / \mathrm{s}$, and average power densities are high, often exceeding $8 \mathrm{~kW} / \mathrm{m}^{2}$ (from Karsten model). Field surveys of the seabed, using high-resolution side-scan sonar systems and a video camera, show the seafloor to be characterized by cobble, boulders, and bedrock outcrops occupied largely by breadcrumb sponge; benthic biodiversity is low at this high flow site (up to $2 \mathrm{~m} / \mathrm{s}$ at $1-2 \mathrm{~m}$ above the bottom). Mobile fauna in the area include American lobster and numerous finfish species, several of which are designated

\footnotetext{
${ }^{1}$ Exceptions may apply under some circumstances.
} 
as being "at risk." The harbor porpoise is the most common marine mammal species in the Minas Passage; harbor seals and white-sided dolphins appear less frequently and in lower abundance.

Marine animal use of the Minas Passage as a migration corridor was examined via acoustic tracking of electronically tagged (Vemco technology) Atlantic lobster, Atlantic sturgeon, striped bass, American eel, and Atlantic salmon. Receiver lines spanning both the FORCE test site and the Minas Passage provided multi-year data sets of animal movements, including the swimming depth of fish. In addition to the high cost of tags, constraints include size-related battery life limits of tags. Tag detection was limited by both distance from the receiver and current speed. In addition, tag detection was better on ebb tide than flood tide, for the same depth-averaged water column speed. All species tagged in Minas Basin were detected in Minas Passage, confirming use of the passage as a migratory corridor. Interestingly, striped bass were detected making numerous non-migratory movements (i.e., bi-directional movement through the passage over a period of days or weeks) throughout the passage, including the FORCE site, and thus are potentially at risk of interacting with turbines. Further studies, using active acoustics, will be required to determine whether striped bass (and other fish species) display turbine avoidance behavior. While American lobster was confirmed to migrate through the passage in spring and fall, less than $40 \%$ of tagged lobsters were detected, suggesting some tag loss prior to migration and/or year-round local residency of a portion of the lobster population.

Short-duration fish studies conducted to date include use of a FEMTO Electronics sonar coupled with mid-water trawl surveys, a Coda Octopus Echoscope three-dimensional (3D) sonar, a Simrad EK60 splitbeam sonar, and Kongsberg Mesotech SM2000 and M3 multibeam sonars (projects lead by Gary Melvin, DFO).

Harbor porpoise detection (joint Sea Mammal Research Unit, Ltd and Acadia project) was determined using an array of C-POD porpoise click detectors, inside and outside the FORCE test site, during May - November of 2011-2012. Challenges experienced included poor detection because of excessive bedform transport noise, leading to memory buffer saturation, solid state memory card performance issues, and device failure caused by flow-induced battery dislodgement. Harbor porpoise detections revealed more activity at night, and seasonal peaks in presence were observed during June and October. The flood tide resulted in greater tilt angles of the device, greater amounts of lost detection time, and fewer porpoise click detections. Large tidal ranges, coupled with site-specific characteristics (e.g., eddies, bedload transport) affected the percent of detection time lost and overall hydrophone performance.

New research is focusing on building the FAST (Fundy Applied Sensor Technology) platform, a large recoverable instrument platform designed to monitor and characterize the FORCE test site. The platform will be built in 2014 and will house multiple underwater sensing instruments. 


\title{
3.2.2 Characterizing Distributions and Habitats of Aquatic Organisms for Marine Renewable Energy
}

\author{
Presenter: John Horne, University of Washington, Northwest National Marine Renewable Energy \\ Center
}

Using a baseline study at Admiralty Inlet, Washington, an approach for monitoring density distributions of animals in the water column at MRE sites was proposed along with current research challenges. The generic approach to monitoring a MRE site includes the following steps:

1. Initiate measurements from site evaluation throughout the MRE site life cycle. Choosing an appropriately scaled spatial and temporal design will determine the amount of variability that can be resolved. At Admiralty Inlet, a nested spatial and temporal design was used that combined ship-based acoustic and trawl surveys with bottom-deployed stationary devices to collect baseline data. These data are used to determine data bin sizes (horizontal and vertical) and to determine point-to-area scaling coefficients for the monitoring program.

2. Determine variables/metrics and measurement currency. It is vital to determine whether direct or derived variables/metrics can be used to meet monitoring objectives. A suite of metrics that combines the two was effectively used to characterize biota density distributions in Admiralty Inlet and is proposed as a general reference set of monitoring variables.

3. Define change, effect, and impact. Statistically significant differences in metric values from the baseline measurements or model predictions are used to define change. The progression from change to effect to impact occurs when thresholds are exceeded. Thresholds are determined using a combination of science and policy.

4. Apply metrics across sites and technologies. A generic approach to evaluating change is needed to facilitate national monitoring policy and to compare MRE sites. An initial evaluation of measurement techniques, monitoring variables, and data analysis is needed to determine if metrics apply across sites and technologies. The three tidal MRE North American sites can be used as a case study.

5. Monitor sites over time. Assuming that stationary, autonomous samples will be cheaper than mobile surveys, three elements are needed to establish a long-term monitoring program: determine the spatial area represented by point samples (by matching temporally to spatially indexed variance); combine this "spatial representativeness" with variable detection probability and thresholds to determine monitoring instrument and instrument density; and detect effects and impacts using statistical tools to track metric values over time. When thresholds are exceeded alerts are issued to alter device operations or to mitigate impacts.

6. Scale from pilot to commercial site domains. Current MRE sites contain one or a few devices. The challenge of scaling environmental monitoring from a pilot to commercial domain parallels that of establishing monitoring around a single device. It is important to determine if the spatial footprint of a device and/or a whole array of devices is more than the sum of the parts. The proposed approach can be used to establish monitoring programs for commercial MRE sites. 


\subsubsection{Hydrodynamics and Beastie Monitoring at United Kingdom Marine Renewable Energy Sites}

\section{Presenter: Paul Bell, National Oceanography Centre}

Using developments in high-resolution physical modeling and state-of-the-art observation systems, FLOWBEC (FLOW and BEnthic Ecology) project aims to identify the physical conditions influencing the behavior of fish, their predators, and benthic communities, by concurrently measuring hydrodynamics and biology at three different MRE test sites. The three main project goals are as follows:

- to improve understanding of the fine-scale details of the flow regime in areas of high tidal and wave energy and the effects of MECs on flow conditions

- to assess the hydrodynamic habitat preferences of various relevant functional ecological groups (benthos, plankton, fish, birds, and mammals), and how individual species may use preferred flow conditions for successful feeding, reproduction, and other major biological activities

- to parameterize the flowfield with and without the effects of both single and multiple MEC deployments and include the mechanistic links to ecological interactions that would enable their inclusion in wider-area models. Such models would allow predictions of the effects of large arrays of MECs on the environment.

The EMEC has both a full-scale wave and full-scale tidal site. A subsea acoustic platform was deployed in summer 2013 to record continuous data with a Simrad EK60 echosounder and an Imagenex Delta T multibeam, as well as a Sontek acoustic Doppler velocimeter on the FLOWBEC frame for two periods of 2 weeks at the EMEC tidal site and then at the EMEC wave site.

Using these acoustic detection devices, the FLOWBEC team can track small targets and whales, as well as bathymetry, currents, and tides simultaneously. At EMEC, the FLOWBEC team has developed radar-derived bathymetry, and both flood and ebb tide radar-derived current vectors, and it is also investigating the implications of variations in sea surface roughness signatures.

Work has also been taking place at the WaveHub site off the southwest coast of the United Kingdom. The University of Plymouth has installed and has been operating a WavE RAdar (WERA) High Frequency radar and are studying waves and currents and their spatial variability across a large area that includes the WaveHub site. The University of Exeter has deployed a number of acoustic Doppler current profilers and wave buoys to study these spatial variations in situ.

The third site is Strangford Lough in Northern Ireland, where Queens University Belfast and the National University of Ireland, Galway, have deployed a drop-down video camera with underwater positioning system to survey the benthos in the general region of the SeaGen turbine to study any changes in the benthos attributable to the turbine, and the extent of any changes.

All three sites are being modeled for their hydrodynamics; Plymouth Marine Laboratory is applying the FVCOM (Finite Volume Coastal Ocean Model) to the WaveHub and EMEC sites, and University of Edinburgh is applying the FLUIDITY model in a Large Eddy Simulation of the Strangford Lough site, including a dynamic representation of the SeaGen device. 
An additional site studied as a result of the FLOWBEC project is the Meygen Tidal Energy Site at Pentland Firth. The PentlandX project involved a short (3-4 month) deployment of marine radar to allow for remote monitoring of currents, depths, small mammals, and whales. Both the Meygen's Inner Sound of Stroma site and Scottish Power Renewables' Ness of Duncansby site were within range of radar. The radar survey has been completed at Meygen and a publicly available report will be available early in 2014. Data analysis is ongoing and comparisons of the radar-derived currents with MIKE21 numerical model predictions are under way.

\subsection{Observing the Effects of Underwater Sound on Marine Animals, and the Regulatory Context that Drives these Observations}

This workshop session featured Probabilistic Models for Acoustic Changes and lessons learned from acoustic monitoring in the United Kingdom.

\subsubsection{Probabilistic Models for Acoustic Changes}

Presenter: Brian Polagye, University of Washington, Northwest National Marine Renewable Energy
Center

Regulatory "bright lines" for marine mammal exposure to underwater noise in the United States lead to a desire for concise answers to the question of "How loud are marine renewable energy converters?" In operation, converter sound is unlikely to exceed the levels established for acoustic injury at any range to a converter, but it may exceed the levels established for "acoustic harassment" or behavioral changes. However, in practice, the effects of MEC sound on marine mammals are likely to defy concise explanation.

As an example, consider the case of marine mammal detection of MEC sound (detection being a necessary, but not a sufficient condition for a behavioral response). To be detected by a marine mammal at a given distance from a MEC, the sound from the MEC at a given frequency must 1) exceed ambient noise levels and 2) exceed the marine mammal's hearing threshold. For urbanized locations, such as Admiralty Inlet in Puget Sound, Washington (United States), the difference between the 5th and 95th percentile ambient noise levels in a one-third octave band may exceed $30 \mathrm{~dB}$. A tidal turbine deployed at this location would also likely exhibit variability in its radiated noise level as a consequence of continual variation in tidal currents (both at turbulent time scales on the order of seconds and time scales on the order of minutes to months associated with mean tidal currents). Variations in turbine sound between the 5th and 95th operating percentiles are also likely to vary by more than $30 \mathrm{~dB}$ and may be correlated or uncorrelated with ambient noise, depending on the frequency band of interest. These variations give rise to a probabilistic model for describing the detection of turbine sound by a marine mammal. Consequently, a more effective approach to describing marine mammal behavioral responses to MEC sound may be one that considers the spatiotemporal variability in MEC-radiated sound and ambient noise in discrete frequency bands, rather than one that focuses on broadband received levels of MECradiated sound at a given instant in time.

Knowledge gaps impede the development of these more nuanced methods. For MECs, there are few publicly available data sets describing MEC sound as a function of inflow condition and operating state. Consequently, no generic models for MEC sound exist that can be incorporated into range-dependent 
acoustic propagation models. Similarly, it is not yet possible to compare the sound from different converters to evaluate commonalities and differences. For marine mammals, frequency-specific hearing thresholds vary with the individual, and identification of hearing thresholds for low-frequency cetaceans remains an active area of research. Until such information is available, it will be challenging to identify thresholds (even broad thresholds) at which the sound from MECs may affect marine mammal behavior.

\subsubsection{Lessons from Acoustic Monitoring in the United Kingdom}

\section{Presenter: Ben Wilson, Scottish Association for Marine Science}

Many lessons have been learned from acoustic monitoring in the United Kingdom. The potential environmental impacts of a single operational device have been gleaned, including turbulence mixing, collisions, noise, fouling and invasive species, artificial reefs, scouring, and electromagnetic fields. When looking at large arrays of devices, some of the same consequences, like collisions and noise, can be problems. Barrier effects and fishery redistributions become potential effects when studying larger arrays.

In wave-energy sites with vertical and oscillatory motion, acoustic recording systems record sound from complex distributed sources, like the Pelamis Wave Device (a floating attenuator WEC system), to gather data at a range of distances. The proper placement of the recorder system can ensure more accurate results.

In tidal-stream sites with horizontal water movement, hydrophone placement differs from placement in wave-energy sites where the hydrophones will move with the current. In this case, drifters are most efficient at recording data and move with the current.

As acoustic monitoring expertise has increased in the United Kingdom, developing converter-specific noise modeling has improved. In the process of modeling an ocean-energy device, it is important to understand how the MEC components generate noise. Modeling in this way allows the noise to originate from specific 3D locations on the MEC, instead of from a generic MEC source level representing the components in aggregate MEC. Further, the MEC noise is potentially amplified by the structure holding the MEC in place.

Tidal-stream energy devices can use acoustic devices to warn marine mammals; this may actually work simply because of the device's operational noise. For an array of devices, if the acoustic warnings or operational noise signals of multiple MECs overlap, an animal will be more likely to use array-scale collision avoidance instead of traveling in between individual devices. However, a noise-sensitive animal may also use array-scale collision avoidance, while a noise-insensitive animal may travel through the array. This example shows how noise can be assessed as more than just hearing damage. If a travelling animal perceives the noise, it may avoid the array and avoid collision. Animal response to detecting the device is a mystery, but the amount of noise may be able to guide the animal toward the proper response. This could lead to marine mammals avoiding a large space. Much of the current research has been done through playbacks of simulated turbine noise to both the nearfield and farfield habitats. Quantifying both the ambient noise and operating device noise will aid in understanding potential noise impacts on marine mammals. 



\subsection{Instrumentation Capabilities}

In considering instrumentation capabilities, each workshop breakout group considered the following questions:

- What are the primary challenges to achieving the desired instrument accuracy?

- What are the cost challenges?

- What are the power-supply challenges?

- What are the data -bandwidth and -processing challenges?

- Are observations seasonally or biologically limited?

- Are there durability or survivability limits for instruments in the marine environment?

- Are instruments safe and likely to be permitted in waters with sensitive species?

- Are deployments challenges caused by limitations associated with moorings or platforms?

Because of the broad disciplinary mix of the breakout groups, each group focused on different aspects of these questions.

\subsection{Active Acoustics}

\begin{tabular}{ll}
\hline Participant & Affiliation \\
\hline Jocelyn Brown-Saracino (Chair) & New West Technologies/Department of Energy \\
Beth Mackey & Royal Haskoning, DHV \\
Bryan Apell & Kleinschmidt \\
Gayle Zydlewski & University of Maine \\
Jeff Condiotty & Kongsberg Mesotech \\
Jim Dawson & BioSonics \\
John Horne & University of Washington \\
Keith Kirkendall & NOAA Northwest Region \\
Matt Cutlip & Federal Energy Regulatory Commission \\
Paul Bell & National Oceanography Centre \\
Peter Stein & Scientific Solutions Inc. \\
Simon Geerlofs & Pacific Northwest National Laboratory \\
Tom Carlson & Pacific Northwest National Laboratory \\
\hline
\end{tabular}

\subsubsection{Introduction}

This group discussed the capabilities and limitations of imaging sonars, scientific echosounders, active tags, and radar for monitoring animal baseline distributions and use and animal interactions with MECs. The discussion of these capabilities highlighted a few overarching points. Monitoring of large areas or volumes (such as the farfield) using active acoustics is a standard measurement with over six decades of supporting research, but applying these techniques to achieve MRE nearfield monitoring objectives requires spatiotemporal resolution (i.e., resolution sufficient to achieve taxonomic classification) that is challenging to achieve affordably. This economic challenge is compounded by what 
the group identified as a lack of individuals qualified to operate and customize existing software to meet the needs of the MRE industry. The group agreed that addressing the "educational gap" by training more students and/or technicians to work in conjunction with sensor manufacturers would be advantageous to the industry and more desirable than outsourcing this development to software companies.

\subsubsection{General Capabilities and Gaps for Imaging Sonars and Echosounders}

\subsubsection{Spatial and Temporal Limitations}

Most acoustic technologies are flexible in the choice of range/swath, frequency, and resolution, depending on configuration, deployment, and operation. Integration of multiple technologies can help achieve monitoring objectives and the resulting costs will depend on the type and number of instruments used in a monitoring program. For MRE monitoring, the group agreed that integration of technologies and devices may be the most feasible way to accomplish monitoring objectives at acceptable cost. This is challenging because integrated instrumentation packages may need to have cross-manufacturer communication capabilities. Currently this is a difficult task, because there has been limited demand for this capability in other areas of research. It was suggested that MRE researchers should agree on a set of operational requirements for monitoring programs and encourage development of open-source data formats that allow cross-manufacturer communications among and between instruments. One such common communication protocol might be XML syntax over the Ethernet.

Another challenge when using active acoustic instruments is the resolution of "near boundary" measurements (i.e., at the MEC, seabed, or water surface). The interface between a marine animal and the boundary may be hard to detect, which may obscure interactions between MECs and biological receptors. Military sonars for the detection of small objects in high-clutter environments (e.g., diver detection sonars) using track-before-alert processing offer some hope of following targets near boundaries. However, extensive work is required to train these systems to detect and track the receptors of interest for MRE projects (e.g., fish, marine mammals).

\subsubsection{Data Bandwidth and Power Requirements}

Data bandwidth (or data volume for storage) depends on how data are acquired and transferred from a device to the receiver (e.g., transmitting acquired data via satellite for systems with a surface expression, using acoustic modems for systems without a surface expression, using fiber-optic cables). In general, active acoustic instruments have high data bandwidth and storage needs — ranging from "high" to "very high" relative to other conventional oceanic instruments (e.g., water-quality sensors). Single-beam sonars have the lowest data bandwidth of the active acoustic instruments discussed by this group, but they are still relatively high in absolute terms, producing on the order of tens of megabytes per day, depending on the sampling range, sampling frequency, and duty cycle. To illustrate other technologies by example, a BioSonics DTX split-beam echosounder can produce approximately $15 \mathrm{~GB}$ of raw data in a 24-hour period, while a multi-beam sonar could produce more than $1000 \mathrm{~GB}$ of raw data within the same period. Data compression that covers several orders of magnitude is achievable through post-processing, depending on the observations of interest (e.g., extracting target tracks from raw split-beam or multi-beam sonar data). 
The group discussed examples of how operations involving active acoustic instruments can be complicated due to data bandwidth issues:

- A surface-deployed echosounder sends raw data over satellite internet, which then relays to a shore station for processing; however, the limited transmission speed may constrain communication with the instrument.

- Some satellite radio modem providers do not allow raw data to be transferred - rather they only allow short text messages, which can only be used for command and control purposes.

From the standpoint of power to operate these devices, short-term (i.e., days to months) autonomous deployments are possible, but, in general, sonars and echosounders require external power for extended deployments (i.e., more than a few months). The limitations placed on data and power by autonomous operation can be addressed by tying instruments into the power and communications cables for a MEC (post-MEC installation), though this can result in electrical interference if certain precautions are not taken. An alternative is to lay a dedicated cable from the instrument to shore (pre- or post-MEC installation). However, dedicated cables may require environmental permitting, are expensive, and can be at risk of failure in high-energy environments if appropriate protection measures are not used (e.g., armoring, trenching). For example, cables have been snagged by fisherman or damaged by currents and material such as gravel or cobbles moving along the seabed. Based on the group's experience, instrumentation cables at MRE sites may only last months unless armored cables are trenched into the seabed. Deployment of cables is often challenging and labor intensive, and the group agreed that instrumentation-specific seabed cabling will likely be cost prohibitive for most MRE applications. This presents a significant challenge to the use of active acoustics in a pre-MEC installation setting or postMEC installation remote from the MEC itself.

\subsubsection{Data Processing}

Automated data processing was identified as a high-priority for research and development. Large volumes of data are collected by active acoustic instruments over short time frames. The limiting factor in data processing is often manual inspection of data for bottom or surface inclusions or regions of bad data. This pre-processing is an area that would benefit from greater automation. The group estimated that in some cases, it would be possible to eliminate approximately $90 \%$ of the incoming data if measurement objectives are well-defined (e.g., marine animal tracks). Storage and bandwidth needs can be greatly reduced by filtering irrelevant data (i.e., empty water) using automated data processing algorithms, thereby reducing the amount of data that need to be post-processed and analyzed, or, if filtering can occur in situ, the amount of data that need to be stored or transmitted to shore.

The "holy grail" of active acoustics is species identification, but this is an area that requires further research and development. The challenge of species verification to identify acoustic targets is universal to all remote-sensing applications and improved processing algorithms are unlikely to fully address this problem. The general consensus among the group was that no algorithm could be expected to achieve perfect species identification; instead, algorithms will only be capable of classifying organisms into broad categories. The group disagreed on the suitability of split-/multi-beam echosounders to perform species identification. Split-beam echosounders cannot identify species unless multi-frequency arrangements are used to acquire data. Some members of the group felt that the industry was on the cusp of a research and development breakthrough for species identification using these systems, but there was not universal 
agreement on this point. For example, major advancements in military sonar processing may not be immediately available to the environmental monitoring community.

Automatic detection and tracking of animals is another high priority for research and development. Some existing specialized commercial software packages include such capabilities, but the software is not yet packaged in a form that is easily accessible to MEC developers. Algorithms in existing software are either open to public scrutiny or guarded by manufacturers, with the degree of transparency being dependent on the manufacturer. Some organizations maintain competitive advantages by having exclusive rights to their automated processing algorithms and it is unlikely that MEC developers or researchers will have access to the details of these algorithms. However, other organizations freely document their automated processing algorithms (e.g., VisualAcquisition by BioSonics, Echoview by Myriax).

\subsubsection{Seasonal, Biological, Atmospheric, and Environmental Limitations}

The overall ability to collect high- quality data depends on environmental conditions (weather), noise/clutter from boundaries, and entrained bubbles. Active acoustic instruments operate most effectively when signal-to-noise ratios (SNRs) are high, and the SNR may be dependent on both the site (e.g., variations between a site with heavy sediment loads versus clear water) and species of interest. Air entrainment (i.e., bubbles) will limit all types of active acoustic measurements. Bubbles can be present near the surface and extend to depth in high-energy environments. Biofouling on transducer heads can weaken signal strength, requiring shorter maintenance intervals or increased anti-fouling measures. There is also potential for the signals emitted from active acoustic instruments to bias the behavior of certain species (i.e., if animal avoidance is observed in close proximity to the MEC is the animal avoiding the MEC or the sonar signal?). Behavior modification will depend on the overlap between the auditory bandwidth of an animal and the broadcast frequency and source level of the active acoustic instrument. Currently, in the United States, operating frequencies and source levels are regulated for observations of marine mammals.

\subsubsection{Safety and Permitting Challenges}

All active acoustic technologies used in the United States must abide by the Marine Mammal Protection Act. Because active acoustic technologies generate noise as an inherent part of their function, there may be instances when the use of these devices is not permitted, or when it requires risk mitigation measures, either because of device properties or the presence of marine species. Different countries have different regulatory frameworks, and consent to use these devices to monitor MRE projects is likely to vary among countries. In regard to human safety associated with the use of active acoustic instruments, safety margins for vessel-based operation of active sonars decrease with current speed and, in nearshore operations, with decreasing boat size and inclement weather.

\subsubsection{Mooring and Platform Challenges}

Ensuring long-term survival of deployed acoustic infrastructure and retrieval of data requires improved mooring and/or platform design and, perhaps even more importantly, enhanced deployment strategies. Some MRE projects have reported an $\sim 50 \%$ occurrence of data and/or the instrumentation loss because of poor deployments or conflicts in deployment areas with other users of the ocean (e.g., fishing, 
recreation, military). This conflict of interests challenges researchers to design and implement 10- to 20-year data collection programs at costs affordable to the emerging MRE industry.

The group believes that the reliability of MRE moorings and/or platforms can be improved through closer discussions with ocean engineers who have had experience designing 10- to 20-year data collection programs. It is practical to assume that not all deployments will be successful when testing mooring and/or platform designs. Flexibility in costs and planning should be built into every project.

\subsubsection{Single-Beam and Split-Beam Echosounders}

Single-beam instruments are not well suited for monitoring direct interaction with MECs, but are appropriate for monitoring organisms in the nearfield, acting as triggering mechanisms for other instruments, or monitoring organisms in the farfield. For example, single-beam echosounders (e.g., a Simrad ES60) could be used to trigger other instruments within an integrated package. High-resolution (i.e., millimeter-scale) observations are possible, but necessitate a reduction in range/coverage. One basic challenge for monitoring MRE sites is deploying enough instruments to obtain sufficient coverage to address questions of interest (the definition of "sufficient" coverage being a subjective, case-by-case decision, at present). High spatial resolution sampling typically reduces range, but sampling domains can be increased by coupling instruments in an array. It is possible to manufacture affordable transducers and coordinate sampling (i.e., multiplexing) at high speed to achieve sampling of large domains at high resolution.

Split-beam echosounders (e.g., Simrad EK60 or BioSonics DT-X) can provide target trajectory and target size estimation. In the context of monitoring MRE projects, these instruments are likely best suited for long-range detection, tracking, and acting as "trigger mechanisms" for other systems. Data can be processed by the instrument during acquisition or remotely depending on the required precision and timeliness of data reception. Automatic data processing is currently available for some data attributes (e.g., fish tracking), but other data attributes may require further development and/or software customization; software licensing costs can be substantial.

Data retrieval was identified as one of the highest priority research and development needs for active acoustic technologies. The group felt that the odds of a successful deployment/recovery is currently somewhat low, primarily due to approaches for deployment/recovery, as well as survivability of underwater cables and connectors, although the instruments themselves appear to be more robust.

Development effort is needed on the integration of acoustic instruments with other sensors to reduce data bandwidth and improve data interpretation. For example, detection by a split-beam echosounder could trigger an optical (or acoustic) camera to initiate higher resolution recordings that allow for species identification. Development of integrated instrumentation should be coupled with automated pre- and post-processing software. Processing algorithms for split-beam echosounders are generally welldocumented in the scientific literature. A limited number of commercial packages are currently available (e.g., Echoview, SonarX, LSSS), but the purchase and maintenance costs may be prohibitive for MRE monitoring programs. Some members of the group suggested that processing software can be difficult to customize for specific needs of the MRE industry, though this was not universally agreed upon. 


\subsubsection{Multi-Beam Echosounder}

Multi-beam echosounders are similar to split-beam echosounders, but they have much wider beam angles (e.g., 90 to $180^{\circ}$ versus 10 to $20^{\circ}$ in split-beam echosounders). These echosounders are not appropriate for monitoring direct interactions with a MEC. However, they may be well-suited for observing the interface between the nearfield and the farfield from a deployment point on or near a MEC. A new generation of multi-beam sonars designed for quantitative investigation may be of greater utility for MRE monitoring than existing instruments designed for imaging or bathymetric mapping.

\subsubsection{Two-Dimensional Imaging Sonar}

Two-dimensional (2D) imaging sonar may allow an operator to differentiate between a biological target and a MEC, making it suitable for short-range observations of interactions between MECs and larger animals. This technology is suitable for "near boundary" type measurements, but has limited range (depending on the deployment strategy), may have limited areal coverage, and may not be suitable for quantitative applications. Feature extraction capabilities and automated algorithms for counting animals need to be developed. To increase the number of instruments that can be used in standard monitoring packages, standard data formats that can be input into a wider range of image processing software for automated processing and subsequent analysis are needed. The cost of imaging sonars ranges in price from equivalent to much more expensive than single- and split-beam echosounders. Higher costs associated with less mature post-processing methods are a weakness when comparing system costs for imaging sonars to more mature technologies.

\subsubsection{Three-Dimensional Scanning Sonar}

Three-dimensional imaging sonar can be used to observe animal behaviors over a wide area, but are not appropriate for detecting interactions with MECs. Future research and development is needed to improve the quantitative abilities of this technology and in automated processing.

\subsubsection{Broadband Multi-Beam Echosounders}

Broadband multi-beam echosounders increase the operating frequency spectrum of 2D or 3D sonars with comparable beam swaths and sampling resolution. The wider frequency bandwidth potentially improves target detection and identification relative to single-frequency instruments in the presence of ambient noise (i.e., "clutter"). These instruments are not appropriate for observing direct interactions with a MEC. The price of this technology is comparable to other active acoustic instruments for qualitative evaluations, but broadband scientific echosounders for quantitative study may be an order of magnitude more expensive. Automated data processing software is not yet widely available for these instruments and has not been customized for MRE applications.

\subsubsection{Radar}

Radar can be used to track very small targets (e.g., birds, insects) at a range of several kilometers, regardless of ambient light conditions, making it an attractive technology for monitoring species distribution and presence at the air-sea interface around MECs. Like other acoustic technologies, radar 
can be used to trigger other instruments as part of an integrated package. Radar is generally limited to detecting presence and trajectories of targets and cannot be used to identify species. Clutter from ocean waves can interfere with radar measurements near the surface, resulting in the reduction or elimination of detections of interactions with MECs at the air-sea interface (similar to "near boundary" limitations of underwater acoustics). Platform stability is a challenge if radar is deployed on ocean-surface platforms (e.g., mooring, surface vessel) during a mobile survey. Radar is likely to be more effective when deployed from a high vantage point on shore and can provide coverage of an entire MRE project site. Radar can be relatively inexpensive to deploy and can also measure wave fields and surface currents to help predict movement of organisms in a project area.

Manual processing of radar data is nearly impossible because of the data volume (on the order of 5-10 GB per day after automated post-processing and compression; these data still require considerable additional processing to extract hydrodynamic information or track marine animals), and the group suggested that research and development could advance automated data processing. Stabilization of radar on mobile platforms is another challenge that might be addressed by further development of affordable stabilization platforms or movement correction algorithms. Finally, work to enhance integration of radar with other ocean observatory systems would be beneficial.

\subsubsection{Active Tags}

Active acoustic tags can provide data on species' movements around MRE projects. However, tagging can bias observations; tags cannot be attached to all species; the cost to tag a sufficient number of individuals within a population may be unacceptably high; and tag battery life often limits the extent of data sets. Improved quantitative assessments to counter bias would require new approaches in tagging. There is also opportunity for false-positive detections (i.e., tag receivers detect random "pings" as a tag). Increasing the number of tagged animals will increase costs, and there is a corresponding overhead cost for validating detection (i.e., minimizing false positives) that further increases costs for larger tagging studies. Split-beam and multi-beam echosounder systems can be used to listen to and track acoustic tags, but to do so, the tag must pass through the acoustic beam to be detected (at which point a pan-and-tilt system could be used to track the tag and keep it within the acoustic field). As an alternative approach, omnidirectional passive acoustic arrays (using beamforming) could also be used to detect and localize tags, then pass this information to an active acoustic or optical instrumentation package (e.g., McMichael et al. 2010).

\subsubsection{Conclusions}

Integrated monitoring packages can be designed to provide measurements at an appropriate resolution, range, and duty cycle to meet MRE monitoring objectives. Measurements of habitat use and distribution should ideally use spatial surveys (e.g., manned vessels, autonomous vehicles) for reconnaissance, followed by the use of bottom-deployed, stationary platforms for long-term monitoring. In addition, the following conclusions were derived from the discussion:

- Data processing and automation pose significant challenges. Given the data-intensity of active acoustic monitoring, automated data processing and the integration of multiple instruments were the two most common topics identified for further research and development. For high-resolution observations in the nearfield of a MEC, automation of most data processing is needed to minimize cost. 
- Direct interaction with a MEC (strike, collision, abrasion) is not currently observable with most of these technologies. While, 2D imaging sonar can measure direct interaction, shortcomings in automated data processing and instrument integration still need to be addressed. Software developers are exploring techniques to process 2D imaging sonar data, including motion-detection and patternrecognition algorithms, but these are not yet commercially available and are analogous to the challenges faced in optical image processing Section 4.3.1). Automated processing of split-beam acoustic data is routine, and while these systems are not suitable for observation of direct interaction with a MEC, they can be used to characterize animal density in close proximity to a MEC and/or throughout a MRE site.

- Integration of multiple instrument systems offers great potential to improve overall monitoring capabilities. The group suggested that integration of instruments could help fill the large knowledge gap at the interface between the nearfield and farfield. The group recommended that future discussions examine all categories of instruments to leverage the relative strengths of each instrument within an integrated package. The group consensus is that no single instrument will be a "silver bullet" for MRE monitoring and that the most feasible solution will include a network of instruments that can "trigger" other instruments as organisms come within the threshold proximity of a MEC. Networks of instruments, along with automated processing, can help to alleviate the data bandwidth and storage problems commonly associated with continuous operation of active acoustic instruments. An integrated system with automated data processing will help to minimize monitoring costs by concentrating analysis time on highest priority data. Other deployment and operational costs associated with deploying suites of instrument packages in high-energy environments may negate the value of gains in data processing, particularly if the sensors require separate mounting platforms and interconnection cables in these environments. Given the niche nature of the MRE monitoring market, the translation of MRE objectives to generic environmental monitoring is a potential path to encouraging equipment manufacturers and software developers to invest in product research and development.

- Deployment and survival in a high-energy environment is challenging. Monitoring capabilities would be enhanced by research that increases the survivability of instrument packages in high-energy environments and further development of reliable remote instrumentation deployment and retrieval systems.

\subsection{Passive Acoustics}

\begin{tabular}{ll}
\hline Participant & Affiliation \\
\hline Hoyt Battey (chair) & U.S. Department of Energy \\
Chris Bassett & University of Washington \\
Manuel Castellote & National Marine Mammal Laboratory, Alaska \\
& Fisheries Science Center, NMFS/NOAA. \\
Andrea Copping & Pacific Northwest National Laboratory \\
Peter Dahl & University of Washington \\
Joe Haxel & Oregon State University \\
Erick Johnson & University of Montana \\
Nathan Johnson & Ocean Renewable Power Company \\
Sharon Nieukirk & Oregon State University \\
Anna Redden & Acadia University
\end{tabular}




\begin{tabular}{ll}
\hline Participant & Affiliation \\
\hline Greg Sanders & Bureau of Ocean Energy Management \\
Courtney Smith & U.S. Department of Energy \\
Paul Thompson & University of Aberdeen \\
Ben Wilson & Scottish Association for Marine Science \\
\hline
\end{tabular}

\subsubsection{Introduction}

Participants in the passive acoustic breakout session broadly discussed available passive acoustic monitoring (PAM) instrumentation devices; specifically, the use of fixed listening devices (hydrophones) versus drifting platforms, as well as instruments that also measure particle motion (i.e., vector sensors). Much of the discussion focused on the challenges of obtaining measurements in extreme environments and the costs and benefits of deploying PAM instrumentation in these settings.

PAM tools can also be useful for assessing the overall distribution of some marine species, as well as how they behave or use the nearfield of MECs. These nearfield areas are difficult to monitor, but PAM at nearby, less energetic control sites may help to provide information about the habitat use and distribution of animals in the vicinity of MECs. The group also agreed that well-placed hydrophones and hydrophone arrays could be used to localize and potentially track animals in the nearfield of an operating MEC. ${ }^{1}$ However, this is only useful when the animal is acoustically active (vocalizing or echolocating). It should be noted that monitoring for some pinnipeds may be challenging, because they do not echolocate and are believed to have evolved to communicate through visual or tactile modalities, rather than acoustically (Schusterman et al. 2000), and their acoustic displays tend to be seasonally associated with breeding periods. Directionality of the acoustic signals is also a limiting factor in detecting and tracking echolocating odontocetes in the nearfield. For example, harbor porpoise echolocation clicks are highly directional and detection may vary with instrument placement/orientation. The group's discussions focused on instrumentation to monitor and detect marine mammals, even though some fish produce sound. The acoustic signals from fish are harder to detect and identify because they tend to be relatively quiet, their frequency ranges fall within that of background noise, and there is general uncertainty about how to classify and process PAM signals for fish.

Ambient noise inherent to high-energy environments are a hindrance to PAM, raising the question of whether detecting marine species is possible under all MEC operating conditions. Monitoring in tidal channels is likely to be more difficult than monitoring around WECs because of high-velocity flows. Sound generated by sediment transport during tidal exchange can be intense and affect frequencies above $1000 \mathrm{~Hz}$, often covering the entire range of mid-frequency cetacean echolocation frequencies. Baleen whales may also be present in certain tidal sites, migrating through narrow corridors and entering constricted spaces (e.g., False Pass, Alaska, USA). At low frequencies (below $1000 \mathrm{~Hz}$ ), noise associated with wave action or tidal currents may mask baleen whale signals.

\footnotetext{
${ }^{1}$ Localization was also discussed in another breakout session (see Section 5.2.1). That group agreed that while it should be possible to obtain the horizontal position of an animal relative to the receiver array, estimating animal depth in shallow-water environments would be quite difficult. Further, the group noted that for localization around tidal (current) energy converters there are asymmetrical detection requirements and upstream position information are more important. Hydrophone arrays may be better suited to definitive classification of sources, while providing a coarse degree of localization that could serve as a triggering/aiming mechanism for active sonars.
} 
The group also discussed the general uncertainty around sound exposure criteria (e.g., Southall et al. 2007), emphasizing the thresholds set for marine mammals. In the United States, these thresholds are currently undergoing revision (NOAA Fisheries 2013). In cases where acoustic signals (biological or sound from a MEC) have a low source level amid high ambient noise conditions, low SNRs will occur. This makes it difficult to understand when or how an animal might perceive noise from a MEC. Understanding how noise propagates from a MEC and at what distance an animal receives it is important in characterizing thresholds for behavioral changes.

\subsubsection{Hydrophones}

\subsubsection{Fixed Hydrophones}

Fixed PAM systems based on hydrophones have been used extensively for marine bioacoustic monitoring. These systems are generally split into two categories: cabled and autonomous. Cabled hydrophone systems are usually permanent or semi-permanent deployments and often costly to maintain, but enable continuous near real-time monitoring and allow instrument failures to be rapidly detected and corrected. However, because of the large differences in costs and portability, environmental studies used for siting of MECs generally use autonomous systems. Autonomous systems are fixed to the seafloor and are designed to include at a minimum, hydrophones and battery-powered recording and data storage systems. There are dozens of autonomous recorders used for PAM (see Sousa-Lima et al. 2013 for a review), each varying in design, capability, and cost. Pre-processing within autonomous recorders allows the user to program detection thresholds at set frequency bandwidths and duty cycles (scheduled periods of recording) so that only signals of interest are recorded. This limits the amount of "dead space" recorded which maximizes storage space for usable data, and minimizes the need for post-processing detection and filtering for signals of interest. However, autonomous recorders require retrieval of the unit to process data and in some cases the units may be lost, intercepted, stolen, or damaged by other parties (Sousa-Lima et al. 2013).

Participants in the breakout group stated that C-PODs, a type of small autonomous echolocation logger, are effective for monitoring harbor porpoises and other odontocetes except sperm whales, for siting and construction of marine renewable devices. C-PODs require user calibrations, and it may be challenging to determine if the units are working consistently across time and across devices, particularly with shifts in sensitivities (Dähne et al. 2013). In spite of these limitations, the group generally agreed that C-PODs are ideal for monitoring. It should be noted that cetacean echolocation signals do not propagate as well as social signals in seawater; PAM monitoring programs that rely on echolocation detection will require a higher density of instrumentation per unit area than a program relying on detection of social signals.

Fixed PAM systems have been used to measure sound signatures and ambient noise fields during site characterizations studies for proposed MEC deployments. The major challenge associated with fixed PAM systems in high-energy areas is the masking associated with flow-noise generated by the water flowing around the hydrophone capsule or self noise from the mooring structure. Post-processing filtering that removes low-frequency flow noise and self noise from fixed hydrophones can be problematic if this excludes signals of interest. Mitigation techniques, such as flow shields, could maximize data capture. However, flow shields are also subject to the destructive force of waves and tides 
(this topic is discussed further in Section 5.2.1). An alternative to flow shielding is beamforming in which signal correlations between arrays of hydrophones are used to differentiate between point sources of sound and ambient noise.

Many different hydrophone systems are currently being used; many researchers or technical designers shield them differently. There are concerns that shielding may attenuate the acoustic signal of interest, thus limiting the detection range of the PAM system. Standardizing flow-noise mitigation with an engineering solution (i.e., a uniform shielding system) may be helpful. The incorporation of high-quality clocks within individual PAM devices is encouraged to synchronize multiple, autonomous systems. At tidal energy sites, placement of the fixed PAM instrumentation should be well off the seafloor so that sediment transport noise will not unduly mask signals of interest, to reduce the opportunity for damage to the PAM system.

When using autonomous fixed hydrophones, it is important to have a reliable acoustic release system with limited vibration, because this will reduce self noise. When deploying fixed systems, it is also important to determine whether mobile seabed sediments might bury fixed hydrophones.

\subsubsection{Hydrophone Arrays}

The detection range of fixed PAM systems may also be a challenge for monitoring. Sound propagation is highly variable, depending on sound speed profiles, bathymetry, and the composition of the seabed. The use of multiple hydrophones in a spatially distributed arrangement may be one way to improve SNRs for acoustic detection of marine animals and MECs. The group discussed whether it was possible, with such an arrangement, to simultaneously monitor for both animals and MECs. It may be possible to use some of the hydrophones within a spatially distributed network to monitor the MEC and others to monitor animals. Some participants argued that monitoring noise generated by MECs is a shortterm measurement (that is, the fully characterized acoustic signature of the converter is unlikely to change much over the course of a deployment), whereas monitoring for animal presence and distribution to assess potential impacts and effects would require longer-term monitoring.

One of the greatest challenges to PAM use around WECs is the high variability in the WEC design. In general, the participants concluded that fixed hydrophones (individual hydrophones, distributed arrays, or small-aperture arrays) are needed to monitor the environment around WECs. This will enable the characterization of the noise from the WEC device itself, as well as monitoring for species of interest in the vicinity of the WEC. However, ambient noise conditions and noise from WECs may cause some masking of low-frequency bioacoustic signals. This may be alleviated by the use of multiple fixed PAM devices synchronized to allow beamforming capabilities, boosting the SNR when undesired noise and signals of interest have different angles of arrival. Finally, the group agreed that fixed arrays could be used at planned WEC sites to characterize shifts in ambient noise levels before and after the WECs are deployed. Further discussion of WEC sound monitoring is presented in Section 0.

\subsubsection{Drifting Hydrophones}

Drifting hydrophones have been proposed as a solution to mitigating flow noise, because a drifting system is able to minimize the relative velocity between the water and hydrophone. Drifting systems are often packaged with Global Positioning System (GPS) units, allowing them to investigate spatial 
variability in the acoustic soundscape of an MRE site. This combination of acoustic and spatial data could also enable localization and tracking of some marine species, though it may involve intensive postprocessing and modeling. Given that drifting hydrophones move with tides and currents, geo-referencing these areas of high-flow energy might help to identify locations ideal for fixed mooring systems. Overall, the participants agreed that drifting hydrophones are ideal for monitoring of tidal (current) energy converter (TEC) sound and may be helpful for characterizing marine animal presence/absence (Wilson et al. 2013). However, in some cases, a high level of survey effort would be required to develop statistically representative descriptions of ambient noise and marine mammal presence. The high-energy wave climate makes use of a drifting sensor much more challenging, with an increased risk of instrumentation loss and, in these environments, fixed hydrophones may be more suitable, as discussed in Section 5.3.

Limitations of drifting systems include the duration of sampling, given the costs associated with deploying and recovering drifters. Depending on the site characteristics, drifting systems may need to be monitored visually to retrieve them before they are at risk of destruction (e.g., Macaulay et al. 2013). This can be a limiting factor, because long-term recordings are needed to characterize a site and to assess how marine species are using an area. Used in combination with fixed arrays placed in high-energy areas, drifting hydrophones could be a powerful tool for gathering information about movements and habitat use of animals and their associated behaviors. It was also suggested that the presence of drifting buoys may influence the behavior of some species, which may be exacerbated in areas of high animal density.

For TECs, it was suggested that drifters could be deployed for TEC sound characterization only when the converter is operating (which can be largely predicted), thus eliminating the need for continuously operating PAM infrastructure to characterize TEC sound. While drifting hydrophones at TEC sites would be hard-pressed to characterize animal habitat use, this may be possible in areas with known high animal density. For example, drifting arrays are currently being used in the United Kingdom to quantify porpoise diving behavior in tidal sites (Macaulay et al. 2013).

\subsubsection{Vector Sensors}

Vector sensors are able to measure both the particle motion and pressure changes associated with sound waves. This allows the instrument to determine the directionality of an acoustic signal from a point measurement. This could be an ideal tool for determining the noise signatures of MECs, as well as localizing biological signals of interest (such as marine mammal vocalizations), which would otherwise require an array of synchronized hydrophones. Unfortunately, there is no experience with vector sensor performance in high wave and tidal environments. Several participants also asserted that calibrating vector sensors is incredibly challenging, particularly for larger wavelengths (i.e., lower frequencies).

\subsubsection{Data Processing}

The relatively low power and storage requirements of PAM systems make for an efficient dataacquisition system, often resulting in the generation of large amounts of data in a relatively short time span. As a result, data management and pre- and post-processing of PAM systems are high priorities for development. Pre-processing measures, such as automatic detection thresholds for specific species, is one strategy for reducing efforts in sorting through data to identify the presence/absence species of interest. The C-POD is a highly effective tool for this, because it can be set to recognize and record clicks from 
specific species. Likewise, post-processing signal detection (with species-specific detection codes) can be implemented to filter large data sets. The group agreed that there is much work to be done in quantitatively assessing the detection, classification, and localization of marine mammal species.

The discussion also included a point that, in the United States, the U.S. Navy desires and often has authority/control over all PAM deployments and the data accrued from these systems. In some cases, this imposes limitations in monitoring certain frequency bands (particularly low frequencies), and the U.S. Navy has been known to censor data sets or require special permits for PAM deployments. The group suggested that clear coordination between research and industry groups and federal agencies would be useful in maximizing the amount of useful information collected.

The group also discussed whether there was a more cost-effective way to process broadband data generated from PAM systems. In addition to tailoring instrumentation specifically for a site, the participants generally concluded that collaborative efforts should increase between parties working in wave and tidal energy sites as a means to leverage the knowledge. For example, collaboration between research/academic groups and industry partners on developing devices that would meet the needs discussed in the workshop itself should be more prevalent. The participants also pointed out that most monitoring technologies and devices are produced by small, low-capitalized companies that are also small enough to cater to the thoughts and needs of the research community.

It was discussed whether there is a single instrument or pre-processing software that could be a catchall for measuring and monitoring all aspects of interest (noise signature of MECs, biological sounds, ambient conditions). The group consensus was that this was an unrealistic expectation and that PAM tools should be tailored specifically for sites and individual needs (e.g., C-PODs are appropriate for monitoring most odontocetes species, but will not detect or record baleen whales). The group also agreed that it is better to avoid developing new approaches for all environments and instead use the existing technology in configurations that have already been proven in a specific environment. It may also be helpful to combine existing technologies into packages fit for specific sites.

\subsubsection{Conclusions}

PAM systems must be sufficiently robust to withstand the high-energy environments that are most conducive to harnessing wave and tidal energy. Monitoring in energetic environments presents unique challenges for characterizing the noise signatures of MECs, as well as biological organisms (notably marine mammals) that may be affected by MECs. Mitigation measures, such as flow shields or multielement hydrophone arrays, can reduce flow noise for fixed hydrophones, although further development is required in the area of flow-noise minimization. In addition, fixed equipment is more likely to be damaged or lost in tidal current areas than in more conventional PAM deployments.

PAM systems should be highly tailored and specific to the MEC site (mode of deployment), the MEC itself (type of device), and the species that are most likely to be encountered or of concern (PAM detection and identification capabilities). For example, if a site has few baleen whales, but is well known for porpoises, C-PODs or other automated detections systems can use pre-processing to reduce the volume of useless data that would otherwise be collected by continuous monitoring. 
The technologies for comprehensive PAM exists, but should be integrated into packages specific to the sites of the MEC to be monitored. Multiple systems should be packaged to allow for concurrent monitoring of biological signals, noise generated from the MEC, and ambient noise.

\subsection{Optical Technologies}

\begin{tabular}{ll}
\hline Participant & Affiliation \\
\hline Sharon Kramer (chair) & H.T. Harvey \& Associates \\
Brian Polagye & University of Washington \\
Gretchen Steiger & Cascadia Research \\
Hoyt Battey & U.S. Department of Energy \\
Ian Hutchison & Aquatera \\
Jesse Roberts & Sandia National Laboratories \\
Jim Boutiller & DFO Canada, Pacific Biological Station \\
Kate Mansfield & Florida International University \\
Mel Broadhurst & Alderney Wildlife Trust \\
Rob Suryan & Oregon State University \\
Rodrigo Hucke G. & Universidad Austral de Chile \\
\hline
\end{tabular}

\subsubsection{Introduction}

Breakout group discussions focused on the deployment of optical monitoring technologies from various platforms, as follows:

- remotely operated vehicles (ROVs)

- manned submersibles

- surface vessels

- landers and sleds

- autonomous underwater vehicles (AUVs)

- animal-borne "critter cams"

- fixed, cabled vantage points above the water surface

- fixed, cabled vantage points below the water surface

- aerial vehicles, including unmanned aerial vehicles (UAVs).

While these discussions focused on optical monitoring technologies, similar considerations often apply to the deployment of active acoustic instrumentation from these platforms (see Section 4.1); for example, ROVs can support imaging sonars. 
These platforms were evaluated for monitoring around WECs and TECs for nearfield converter interactions with organisms, as well as changes in species distribution and habitat use at the array scale. The evaluations were made in terms of

- general suitability, including cost considerations

- limitations associated with seasonal, biological, water quality, or atmospheric factors

- durability and survivability in the marine environment

- safety and permitting.

Not all combinations of platform, MEC, and survey type were discussed. In the summary tables in the following sections, "white" cells denote a combination that was not discussed in detail; "green" cells denote an area with few challenges, "yellow" cells denote an area with moderate challenges, and "red" cells denote an area with significant challenges.

Optical monitoring has the potential to rapidly produce large volumes of data (e.g., >100 MB/s). Effective use of optical monitoring data often requires automated post-processing and duty cycling. The needs for automated image processing in the context of MRE are similar to those in other contexts, such as aquaculture density counting (Petrell et al. 1997). Two illustrative examples are given here.

Boom et al. (2012) describe an automated system for detection and classification of fish recorded by an undersea observation network of 10 cameras operating for 12 hours each day. The automated system uses a 96-processor computing cluster, populating a database of detections and classifications that are then accessible by marine biologists. Early results from the system are promising; the system provides coarse taxonomic classification by matching color, contour, and texture under a hierarchical classification scheme (described further by Huang et al. [2012]). However, the system remains under development and, with existing computing hardware, is only able to process 4 hours of video footage each day.

Matai et al. (2012) describe the development and testing of algorithms to detect and identify fish species in still images. The algorithm was able to detect more than $60 \%$ of the fish in a training data set consisting of images of Scythe butterfly fish collected in an aquarium with an acceptable false-positive rate. However, the algorithm detected fewer than half of the fish in a training data set consisting of images of flagg rockfish collected in situ by an ROV. Identification algorithms functioned well in controlled cases (i.e., controlled aspect and illumination of images), but were not tested on in situ images.

These examples demonstrate both the promise and the challenge of automated processing of optical imagery. 


\subsubsection{Remotely Operated Vehicles}

ROVs can deploy video, still, or stereo optical cameras with infrared/far-red, strobe, or continuous sources of illumination. ROV capabilities are summarized in Table 4.1.

Table 4.1. Optical capability summary for remotely operated vehicles.

\begin{tabular}{|c|c|c|c|c|c|}
\hline & & Suitability & $\begin{array}{c}\text { Seasonal or } \\
\text { Biological } \\
\text { Limitations }\end{array}$ & $\begin{array}{c}\text { Marine } \\
\text { Durability and } \\
\text { Survivability }\end{array}$ & $\begin{array}{l}\text { Safety and } \\
\text { Permitting }\end{array}$ \\
\hline Near-MEC & TEC & & & & \\
\hline Interactions & WEC & & & & \\
\hline Distribution and & TEC & & & & \\
\hline Use & WEC & & & & \\
\hline
\end{tabular}

White cells denote a combination that was not discussed in detail, green cells denote an area with few challenges, and yellow cells denote an area with moderate challenges.

\subsubsection{Suitability}

Optical monitoring by ROVs is a proven technology for evaluating subsea equipment, invertebrate colonization, and benthic habitat. This makes ROVs well-suited for observations of static interactions with individual MECs, but they may not be practical for monitoring large areas or large MEC arrays. Affordable ROVs have limited capabilities to operate in strong currents or energetic wave conditions. However, ROVs are also used by developers to inspect MECs and, therefore, likely to be available for opportunistic environmental observations.

\subsubsection{Seasonal or Biological Limitations}

Observations from ROVs are limited by water clarity. Artificial lighting that could affect motile species behavior is required at night or at depth. Similarly, the noise from ROVs may affect motile species behavior.

\subsubsection{Marine Durability and Survivability}

Around TECs, ROVs can only realistically be deployed during the weakest neap tides or during short periods of slack water. This limits observations to periods during which TECs would be idle. Similar considerations apply to observations during high-energy wave conditions, but pose fewer restrictions for monitoring WECs.

\subsubsection{Safety and Permitting}

Moderate safety concerns are associated with deploying ROVs around TECs because of the persistence of currents. Some developers restrict how close an ROV and its support vessel can be operated near a MEC out of concern for ROV umbilical entanglement with the MEC mooring or structure. Limited or no permits are currently required for ROV surveys (limited in the United States, none in the United Kingdom), but could become more burdensome in the future. For example, aerial 
observation of a sea turtle is counted as a "take" in the United States. Similar application of "take" to ROV observations would severely restrict their utility.

\subsubsection{Manned Submersibles}

Manned submersibles can deploy video, still, or stereo optical cameras with infrared/far-red, strobe, or continuous sources of illumination. Their capabilities are summarized in Table 4.2.

Table 4.2. Optical capability summary for manned submersibles.

\begin{tabular}{ccccc}
\hline & Suitability & $\begin{array}{c}\text { Seasonal or } \\
\text { Biological } \\
\text { Limitations }\end{array}$ & $\begin{array}{c}\text { Marine } \\
\text { Durability and } \\
\text { Survivability }\end{array}$ & $\begin{array}{c}\text { Safety and } \\
\text { Permitting }\end{array}$ \\
\hline Near-MEC & TEC & & & \\
Interactions & WEC & & & \\
Distribution and & TEC & & & \\
Use & WEC & & & \\
\hline
\end{tabular}

White cells denote a combination that was not discussed in detail, green cells denote an area with few challenges, yellow cells denote an area with moderate challenges, and red cells denote an area with significant challenges.

\subsubsection{Suitability}

Submersibles have many of the same limitations as ROVs, but have more limited bottom time and are more costly to operate. This makes them particularly poorly suited for studies of species distribution and habitat use and only of moderate interest for near-MEC interaction studies. Submersibles face many of the same challenges to operating in strong currents as ROVs, but may be able to operate more freely at wave-energy sites if they can be decoupled from a surface vessel.

\subsubsection{Seasonal or Biological Limitations}

Observations from submersibles are limited by water clarity. Artificial lighting that could affect species behavior is required at night or at depth. Similarly, the noise from submersibles may affect species behavior.

\subsubsection{Marine Durability and Survivability}

Around TECs, submersibles can only realistically be deployed during the weakest neap tides or during short periods of slack water. This limits observations to periods during which TECs would be idle.

\subsubsection{Safety and Permitting}

In addition to the safety and permitting concerns for ROVs, manned submersibles introduce a range of non-trivial human safety concerns. 


\subsubsection{Surface Vessels}

Surface vessels can support cameras or human observers. Their capabilities are summarized in Table 4.3.

Table 4.3. Optical capability summary for surface vessels.

\begin{tabular}{|c|c|c|c|c|c|}
\hline & & Suitability & $\begin{array}{l}\text { Seasonal or } \\
\text { Biological } \\
\text { Limitations }\end{array}$ & $\begin{array}{c}\text { Marine } \\
\text { Durability and } \\
\text { Survivability }\end{array}$ & $\begin{array}{l}\text { Safety and } \\
\text { Permitting }\end{array}$ \\
\hline $\begin{array}{l}\text { Near-MEC } \\
\text { Interactions }\end{array}$ & $\begin{array}{l}\text { TEC } \\
\text { WEC }\end{array}$ & & & & \\
\hline $\begin{array}{c}\text { Distribution and } \\
\text { Use }\end{array}$ & $\begin{array}{l}\text { TEC } \\
\text { WEC }\end{array}$ & & & & \\
\hline
\end{tabular}

White cells denote a combination that was not discussed in detail, green cells denote an area with few challenges, yellow cells denote an area with moderate challenges, and red cells denote an area with significant challenges.

\subsubsection{Suitability}

Observations of species distribution and habitat use from surface vessels are common (e.g., line transect analysis) and may be particularly well-suited to observations from work boats that are regularly active on site. Vessel-based optical surveys are most relevant for marine mammals, turtles, and birds. Studying near-MEC interactions from surface vessels may be possible for seabirds, but would be of limited utility for marine mammals and sea turtles (unless the interaction of interest takes place above the water surface).

\subsubsection{Seasonal or Biological Limitations}

Observations from surface vessels are limited by atmospheric conditions and light. The noise and presence of the surface vessel may affect species behavior.

\subsubsection{Marine Durability and Survivability}

Vessel operations are challenging during periods of energetic currents or waves and may be restricted in marine "safety zones" established around MECs and MEC arrays. 


\subsubsection{Landers and Sleds}

Bottom landers or sleds controlled by a surface vessel can deploy video, still, or stereo optical cameras with infrared/far-red, strobe, or continuous sources of illumination. Their capabilities are summarized in Table 4.4.

Table 4.4. Optical capability summary for landers and sleds.

\begin{tabular}{|c|c|c|c|c|c|}
\hline & & Suitability & $\begin{array}{c}\text { Seasonal or } \\
\text { Biological } \\
\text { Limitations }\end{array}$ & $\begin{array}{c}\text { Marine } \\
\text { Durability and } \\
\text { Survivability }\end{array}$ & $\begin{array}{l}\text { Safety and } \\
\text { Permitting }\end{array}$ \\
\hline $\begin{array}{l}\text { Near-MEC } \\
\text { Interactions }\end{array}$ & $\begin{array}{l}\text { TEC } \\
\text { WEC }\end{array}$ & & & & \\
\hline $\begin{array}{c}\text { Distribution and } \\
\text { Use }\end{array}$ & $\begin{array}{l}\text { TEC } \\
\text { WEC }\end{array}$ & & & & \\
\hline \multicolumn{6}{|c|}{$\begin{array}{l}\text { White cells denote a combination that was not discussed in detail, green cells denote an area with few } \\
\text { challenges, yellow cells denote an area with moderate challenges, and red cells denote an area with } \\
\text { significant challenges. }\end{array}$} \\
\hline
\end{tabular}

\subsubsection{Suitability}

Bottom landers and sleds are in routine oceanographic use and may be moderately well-suited for observations of species distribution and habitat use. However, it is unlikely that these units could be maneuvered close enough to a MEC to monitor near-MEC interactions. Depending on the arrangement of a MEC array, it may not be possible to deploy these platforms within an array, but rather only along the periphery.

\subsubsection{Seasonal or Biological Limitations}

The seasonal and biological limitations of bottom landers or sleds are similar to those of ROVs.

\subsubsection{Marine Durability and Survivability}

In addition to the challenges of deploying landers and sleds during strong currents or energetic wave conditions, it may be difficult to deploy these platforms on complex substrates.

\subsubsection{Safety and Permitting}

In addition having the same safety and permitting concerns noted for ROVs, the entanglement of a sled with moorings could pose a human safety risk for vessel operators. The group felt that this latter concern would limit the ability to deploy these platforms in close proximity to MECs, particularly WECs. 


\subsubsection{Autonomous Underwater Vehicles}

Autonomous underwater vehicles can deploy video or still cameras, but are unlikely to support artificial sources of illumination due to power restrictions. Their capabilities are summarized in Table 4.5.

Table 4.5. Optical capability summary for autonomous underwater vehicles.

\begin{tabular}{|c|c|c|c|c|c|}
\hline & & Suitability & $\begin{array}{c}\text { Seasonal or } \\
\text { Biological } \\
\text { Limitations }\end{array}$ & $\begin{array}{c}\text { Marine } \\
\text { Durability and } \\
\text { Survivability }\end{array}$ & $\begin{array}{l}\text { Safety and } \\
\text { Permitting }\end{array}$ \\
\hline $\begin{array}{l}\text { Near-MEC } \\
\text { Interactions }\end{array}$ & $\begin{array}{c}\text { TEC } \\
\text { WEC }\end{array}$ & & & & \\
\hline $\begin{array}{c}\text { Distribution and } \\
\text { Use }\end{array}$ & $\begin{array}{l}\text { TEC } \\
\text { WEC }\end{array}$ & & & & \\
\hline
\end{tabular}

\subsubsection{Suitability}

The group felt that AUVs were a particularly promising technology for MEC observation, being able to potentially offer many of the benefits of ROVs without the limitations of an umbilical cable. However, the group was unaware of any AUV deployments in conjunction with MRE projects so there may be unknown suitability challenges. The ability to track AUV position needs improvement, but active or passive acoustic instrumentation incorporated into a MEC structure could facilitate this. For observations around TECs, the most suitable type of AUV is likely to be a low-cost, neutral drifter used for short-term deployments. For observations around WECs, long-term deployments of larger AUVs with navigation and maneuvering capabilities may be possible, but would require a charging station and data offload point within an array and greater maneuverability than afforded by the current generation of gliders. However, if these challenges are overcome, AUVs could operate more effectively than ROVs during stormy weather at WEC sites.

\subsubsection{Seasonal or Biological Limitations}

The seasonal and biological limitations of AUVs are similar to those of ROVs, with the additional limitation that artificial lighting is unlikely to be available for optical imaging from an AUV platform.

\subsubsection{Marine Durability and Survivability}

The current generation of AUVs would be difficult to deploy in close proximity to a MEC without risk of collision or entanglement, but these risks are less of a concern when studying species distribution and habitat use. 


\subsubsection{Safety and Permitting}

The AUV safety and permitting concerns are likely to be similar to those for ROVs. However, because an AUV does not remain tethered to a surface vessel throughout its deployment, there may be additional permitting concerns in terms of the likelihood of equipment recovery at the conclusion of a mission.

\subsubsection{Animal-Borne Cameras ("Critter Cams")}

Animal-borne cameras record video imagery and cannot support artificial illumination. Their capabilities are summarized in Table 4.6.

Table 4.6. Optical capability summary for animal-borne cameras.

\begin{tabular}{|c|c|c|c|c|c|}
\hline & & Suitability & $\begin{array}{c}\text { Seasonal or } \\
\text { Biological } \\
\text { Limitations }\end{array}$ & $\begin{array}{c}\text { Marine } \\
\text { Durability and } \\
\text { Survivability }\end{array}$ & $\begin{array}{l}\text { Safety and } \\
\text { Permitting }\end{array}$ \\
\hline Near-MEC & TEC & & & & \\
\hline Interactions & WEC & & & & \\
\hline Distribution and & TEC & & & & \\
\hline Use & WEC & & & & \\
\hline
\end{tabular}

Green cells denote an area with few challenges, yellow cells denote an area with moderate challenges, and red cells denote an area with significant challenges.

\subsubsection{Suitability}

Animal-borne cameras, such as "critter cams," capture footage of what animals see and experience in the natural environment that cannot be obtained through any other type of optical camera platform. Given the limited field of view and range of such cameras and the limited number of animals that could be equipped with cameras at any given time, the group felt that it was unlikely for an animal equipped with a "critter cam" to swim close enough to a MEC for visual observations of near-MEC interactions (however, such footage would be amazing to behold). This would, however, be less of a concern for observations of species distribution and habitat use.

\subsubsection{Seasonal or Biological Limitations}

Observations derived from animal-borne cameras would be limited by water quality and availability of ambient light because artificial illumination is not available.

\subsubsection{Marine Durability and Survivability}

"Critter cams" are difficult to attach to animals and must be retrieved to recover data. Onboard storage and battery life precludes anything beyond a short-term deployment. 


\subsubsection{Safety and Permitting}

Obtaining permission to attach "critter cams" to marine animals is extremely difficult.

\subsubsection{Fixed, Cabled Vantage Points above the Water Surface}

Fixed, cabled vantage points above the water surface can support video, still, and stereo optical imagery, but are unlikely to use artificial illumination. These platforms can also support human observers. The fixed, cabled platform capabilities are summarized in Table 4.7.

Table 4.7. Optical capability summary for fixed, cabled platforms above the water surface.

\begin{tabular}{|c|c|c|c|c|c|}
\hline & & Suitability & $\begin{array}{c}\text { Seasonal or } \\
\text { Biological } \\
\text { Limitations }\end{array}$ & $\begin{array}{c}\text { Marine } \\
\text { Durability and } \\
\text { Survivability }\end{array}$ & $\begin{array}{l}\text { Safety and } \\
\text { Permitting }\end{array}$ \\
\hline \multirow{2}{*}{$\begin{array}{l}\text { Near-MEC } \\
\text { Interactions }\end{array}$} & TEC & & & & \\
\hline & WEC & & & & \\
\hline \multirow{2}{*}{$\begin{array}{l}\text { Distribution and } \\
\text { Use }\end{array}$} & TEC & & & & \\
\hline & WEC & & & & \\
\hline
\end{tabular}

Green cells denote an area with few challenges, yellow cells denote an area with moderate challenges, and red cells denote an area with significant challenges.

\subsubsection{Suitability}

Observations from fixed, cabled platforms above the water surface are in common use. These observations are, however, limited to above-water activity and the animals being observed need to be relatively close to the camera. This provides limited opportunity to address the highest priority concerns for near-MEC interactions (e.g., collision, entanglement). Optical observations from fixed platforms have been primarily used for bird monitoring, but can be used for marine mammal monitoring from a sufficiently high vantage point. Cameras attached to WECs are particularly well-suited for observing bird collisions or pinniped haul-out. Image registration associated with a moving platform (WEC or surface vessel) involves non-trivial computational effort.

\subsubsection{Seasonal or Biological Limitations}

Observations are primarily limited by atmospheric conditions and are difficult during periods of rain, fog, or darkness. The use of infrared cameras can extend operating conditions, particularly at night, but these cameras are much more expensive than visual-spectrum cameras and only marginally more effective in rain or fog.

\subsubsection{Marine Durability and Survivability}

Cameras on fixed platforms deployed near the spray zone would be susceptible to both corrosion and biofouling (as in the case of a camera attached to a WEC). Observations from other vantage points are unlikely to face durability challenges. 


\subsubsection{Safety and Permitting}

Safety and permitting concerns for fixed, cabled observations are likely to be limited to the viewshed impacts of such platforms.

\subsubsection{Fixed, Cabled Vantage Points below the Water Surface}

Fixed, cabled vantage points below the water surface can support video, still, and stereo optical imagery and infrared/far-red, strobe, and continuous illumination sources. Their capabilities are summarized in Table 4.8.

Table 4.8. Optical capability summary for fixed, cabled platforms below the water surface.

\begin{tabular}{ccccc}
\hline & Suitability & $\begin{array}{c}\text { Seasonal or } \\
\text { Biological } \\
\text { Limitations }\end{array}$ & $\begin{array}{c}\text { Marine } \\
\text { Durability and } \\
\text { Survivability }\end{array}$ & $\begin{array}{c}\text { Safety and } \\
\text { Permitting }\end{array}$ \\
\hline $\begin{array}{c}\text { Near-MEC } \\
\text { Interactions }\end{array}$ & TEC & & \\
DEC & & & \\
Distribution and & TEC & WEC
\end{tabular}

\subsubsection{Suitability}

Mounting optical cameras on or near a MEC would increase the likelihood of observing near-MEC interactions. This type of cabled monitoring overcomes the limited observation duration associated with other monitoring platforms (e.g., ROVs, AUVs). Optical cameras may also be deployed to monitor the condition of a MEC, providing an opportunity to leverage engineering infrastructure for environmental monitoring. However, the field of view and range for these systems is limited and monitoring will result in high data bandwidths, necessitating specialization of infrastructure. The data streams from continuous optical monitoring are potentially massive. These problems are compounded for studies of species distribution and habitat use due to the range limitations of underwater observations from a fixed position. Scale-up would be very expensive in terms of both equipment and data processing requirements.

\subsubsection{Seasonal or Biological Limitations}

Seasonal and biological limitations for cameras deployed from fixed, cabled vantage points are similar to those for cameras deployed from ROVs. However, in terms of continuous monitoring capabilities, the range is likely to be highly dependent on location and season, such that the effectiveness of underwater video can range from exceptional to non-existent. 


\subsubsection{Marine Durability and Survivability}

Deployment of cameras from fixed, cabled platforms below the water surface faces significant biofouling challenges, but results from recent endurance tests including wipers and optical clear coats are promising. The small field of view for individual, high-resolution cameras can be addressed with traversing or pan-and-tilt mechanisms, but only at increased cost and risk of failure.

\subsubsection{Safety and Permitting}

Safety and permitting challenges are likely to be limited to the difficulty of obtaining developer permission to attach/integrate cameras with MECs. This difficulty is obviated if the developer is leading the monitoring program (common in the United Kingdom). Further, this integration poses fewer safety issues than entanglement of mobile observation platforms (ROVs or AUVs).

\subsubsection{Aerial Vehicles}

Aerial vehicles can support video and still optical imagery, but are unlikely to use artificial illumination. Their capabilities are summarized in Table 4.9.

Table 4.9. Optical capability summary for aerial vehicles.

\begin{tabular}{|c|c|c|c|c|c|}
\hline & & Suitability & $\begin{array}{c}\text { Seasonal or } \\
\text { Biological } \\
\text { Limitations }\end{array}$ & $\begin{array}{c}\text { Marine } \\
\text { Durability and } \\
\text { Survivability }\end{array}$ & $\begin{array}{l}\text { Safety and } \\
\text { Permitting }\end{array}$ \\
\hline Near-MEC & TEC & & & & \\
\hline Interactions & WEC & & & & \\
\hline Distribution and & TEC & & & & \\
\hline Use & WEC & & & & \\
\hline
\end{tabular}

White cells denote a combination that was not discussed in detail, yellow cells denote an area with moderate challenges, and red cells denote an area with significant challenges.

In terms of suitability, observations from aerial vehicles are unlikely to provide information about near-TEC interactions and may be of limited use to describe near-WEC interactions because of camera resolution and sampling frequency. For WECs, other platforms are likely superior for collecting nearconverter information.

For studies of species distribution and habitat use, aerial camera deployments may useful, particularly if cameras can be deployed on UAVs for routine observations. At present, onboard power and storage for UAVs will likely limit observations to a few hours and camera resolution may not be sufficient for species identification. While visual-spectrum cameras will be primarily useful for monitoring bird, marine mammal, and seabirds on the surface, hyper-spectral cameras could help to image subsurface marine mammals and sea turtles. 


\subsubsection{Conclusions}

Depending on the monitoring objective, the type of optical camera (e.g., video, still, stereo), method of deployment (e.g., fixed, cabled deployments versus mobile deployments), the lighting requirements (e.g., strobe, far-red) will vary. Monitoring nearfield interactions for TECs is most challenging because of strong tidal currents, and it will require that optical systems be securely mounted to the TEC or a bottom mooring. Evaluating changes in habitat use or species distribution will require monitoring larger spatial scales. For example for WEC arrays, optical systems could be deployed on ROVs/AUVs for subsurface evaluations and for surface-oriented animals (e.g., turtles, whales), and UAVs could be extremely promising, especially if there is no other vantage point for observations either by cameras or humans. However, the group did not identify feasible approaches for using optical cameras to study subsurface species distribution and habitat use around TECs.

In general, optical sensing of environmental interactions from below the water surface will be challenging. However, developers will also need to evaluate MECs and their moorings using optical monitoring. Ship time can be very expensive, so combining technical inspection work with optical systems can allow for evaluation of environmental effects such as artificial reef and invertebrate colonization.

If continuous monitoring is required to detect nearfield interactions such as interactions of fish with TECs blades, or interactions of seabirds on WECs, optical systems could be integrated with the MECs. Water clarity, observation range, field of view, and requirements for level of taxonomic identification of organisms (e.g., species versus family) and the potential for bias due to artificial lighting (e.g., attraction, avoidance) all need to be considered. Having fiber-optic cables available will make continuous monitoring possible, but handling the volume of data produced can be daunting.

Optical systems will likely require an approach to reduce data analyses and image processing either in real time or during post-processing. Approaches could include combining techniques (e.g., active acoustic) with optical systems as a triggering mechanism (provided that cross-manufacturer integration can be addressed), and improving automated post-processing. 



\subsection{Instrumentation Needs, Gaps, and Solutions}

Significant instrument needs, gaps, and solutions were identified associated with marine species found near MECs (nearfield), determining the distribution and habitat use of these species, and sound produced by MECs, as discussed in the ensuing sections.

\subsection{Marine Species near Marine Renewable Energy Converters}

\begin{tabular}{ll}
\hline Participant & Affiliation \\
\hline Andrea Copping (chair) & Pacific Northwest National Laboratory \\
Jeff Condiotty-Kongsberg & Mesotech \\
Mel Broadhurst & Alderney Wildlife Trust \\
Beth Mackey & Royal Haskoning DHV \\
Jim Dawson & BioSonics, Inc \\
Jesse Roberts & Sandia National Laboratories \\
Hoyt Battey & U.S. Department of Energy \\
Greg Sanders & Bureau of Ocean Energy Management \\
Gayle Zydlewski & University of Maine \\
Gretchen Steiger & Cascadia Research \\
Sharon Nieukirk & Oregon State University \\
Bryan Apell & Kleinschmidt \\
\hline
\end{tabular}

\section{Questions Addressed:}

- Which species or groups of species are most difficult to monitor and/or are of particular importance when interacting with marine energy converters?

- What level of behavioral change do we need to be able to detect?

- At what frequency should we be collecting data/observations around marine energy converters?

- How does animal behavior affect our ability to monitor interactions?

\subsubsection{Introduction}

The interaction of marine animals with MECs is of paramount interest and importance to regulators and stakeholders as deployments of WECs and TECs proceed. These concerns for marine animal safety differ between WECs and TECs and, in all cases, the risks to marine animals depend on both the severity of an interaction with a converter and the rate at which this interaction is likely to occur. Concerns have been expressed by some regulators and stakeholders that WECs may create risk to marine mammals and sea turtles from potential collisions with the converter hull, mooring lines or anchors; or as fish attraction devices that may put endangered populations at risk from predators; however, more monitoring data are needed before these risks can be confirmed. Rotating blades on TECs are viewed as a potential strike risk to marine mammals, fish and sea turtles; however, initial data from flume and field studies suggest that strike risk may be lower than initially hypothesized; the flume studies show high rates of fish avoidance and survival (Jacobson et al. 2013; Normandeau Associates 2009). Avoidance is not universally observed; another field study (Viehman 2012) indicated that less than $1 \%$ of individuals and only about $15 \%$ of schools were able to avoid a TEC. Turbine rotation reduced the probability of species entering 
the TEC-swept area and increased the probability of avoidance (Viehman and Zydlewski in revision). Seabirds may be at risk from hitting superstructures of WECs, as they might with any surface structures in the marine environment, and perhaps colliding with mooring lines or TEC blades when diving.

Defining nearfield interactions is not necessarily straightforward. Defining a collision may be simple. However, if a fish or marine mammal takes evasive action in response to a MEC, that action may be initiated in close proximity to the MEC (i.e., in the nearfield) or at a considerable distance away. The resulting observation in the nearfield may not be seen clearly as an evasion, rather simply as the absence of an animal.

The ability to observe close interactions between marine animals and MECs is challenged by the need to deploy, maintain, and recover instrumentation in close proximity to MECs operating in energetic environments, as well as the need to collect sufficient data to capture rare events (i.e., animals interacting with the converters). Instrument packages are likely to consist of some of the following devices: optical cameras to observe interactions; passive acoustic devices to listen for marine mammals and some fish in close proximity; active acoustic detectors to view acoustic images of animals near devices; accelerometers to measure collision of animals under water with devices; and radar and optical/infrared camera systems to detect birds above the waterline. It is assumed that all nearfield monitoring will take place after MEC deployment (as opposed to baselines data collection before MECs are deployed) and will use power and data export capabilities associated with the MEC itself, potentially producing large streams of data. For non-grid-connected MECs, battery power and data storage may be needed, which would significantly limit the volume of data that could be collected. In some cases, the monitoring instrumentation may be mounted at a distance from the device, while other packages will be deployed as an integral component of the MEC. Whether monitoring systems are mounted on or at a distance from the MEC, data streams from nearfield monitoring may be parsed from monitoring data streams associated with MEC performance and condition health, allowing data connectivity to shore to serve both purposes. The workshop group felt strongly that tagging of animals was not a viable means of observing collisions with converters in the nearfield because of interference from MECs which might cause tagged animals to exhibit a change in behavior when the animal detects and approaches a MEC. In addition, tags may not be useful for detecting nearfield interactions if the sound from the MEC masks the output of the tag. ${ }^{1}$ However, the group acknowledged that observations from further afield could benefit from existing and improved tagging and tracking technologies.

Throughout the breakout group discussion, it was agreed that the optimum monitoring regime and the instruments best suited for collecting data depend strongly on the questions being asked and the locale of the MEC. For example, the need to observe blade strike of fish around a TEC versus observing evasion of fish around the area of a TEC require different configurations of instrument deployment and, perhaps, a different mix of instruments. Similarly, determining whether a marine mammal approaches a TEC may require deployment of instruments (acoustic or optical) on both sides of the rotor.

Sampling frequency must be determined based on the expected frequency of the occurrence of an event (for example, a direct interaction of a marine mammal with a MEC may be a rare event and thus the likelihood of observation will increase with sampling frequency, while attraction of shoaling fish to a

\footnotetext{
${ }^{1}$ MEC sound is often most intense below $1 \mathrm{kHz}$, while active tags operate at frequencies on the order of 10s or 100s of kilohertz. The masking of tag frequencies by MEC sound is unlikely in most cases, but is worth considering during the design of any monitoring program involving active tags.
} 
MEC may be ongoing, requiring only periodic sampling on a low duty cycle). Sampling frequency should also be tailored to natural periodicities such as tidal and diurnal cycles.

\subsubsection{Setting Priorities for Nearfield Monitoring}

Many species and life stages of marine animals live in waters that may be attractive for MEC deployment. These animals will differ greatly in size, speed of movement, and behavior. Accurately measuring nearfield interactions for all these animals would require capturing the presence, behavior, and movement of animals that range in size from millimeters (such as fish larvae) to tens of meters (such as adult cetaceans), that move at speeds that may approach tens of meters per second, and that may react to the presence of a MEC instantly or over the course of several years. Developing and operating instrument packages that can span these temporal and spatial scales will be prohibitively expensive and would produce unmanageable volumes of raw data. Priorities must be set to examine the MEC/animal interactions that are most likely to create a significant risk.

Carrying out a risk-based assessment prior to designing a monitoring system will allow the instruments and methods used to efficiently target the most likely and important interactions and will result in instrument packages that are efficient and data streams that are manageable. Such an assessment account for the likelihood of specific animal species or groups being in the vicinity, define a plausible pathway for potential harm, and prioritize the populations that are depleted or otherwise afforded special protection, as well as key commercial species.

For marine animal groups of interest, the group determined that monitoring over differing functional classifications will be needed. For marine mammals and sea turtles, nearfield monitoring should be targeted at the individual animal, while fish and seabirds should be monitored at the population level (excepting some larger fishes, such as sharks). Because of the constraints of monitoring instruments, in general, fish should be monitored as functional groups (for example, forage fish, rockfish, migratory salmonids) or by size range, rather than by species. Similarly, distinguishing among functional groups of seabirds (for example, soaring birds, diving birds, dabbling ducks), should be sufficient. However, for certain populations of fish and seabirds that are under special protection, it may be necessary to identify to the species level, and perhaps even to observe individual fish or birds of rare populations.

Concerns from regulators and stakeholders about perceived danger to marine animals around MECs require that a conservative approach be taken in the early stages of single devices and arrays. The breakout group participants agreed that continuous monitoring capable of detecting marine animals should ideally be in place and operational, and any physical interaction between the animal and MEC should be documented. This process would require an integrated instrumentation system and present unique challenges for data processing, deployment, and recovery. Without automated processing, the data streams from continuous observations from some instruments are likely to be difficult to work with and require the development of methodologies to parse the data stream for analysis. For example, while several months of raw split-beam echosounder observations from a single instrument might require on the order of a terabyte of storage, continuous optical imaging with a high-resolution stereo camera could produce several terabytes of data in a single day. Consequently, while integration (i.e., triggering) and automated pre- and post-processing are likely to benefit all instrumentation, the degree of development required to enable continuous monitoring will vary by instrument. The group also felt that nearfield monitoring was likely to be necessary at some level throughout the life of early MEC projects, 
particularly if animals under special protection are involved. However, the frequency and focus of the monitoring is likely to shift and decrease over time as additional experience, risk modeling, and regulatory confidence increases.

\subsubsection{Scales for Measuring Nearfield Interactions}

The definition of the extent of the nearfield is contingent on whether interactions with devices are viewed solely as direct (collision, strike, running into mooring lines), or whether avoidance of the MEC is also considered. Nearfield attraction of animals (particularly fish, sea turtles, and seabirds) may be viewed at the same scale as that of direct interactions. Understanding whether marine animals are evading the MEC, mooring lines, surface floats, or anchors was also considered to be of prime importance and more likely to be observed than direct contact between the animals and the systems. For the balance, for the purposes of the breakout discussion, evasion was considered to be within the scope of nearfield interactions and would be targeted with the same monitoring strategies and instruments as strike or collision.

The group defined the nearfield as a radius equivalent to several lengths of the MEC, which for most MECs will amount to a radius of 20 to $30 \mathrm{~m}$. However, it should be noted that for large WECs such as oscillating water columns (e.g., OceanLinx, Ocean Energy), linear surface attenuators (e.g., Pelamis), or overtopping devices (e.g., Wave Dragon), the nearfield may be considerably larger, with anisotropic geometry. It was agreed that the spatial and temporal scales needed to examine large-scale animal avoidance of MECs (such as alterations of migratory patterns or movements) will be much larger and fall outside the realm of nearfield detection. ${ }^{1}$

To date, most nearfield monitoring has taken place around single or very small numbers of converters; scaling the necessary monitoring focus to arrays is challenging. The lack of experience worldwide of monitoring around arrays of MECs does not allow for an empirical assessment of how many instrument packages are needed to determine nearfield interactions with each converter in order to scale from interactions around a single converter to multiple converters. The breakout group felt that an aggressive approach to continuous monitoring of early converter deployments to gain experience and bolster regulatory confidence was most likely to provide for successful scaling to arrays without needing to place instrumentation packages around every MEC in an array. However, continuous monitoring that does not result in overly burdensome volumes of data (e.g., a volume of data required petabyte storage solutions) is only currently possible with a subset of active acoustic and passive acoustic sensors.

The instrument packages best suited for recording nearfield interactions will be dependent on the particular animal group or species of concern, the life stages of interest, and major behavioral attributes (e.g., whether fish species are resident or migratory). Similarly, the accuracy and precision of measurements, and rate of data collection, will depend on the specific size, life stage, and behavior of the animals of interest.

\footnotetext{
${ }^{1}$ These types of environmental changes are discussed in Section 5.2.
} 


\subsubsection{Nearfield Interactions of Interest}

Five interactions between MECs and marine animals were examined in detail; recommendations for which functional groups should be targeted, preferred instruments, desired spatial resolution, and necessary data rates and duty cycles were identified. The five interactions, each of which is analyzed in the following sections, are:

- direct interaction of marine mammals and sea turtles

- direct interaction of fish with MEC

- attraction of fish species to a MEC

- interaction of seabirds with MECs below the water surface

- interaction of seabirds with MECs above the water surface.

\subsubsection{Direct Interaction of Marine Mammals and Sea Turtles}

It has been hypothesized that risk to marine mammals from MECs could occur if the movement of these animals takes them into the pathway of a MEC, either while foraging, travelling, or migrating. Large cetaceans are more likely to be at risk from arrays of WECs because they are less maneuverable than smaller marine mammals and may enter arrays and be unable to exit easily. Smaller, more maneuverable marine mammals may be able to avoid collisions or entanglement around WECs. However, smaller cetaceans and pinnipeds may be at greater risk from TECs in estuarine and coastal areas than large cetaceans simply because these high-current environments are less likely to provide habitat for large cetaceans. Sea turtle populations are depleted throughout most world oceans, suggesting that monitoring of individuals and populations is needed around MECs until any potential interactions can be determined. While it is not clear whether sea turtles are likely to surface in high-energy areas, regulators are concerned that the turtles may be affected by WECs. TECs are not likely to create risk for sea turtles because most do not venture into the estuarine and near coastal areas where tidal energy development is feasible.

The spatial resolution at which marine mammals and sea turtles must be detected to determine if strike, collision, abrasion, or evasion of a MEC varies based on their body size and ability to maneuver in tight spaces - from approximately 5 to $10 \mathrm{~m}$ for large cetaceans to approximately $5 \mathrm{~m}$ for smaller cetaceans, pinnipeds, and adult sea turtles, and down to centimeters for juvenile sea turtles. In general, the level of taxonomic classification should be limited to identifying large cetaceans, small cetaceans, pinnipeds, or sea turtles. In a few cases where there is a specific highly endangered marine mammal, it may be necessary to detect and classify the animal to the species level, as well as detecting and tracking each individual as it passes through the field of detection (e.g., the ensonified field from a split-beam echosounder). However, achieving this level of specificity will require more extensive development of optical and acoustic libraries and testing procedures than were discussed at the workshop.

Instrumentation needed to observe direct interactions include optical still and video cameras, and active acoustic devices. Because the chance of direct interactions is small, continuous monitoring may be needed to ensure that interactions are observed. One approach to achieving this level of monitoring without generating an unacceptably large volume of data would be for high-bandwidth instruments to be triggered by low-bandwidth instruments, recording the interaction of the sea turtle or marine mammal 
with the MEC. For optical and acoustic imagers, continuous recording will create large and unwieldy data streams; therefore, the workshop group stressed the need to use results from several instruments in series or other filtering mechanisms to process data streams in real time to produce a workable volume of data that has a high probability of documenting direct interaction.

\section{Optical Cameras}

Optical cameras are useful for observing interactions around MECs. The small field of view enables observations of direct interactions of animals with specific parts of the MECs, mooring lines, and anchors. Direct observations of animals interacting with or evading MECs provide a high quality of evidence that an interaction has happened, as opposed to indirect observations using accelerometers incorporated into the MEC structure. Stereo, still, or video cameras aimed at a MEC will provide a virtual threedimensional picture of the interaction that will allow for identification to the functional group and, under optimal conditions, to species. Cameras, however, have a small field of observation, require multiple pairs of cameras to cover a field of MECs, and may require lighting (strobe or continuous) under water that may disturb and cause unnatural behavior in animals. Although strides have been made in underwater optics and camera operation in recent years, fouling of optical lenses in long-term deployments remains a significant concern. ${ }^{1}$

To date there are no standardized methods or techniques for mounting, deploying, or arranging optical cameras arrays around MECs. As previously noted, continuous collection of data can produce huge data streams. Methods to parse the data using triggers are needed; for example, more than one indicator among an optical camera, acoustic camera, and accelerometer would reinforce the occurrence of an interaction and might alert the operator to the need to retain and analyze a time-stamped subset of the raw data stream. The development of algorithms for image capture and recognition would also significantly reduce the present challenges associated with manual post-processing to characterize imagery. By capturing continuous data, a record can be maintained of all potential interactions, allowing for the efficient analysis of only those data clips that are likely to yield information. Mid-range camera systems adequate for these tasks are generally not extremely expensive but their deployment, servicing, and maintenance can considerably increase the cost of their use. Data analysis can easily become the most expensive part of the system unless the quantity of data requiring analysis can be severely reduced relative to the raw data stream associated with continuous operation.

\section{Single-Beam and Split-Beam Active Acoustics}

Active acoustic systems that operate on a single or split beam can be very effective at providing an accurate wide field of observation, provided they can be mounted remotely from the MEC and there is sufficient "training" of the device to recognize specific acoustic shapes, achieved through software development. These devices have the ability for real-time analysis, but the resolution is restricted to the sub-meter scale due to interference, particularly in high-flow environments. Performance can be improved by standing the device off $10 \mathrm{~m}$ or more from the target to avoid acoustic interference from the hard return produced by a MEC. There is a long history of use of these instruments in the marine

\footnotetext{
${ }^{1}$ Joslin J and B Polagye. Field Evaluations of Optical Port Anti-Fouling Methods. Submitted to IEEE Journal of Oceanic Engineering.
} 
environment; however, these devices are generally deployed for short periods of time and used for individual studies, rather than being deployed long-term for ongoing monitoring. In comparison to other active acoustic instruments, they are moderately priced and require less maintenance than optical cameras.

Single-beam and split-beam instruments produce relatively large data streams and there are insufficient algorithms available to automatically detect marine mammal and sea turtle species. Standardized methods for setup, deployment, and recovery of the instrument have not been developed. There is concern that acoustic energy necessary to operate these active acoustic instruments could affect marine mammals adversely, causing behavioral changes in their swimming, hunting, or socializing capabilities.

Single- and split-beam active acoustics are suitable for examining interactions of marine mammals and sea turtles around TECs and, perhaps, around large surface or subsurface floats associated with WECs, but they do not have the resolution to examine the collision or entanglement of animals around WEC mooring lines or mid-water power cables.

\section{Multi-Beam Acoustics and Acoustic Cameras}

Greater resolution can be obtained by placing acoustic cameras and multi-beam instruments around MECs to obtain specific information about individual targets (e.g., body form of the target). This resolution will allow better recognition of functional taxonomic groups and will increase the capability of recording contact between a marine mammal or sea turtle and a MEC. The use of two or more multibeam instruments or acoustic cameras mounted at different angles on a stable platform at a distance from a MEC may resolve both the identity of the target and potential interaction with the MEC. However, multi-beam and acoustic cameras do not have the same extensive history as single-beam and split-beam echosounders. As with the single-beam and split-beam instruments, multi-beam and acoustic cameras are generally deployed for short periods from a vessel or stable platform, and their long-term use in the marine environment has not be tested.

Multi-beam and acoustic cameras can view only a small field of observations and are costly in comparison to single-beam and split-beam instruments; equipment and operational costs for acoustic cameras are higher than for multi-beam sonars. Recent development of high-frequency (higher than $70-100 \mathrm{kHz}$ ), quantitative multi-beam sonars may improve recognition and quantification of targets such as marine mammals and sea turtles at acceptable cost. Both instruments produce very large data streams, similar to optical cameras, and there are insufficient algorithms available to automatically recognize marine mammal or sea turtles functional groups or species. To date, no standardized methods are available for deployment, operation, or data processing of these instruments. As for single-beam and split-beam instruments, there are concerns that acoustic energy from the devices emitted into the water may cause a behavioral response in marine mammals. Identified needs associated with multi-beam acoustics and acoustic cameras include lower cost systems and quantitative analysis software.

\section{Passive Acoustics}

Vocalizing marine mammals can be detected in the vicinity of MECs using passive acoustic instruments. Passive acoustics is a well-developed technology that is inexpensive, and for which 
established sound signatures exist for many marine mammals. ${ }^{1}$ The instruments are robust and can be deployed on frames attached to MECs or on stand-alone platforms for extended periods in the marine environment. However, unless an extensive array of devices is deployed, information on marine mammals will not be directionally specific and cannot be used to infer direct nearfield interactions. Arrays of passive acoustic instruments and algorithms for localizing and classifying marine mammal species of interest need to be developed.

\section{Human Observers}

Marine mammal observers working from vessels or onshore can provide excellent information about the presence of animals in the vicinity of TECs during daylight hours and clear weather. However, underwater interactions of marine mammals and sea turtles with TECs will be beyond observers' field of view. While some nearfield encounters with WECs at sea may be visible from vessel-based observers, in general, MMOs will not be able to distinguish interactions such as strike, collision, or avoidance at a fine scale. Larger scale avoidance of MEC arrays will be more visible to MMOs.

\section{Infrared Cameras}

Infrared cameras have the ability to distinguish warm marine mammals at the surface of cold waters ${ }^{2}$ but cannot penetrate the waters for subsurface detection. As with MMO observations, infrared cameras might be useful for detecting marine mammals in the vicinity of MECs but will not provide significant additional information about the nature of direct nearfield interactions.

\subsubsection{Direct Interaction of Fish with MECs and Attraction of Fish to MECs}

Nearfield monitoring for fish can be used to determine if strike, collision, or evasion of a MEC occurs. Although fish could collide or evade WECs and portions of the WEC system in the nearfield, more commonly fish direct interactions will be monitored around TECs. Monitoring around WECs will most commonly be concerned with the attraction of fish. The major differences in monitoring design and use of instruments between observing direct interactions of fish with MECs and evaluating the attraction of fish to MECs are in the taxonomic classifications that need to be resolved, the scale over which the fish should be observed, and the duty cycle for collection of data.

\subsubsection{Direct Interaction of Fish with MECs}

Unlike marine mammals and sea turtles, fish interacting with MECs in the nearfield will most often be resolved as groups or schools, rather than as individuals. The group acknowledged that there may be a need to identify targets to the individual (i.e., enumeration of targets and species) for certain highly endangered species within the field of observation of a fixed acoustic or optical device, but this will be rare. Initially, if feasible, nearfield monitoring should be continuous with the potential to reduce the duty cycle as additional data provide a pattern of fish use of the nearfield. The change from continuous

\footnotetext{
${ }^{1}$ Though, as discussed in Section 5.2, there is not a global database of vocalizations able to provide uniform detection of all "dialects."

${ }^{2}$ This depends on the angle of incidence between the marine mammal and infrared camera or the presence of a hightemperature whale blow (Graber et al. 2011).
} 
monitoring can occur after patterns of use by fish around MECs have been established and methods are in place to flag portions of data for further analysis. The spatial resolution needed for fish in the nearfield is at the sub-meter scale to distinguish small fish and juveniles. Larger fish and later life stages for many marine fish can be resolved at scales greater than a meter. The group felt strongly that attempts to recognize larval fish in the nearfield were not realistic and should not be the target of monitoring activities.

It is desirable to identify fish to the species level for direct interaction in the nearfield, but in most instances, resolving fish by size classes is more realistic. Recent work in the Gulf of Maine suggests that the extent and scope of monitoring for fish around MECs must be tailored to the species and resolution of the instruments available. In conjunction with nearfield fish monitoring, it is essential that fish stocks in the region be monitored routinely to better correlate nearfield monitoring results with species of interest.

\subsubsection{Attraction of Fish to Devices}

Monitoring efforts to understand the extent to which fish are attracted to MECs should record interactions of groups of fish, although there may be rare instances where fish under special protection should be identified to the species level. A low duty cycle with intermittent sampling can be used to characterize the attraction of fish to a MEC, because schools of shoaling fish are likely to stay in place for significant periods of time, particularly compared to the rapid interactions that are likely to characterize more direct interactions of animals with devices. The sampling interval will depend on the specific characteristics of a technology and the site; fast-moving waters around TECs may allow only small numbers of fish to spend time in proximity to the device, while WECs may attract larger groupings of fish.

Fish attracted to static components of MECs (e.g., foundations and anchors) will need to be observed at scales of a few body lengths, while investigations of fish spending time in the wake of dynamic devices, particularly TECs, may require a field of view that is larger, corresponding to the wake of the MEC.

\section{Optical Cameras}

Optical cameras can provide direct observations of fish in the nearfield around MECs, fish attracted to MECs, and fish aggregating in a MEC wake. Under appropriate light and turbidity conditions, still and video cameras can resolve individual fish and enable identification to an appropriate level (family, species). The use of lighting (probably strobe lights) is necessary and useful to operating cameras at depth, but the artificial light may elicit startle responses, attraction, or avoidance behavior in fish. Fish may acclimate to this stimulus over time and return to a natural pattern of behavior.

Optical cameras are hampered by a small field of observation, potential fouling of lenses, and the potential to produce huge volumes of data. As is the case for use of optical cameras to observe marine mammals, these systems must be operated on a duty cycle or the data streams from continuous operation must be filtered and parsed for the most useful information. This will require the development of algorithms for identification to the appropriate level of taxonomic classification. No standard methods exist for using these instruments for fish monitoring in the nearfield. 


\section{Single-Beam and Split-Beam Acoustics}

The use of single-beam and split-beam active acoustic devices to detect fish interacting with or attracted to MECs provides a good balance between the necessary field of observation (which is smaller for fish than what is needed for marine mammals and sea turtles), with a median price for purchase, operation, and maintenance of the instruments. Single- and split-beam active acoustics may be suitable for examining interactions of fish around TECs and, perhaps, around large surface or subsurface floats associated with WECs, but they do not have the resolution to examine collision of fish around WEC mooring lines or mid-water power cables. The instruments are most likely to be used for short deployments from vessels or on fixed platforms; longer deployments are being tested and may prove to be usable around MECs. There are well-documented standardized methods for deployment of split-beam sensors and processing of split-beam data. Observations may involve placing the sensor at a stand-off distance from a MEC to create an "acoustic curtain." Analysis protocols for single targets and fish schools are well documented in the scientific literature. However, algorithms for distinguishing many populations of fish still require further development and species identification often requires physical sampling. Site-specific issues for deployment and recovery of instrumentation need to be addressed, as do challenges associated with power and communication channels, corrosion protection, biofouling, and design of the sensor platform. There is also some concern that the acoustic energy necessary to operate these active acoustic instruments could affect certain fish species adversely, causing behavioral changes in their swimming, hunting, or socializing capabilities.

\section{Multi-Beam Acoustics and Acoustic Cameras}

Multi-beam acoustic instruments and acoustic cameras can provide very high specificity for target populations or size classes of fish, increasing the likelihood of identifying fish to the family or species level. Like single-beam and split-beam instruments, these devices have largely been deployed for short studies, but experiments are under way to determine whether long-term ongoing deployments are reasonable. Multi-beam and acoustic cameras provide a small field of observations and are more expensive to acquire, operate, and maintain than single- or split-beam instruments. They also produce larger data streams for which there are insufficient algorithms for analysis of fish species. No standard methods exist for their use.

\subsubsection{Interaction of Seabirds with MECs below the Water Surface}

Concerns have been raised about the risk to diving birds around MECs, based on the attraction of birds to the MECs because fish may be attracted and/or TEC blade strike of fish may provide food for birds. These concerns are focused on blade strike or collision with TECs; and strike of subsurface floats, collision, or entanglement with mooring lines and mid-water power cables, and collision with anchors, for WECs. Observations and recording of interactions of birds with MECs should focus on groups of birds, unless there are birds under special protection for which individual monitoring is needed. For observing most bird interactions, a short-term duty cycle should be sufficient. Spatial resolution for bird observations should focus on several times the body length of a bird, recognizing that diving birds will enter and leave optical and acoustic frames very quickly. 


\section{Optical Cameras}

Optical cameras mounted on MECs or on stand-alone platforms have the potential to provide direct observation and identification of individual birds and species. However, capturing stills or video of diving birds is very difficult due to the speed of the dive. Coupled with a small field of observation and the requirement to provide lighting under water that may attract birds, these instruments may be very challenging to use effectively. However, coupled with data from bird observers, triggering systems, and improved image capture algorithms, optical cameras may become useful tools. Cameras produce very large data streams and there are currently insufficient algorithms to resolve individual birds. No standard methods exist for any aspect of underwater bird monitoring by optical camera.

\section{Active Acoustics}

For single-beam, split-beam, multi-beam, and acoustic cameras, observations of diving birds associated with marine energy devices provide similar advantages and suffer from similar drawbacks. However, these technologies have not seen significant use for monitoring of diving seabirds around MECs. Each technology can provide a reasonable field of observations; multi-beam sonars and acoustic cameras provide higher specificity of identification for individual targets, while single-beam and splitbeam might be able to provide detection information at a lower cost. The very high-speed dives of seabirds will make it extremely difficult to resolve targets for all the active acoustic instruments, particularly when coupled with the small field of observation over which the instruments can be aimed. All these instruments produce very large data streams and there are few algorithms that can resolve diving birds. No standardized methods have been developed for this task. There is a need to develop lower-cost active acoustic systems for use under water; when coupled with bird observers, these devices may yield useful monitoring results.

\section{Human Observers}

Human observers can provide a high degree of accuracy in species recognition with training, deployed either on surface vessel or from an onshore vantage point. However, the observers can only record the presence of diving birds at the sea surface, during daylight hours, and in reasonably good weather. There is a need to calibrate observer data and methods with other instruments such as optical cameras and active acoustic devices to improve monitoring of diving bird interactions with MECs.

\subsubsection{Interaction of Seabirds with MECs above the Water Surface}

The superstructure of WECs and surface-piercing TECs has the potential to harm birds, particularly during inclement weather, if the birds collide with these structures. This effect is not unique to MECs but instead a characteristic of all surface structures in the marine environment. Attraction of birds to MECs can be observed in the same manner as collisions.

\section{Optical Cameras}

Cameras deployed on surface floats or structures permit direct observations of multiple birds; under unusual circumstances it may be necessary to identify individual birds under special protection. For most bird monitoring, duty cycles that provide periodic observations should be sufficient. For most birds, 
recognition of birds to the taxonomic family level is probably sufficient; species recognition may be needed for birds under special protection. Optical cameras provide only a small field of view, necessitating the deployment of multiple units if a comprehensive assessment of the interaction with MECs is needed. Cameras have been used for seabird monitoring on offshore platforms such as those for oil and gas exploration or vessels at sea; however, there are few algorithms for data processing, particularly optimized image capture algorithms.

\section{Infrared Cameras}

Infrared cameras are under investigation as a potential means of observing and identifying functional groups of birds in the vicinity of MECs and offshore wind turbines. The small field of observation, lack of standard methods, or algorithms for classification for birds, and lack of experience in the marine environment will require substantial additional development before these devices can be reliably deployed for bird monitoring.

\section{Radar}

Seabirds can be observed using standard technologies such as marine (X-band) radar, upwardslooking radar, and scanning radar. However, observing birds close to MECs will suffer from wave clutter and interference from the MEC superstructure. Radars are relatively expensive systems for which little quantitative analysis software is available for bird detection and characterization. Improved calibration between radar and other methods might allow these instruments to become effective at nearfield bird observations.

\section{Human Observers}

The best known methods for bird recognition in air come from the deployment of trained observers on vessels or on shore. As for the observations of diving birds, observers can only monitor birds during daylight hours and in good weather. The most pressing need to improve monitoring techniques for seabirds above water is to calibrate observer data with other methods.

\subsubsection{Priority Gaps and Solutions}

Evaluation of nearfield interactions of marine animals around MECs can take advantage of existing instrumentation for the most part; however, there are gaps in the process of obtaining, interpreting, and applying the data from these instruments, as well as the need to couple two or more instruments into sequenced instrument packages to effectively gather the information needed to accelerate siting and permitting processes for MECs. Calibration among methodologies will also assist in combining established technologies with those emerging around MEC monitoring. The need for consensus methods for measuring risk was also identified as a missing piece in the application of nearfield monitoring achievement. In addition, the following conclusions were derived from the group discussion:

- Deployment, operation, maintenance, and recovery of instrument packages. There is very little experience worldwide in the deployment of optical cameras in the marine environment for lengths of time that will allow long-term monitoring; acoustic instruments have a longer history of extended use. Standardized means of configuring instrument packages are needed, including but not limited to 
optical cameras, passive and active acoustic instruments, and infrared cameras. Methods for the deployment, retrieval, operation, and maintenance are needed for each instrument type, including the specification of appropriate maintenance intervals and calibration/data validation techniques.

Instrument packages that combine two or more of these technologies become more complicated, and methods for deploying, operating, and maintaining them escalate accordingly (e.g., duty-cycled operation may be needed to prevent interference among instruments). Solutions should focus on a combination on structured field campaigns that test different configurations and methods, as well as directed workshops that bring together scientific and engineering expertise in the design, use, and application of the instruments needed for monitoring.

- Managing data streams. The breakout group participants felt very strongly that, for early marine energy projects, initial array deployments, and emerging MEC designs, that nearfield observations should ideally be continuous, capturing each interaction between an animal and a MEC. However, for most optical and acoustic sensors capable of informing taxonomic identification, continuous recording will result in large "data mortgages" that cannot be readily analyzed or archived. This could reduce the overall effectiveness of a monitoring program by diverting resources from data analysis to the curating of massive data archives. Triggering systems are needed to activate highbandwidth instruments only when an animal is within their field of view. There is a general need to develop pre-processing algorithms that filter the data, allowing only data sequences that are likely to contain images of animals to be retained for post-processing. As more experience in nearfield monitoring is gained, a combination of pre-process parsing of data streams may be combined with triggering of instrument systems to further "distill" the data streams. For example, PAM for vocalizing marine mammals may be used to trigger active acoustic systems to track a cetacean coming towards a MEC, which may, in turn, trigger an optical camera to record the species and individual characteristics of the animal when it is at sufficiently close range. Solutions must include a targeted program of algorithm development for target detection in image sequences (pre-processing), and instrument and algorithm development to allow appropriate triggers to be developed for hand-off between remote-sensing instruments.

- Data processing, interpretation, and storage. The large data streams likely to be generated from nearfield monitoring, coupled with the collection of observations of marine animals in proximity to new technologies, requires that algorithms be available to post-process data to understand the instances of evasion, strike, collision, entanglement, and other close encounters of animals with MECs. Coupled with the development of post-processing algorithms is the need to consistently interpret the output of the analyses in a standardized manner, including agreement on what makes up an instance of each of the nearfield interactions. The large data streams (raw, pre-processed, and post-processed) will require significant data storage capacity. Standards for the storage, retrieval, dissemination, and archiving of these data are needed. Solutions should include a structured program of post-processing algorithm development with a priority on outputs of those instruments for which few exist (e.g., optical and acoustic images), while also encouraging the expansion of vocalization libraries for marine mammals and fish, with an emphasis on species under special protection. Roundrobin comparisons among researchers are needed to ensure that processed images and other data are being interpreted as nearfield interactions in a consistent manner. Enlisting expertise from "Big Data" will help to determine reasonable and workable data storage, retrieval, dissemination, and archiving needs, particularly if a large fraction of raw data from continuous monitoring needs to be retained for verification studies. A series of workshops to bring together scientific practitioners could assist in the initial definition of data needs. 
- Calibration of instruments and methods for monitoring. Methods for observing seabirds, marine mammals, and sea turtles using observers are well established. Radar has been used to recognize flocks of seabirds near offshore wind farms in Europe for a significant period, although these instruments have limitations. Coupling and calibrating these established methods with instrument packages, including passive and active acoustics and optical and infrared cameras (in water and in air), will allow for increased reliability and usage of instruments that reduce the safety risk to human observers or the large-scale expense of radar systems for nearfield monitoring. Key solutions include well-designed field campaigns to put observers at sea (or at strategic shore-based locations) to compare data with nearfield deployed instrument packages; comparisons with radar outputs can similarly calibrate the instrumentation recordings for seabirds.

- Measuring risk. Regulatory and stakeholder concerns about marine animal interactions in close proximity to energy converters may trend toward a desire to monitor a broad set of interactions and species. The breakout group strongly supported the use of risk analyses prior to determining marine animals for which nearfield monitoring should be developed. There is a need for rapid assessments of likely interactions with the MECs, including defining plausible pathways of harm that might befall a particular animal in close proximity to a particular converter, foundation, mooring line, anchor, or power cable. Solutions include convening a group of experts to examine several existing methodologies for rapid risk assessments, including those established in Scotland (Potential Impacts of Wave and Tidal Energy Development; Marine Scotland 2012), Canada (Pathways of Effects; Isaacson and Daborn 2011) and the United States (Environmental Risk Evaluation System; Copping et al. 2012), and to determine criteria for carrying out rapid assessments to guide nearfield monitoring. Because each protected species may have a different level of acceptable risk that varies by nation, there may be value in also separately convening relevant regulators from a specific geographic region to agree on assessing the incremental risks under an adaptive framework.

\subsection{Determining the Distribution and Habitat Use of Marine Species in the Vicinity of Marine Renewable Energy Converters}

\begin{tabular}{ll}
\hline Participant & Affiliation \\
\hline Rob Suryan (Chair) & Oregon State University \\
Anna Redden & Acadia University \\
Ian Hutchison & Aquatera \\
Jim Boutiller & DFO Canada Pacific Biological Station \\
Jocelyn Brown-Saracino & U.S. Department of Energy/New West \\
& Technologies \\
John Horne & University of Washington \\
Kate Mansfield & Florida International University \\
Manuel Castellote & National Marine Mammal Laboratory, Alaska \\
& Fisheries Science Center, NMFS/NOAA \\
Paul Bell & National Oceanography Centre \\
Paul Thompson & University of Aberdeen \\
Sharon Kramer & H.T. Harvey \& Associates \\
Simon Geerlofs & Pacific Northwest National Laboratory \\
Rodrigo Hucke G. & Universidad Austral de Chile \\
\hline
\end{tabular}




\section{Questions Addressed:}

- For what species or groups of species must we be able to measure species distribution and pelagic habitat use in high-energy areas to support decisions about siting and permitting needs for marine energy converters?

- To what extent must we be able to determine the "normal" behavior of animals in high-energy areas (so we can tell if the presence of the marine energy converters changes that behavior)?

- What are the capabilities of the different instruments with respect to each receptor group (e.g., fish, marine mammals) and what platforms can each instrument be operated or deployed from?

- What is the best set of tools available and what major gaps exist or advancements are needed going forward?

\subsubsection{Introduction}

The focus of this group was on the needs and methodologies for determining the distribution of organisms for the purposes of siting and evaluating impacts of MECs. The group discussed key issues of spatial and temporal resolution for nearfield and farfield measurements that will feed into before-after site characterization and impact assessment (Table 5.1). There are several important scales of spatial resolution ranging from pilot-scale MEC deployments to commercial-scale deployments to population scales for receptors. Vertical spatial scale is also important for many species. Desired temporal scales of measurement also range widely and are generally specific to both receptors and regulation. There is also a critical need to understand environmental drivers that are affecting receptor distribution independent of MECs and how these environmental drivers might affect risks associated with MEC deployments.

Table 5.1. Necessary spatial and temporal resolution for receptor monitoring of distribution and habitat use as a function of deployment platform.

\begin{tabular}{|c|c|c|c|c|c|c|c|c|}
\hline & \multicolumn{4}{|c|}{ Spatial Resolution } & \multicolumn{4}{|c|}{ Temporal Resolution } \\
\hline & 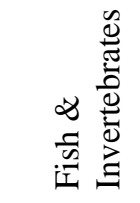 & 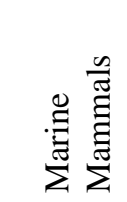 & 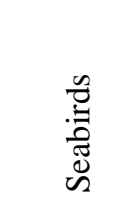 & 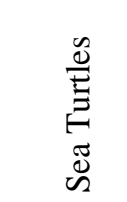 & 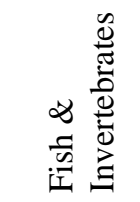 & 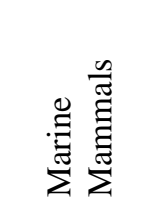 & 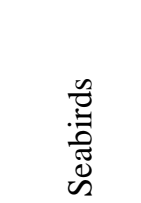 & 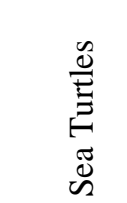 \\
\hline Aerial & $10 \mathrm{~s} \mathrm{~m}$ & $10 \mathrm{~s} \mathrm{~m}$ & $10 \mathrm{~s} \mathrm{~m}$ & $10 \mathrm{~s} \mathrm{~m}$ & Hours & Hours & Hours & Hours \\
\hline Vessel & $10 \mathrm{~m}$ & $50 \mathrm{~m}$ & $50 \mathrm{~m}$ & $50 \mathrm{~m}$ & Days & Days & Days & Days \\
\hline AUV & $10 \mathrm{~s} \mathrm{~m}$ & $1 \mathrm{~km}$ & $1 \mathrm{~km}$ & $1 \mathrm{~km}$ & Days & Hours & Days & Days \\
\hline UAV & $10 \mathrm{~s} \mathrm{~m}$ & $10 \mathrm{~s} \mathrm{~m}$ & $10 \mathrm{~s} \mathrm{~m}$ & $10 \mathrm{~s} \mathrm{~m}$ & Hours & Hours & Hours & Hours \\
\hline ARGOS & $100 \mathrm{~m}$ & $100 \mathrm{~m}$ & $100 \mathrm{~m}$ & $100 \mathrm{~m}$ & Hours & Hours & Hours & Hours \\
\hline Animal-borne & $\begin{array}{l}10 \mathrm{~s} \mathrm{~m}- \\
1 \mathrm{~km}\end{array}$ & $\begin{array}{l}10 \mathrm{~s} \mathrm{~m}- \\
1 \mathrm{~km}\end{array}$ & $\begin{array}{l}10 \mathrm{~s} \mathrm{~m}- \\
1 \mathrm{~km}\end{array}$ & $\begin{array}{l}10 \mathrm{~s} \mathrm{~m}- \\
1 \mathrm{~km}\end{array}$ & $\begin{array}{l}\text { Seconds } \\
\text { to hours }\end{array}$ & $\begin{array}{l}\text { Seconds } \\
\text { to hours }\end{array}$ & $\begin{array}{l}\text { Seconds } \\
\text { to hours }\end{array}$ & $\begin{array}{l}\text { Seconds } \\
\text { to hours }\end{array}$ \\
\hline Fixed & $1 \mathrm{~m}$ & $10 \mathrm{~m}$ & $10 \mathrm{~m}$ & $10 \mathrm{~m}$ & Minutes & $\begin{array}{l}\text { Minutes } \\
\text { to hours }\end{array}$ & $\begin{array}{l}\text { Minutes } \\
\text { to hours }\end{array}$ & $\begin{array}{l}\text { Minutes } \\
\text { to hours }\end{array}$ \\
\hline
\end{tabular}


The group discussed instrumentation for quantifying changes in distribution, patterns of use, and behavior of four receptor groups: fish and invertebrates, marine mammals, seabirds, and sea turtles. Instrumentation platforms for observations of these receptors consisted of animal-borne, aerial, vesselbased (including ROVs), cabled, and autonomous platforms (including AUVs, UAVs, and ARGOS floats). Instrumentation that could be deployed from these platforms included the following:

- split- and multi-beam active acoustics

- acoustic cameras

- animal-borne tags

- optical cameras (still and video, including both visual spectrum and infrared)

- passive acoustic monitoring (PAM)

- human observers

- vessel-based trawls (benthic and pelagic)

- radar

- Light Detection and Ranging (LiDAR).

Discussions focused on the specific needs of individual receptor groups and the capabilities of various instrumentation types when deployed from different platforms, as summarized in Table 5.2 through Table 5.10 (in which the shaded columns represent combinations of instruments and platforms that do not represent a viable combination for MRE monitoring). The group was not focused on broad-scale species distribution, but population changes over areas no greater than an order of magnitude larger than the area occupied by a deployed MEC. Ultimately, though, it will likely be necessary to evaluate the same types of changes at a population level, particular for environmentally sensitive populations. For example, if sound produced by MECs results in a barrier effect, the receptors in the population of interest might never pass through an area being monitored or might only pass through this area for a few days each year. This being said, the methods needed to determine species distribution at the spatial scales discussed by the group are, in some cases, extensible to measuring changes at the population level. Spatial-temporal resolution needs are summarized in Table 5.1. The group considered the question of determining whether MECs are affecting a significant portion of the population to be a site-specific regulatory decision outside of the scope of workshop discussions. 
Table 5.2. Monitoring distribution and habitat use with split-beam and multi-beam active acoustics. Receptors shown in green indicate that the use of the instrument to monitoring that receptor is feasible; those shown in red most likely cannot be monitored using the instrument indicated. Shaded columns represent combinations of instruments and platforms that do not represent a reasonable combination.

\begin{tabular}{|c|c|c|c|c|c|c|c|}
\hline & Aerial & UAV & Vessel & AUV & Fixed & ARGOS & $\begin{array}{l}\text { Animal- } \\
\text { Borne } \\
\text { Loggers }\end{array}$ \\
\hline Positives & & & $\begin{array}{l}\text { High resolution in time and } \\
\text { space } \\
\text { Large spatial coverage } \\
\text { possible } \\
\text { Integration of } \\
\text { ancillary/complementary data } \\
\text { for context }\end{array}$ & $\begin{array}{l}\text { Same as vessel }+ \\
\text { Not dependent on surface } \\
\text { conditions }\end{array}$ & $\begin{array}{l}\text { Same as AUV + } \\
\text { Continuous operation } \\
\text { Not dependent on } \\
\text { subsurface conditions }\end{array}$ & & \\
\hline Negatives & & & $\begin{array}{l}\text { Operations limited by } \\
\text { metocean conditions } \\
\text { Cannot observe near } \\
\text { boundaries (surface, seabed, } \\
\text { or MEC) } \\
\text { Time-consuming post- } \\
\text { processing } \\
\text { Cannot identify species } \\
\text { directly } \\
\text { Avoidance of platform may } \\
\text { bias data }\end{array}$ & $\begin{array}{l}\text { Same as vessel }+ \\
\text { Operations limited by } \\
\text { subsurface conditions }\end{array}$ & $\begin{array}{l}\text { Same as AUV + } \\
\text { Deployment and retrieval } \\
\text { limited by metocean } \\
\text { conditions } \\
\text { Limited spatial coverage }\end{array}$ & & \\
\hline Needs & & & $\begin{array}{l}\text { Automated data processing, } \\
\text { including indirect species } \\
\text { identification }\end{array}$ & Same as vessel & Same as vessel & & \\
\hline $\begin{array}{l}\text { General } \\
\text { Applicability }\end{array}$ & & & $\begin{array}{l}\text { Fish and invertebrates } \\
\text { Marine mammals } \\
\text { Seabirds (diving) } \\
\text { Sea turtles }\end{array}$ & $\begin{array}{l}\text { Fish and invertebrates } \\
\text { Marine mammals } \\
\text { Seabirds (diving) } \\
\text { Sea turtles }\end{array}$ & $\begin{array}{l}\text { Fish and invertebrates } \\
\text { Marine mammals } \\
\text { Seabirds (diving) } \\
\text { Sea turtles }\end{array}$ & & \\
\hline
\end{tabular}


Table 5.3. Monitoring distribution and habitat use with acoustic cameras. Receptors shown in green indicate that the use of the instrument to monitoring that receptor is feasible; those shown in red most likely cannot be monitored using the instrument indicated. Shaded columns represent combinations of instruments and platforms that do not represent a reasonable combination.

\begin{tabular}{|c|c|c|c|c|c|c|c|}
\hline & Aerial & UAV & Vessel & AUV & Fixed & ARGOS & $\begin{array}{l}\text { Animal- } \\
\text { Borne } \\
\text { Loggers }\end{array}$ \\
\hline Positives & & & $\begin{array}{l}\text { Potential for species } \\
\text { identification } \\
\text { Better range than optical } \\
\text { cameras at depth or in turbid } \\
\text { environments }\end{array}$ & $\begin{array}{l}\text { Same as vessel + } \\
\text { Not dependent on surface } \\
\text { conditions }\end{array}$ & $\begin{array}{l}\text { Same as AUV + } \\
\text { Not dependent on subsurface } \\
\text { conditions } \\
\text { Continuous sampling }\end{array}$ & & \\
\hline Negatives & & & $\begin{array}{l}\text { Dependent on metocean } \\
\text { conditions } \\
\text { Species identification limited } \\
\text { in high-diversity areas } \\
\text { Short range and narrow field } \\
\text { of view relative other active } \\
\text { acoustics } \\
\text { Limited ability to observe fast- } \\
\text { moving species }\end{array}$ & $\begin{array}{l}\text { Same as vessel }+ \\
\text { Dependent on subsurface } \\
\text { conditions } \\
\text { Infrequent encounters (marine } \\
\text { mammals) }\end{array}$ & $\begin{array}{l}\text { Same as AUV + } \\
\text { Deployment and retrieval } \\
\text { limited by metocean } \\
\text { conditions } \\
\text { Limited spatial coverage }\end{array}$ & & \\
\hline Needs & & & $\begin{array}{l}\text { Automated data processing, } \\
\text { including species identification } \\
\text { in areas with high diversity }\end{array}$ & Same as vessel & Same as AUV & & \\
\hline $\begin{array}{l}\text { General } \\
\text { Applicability }\end{array}$ & & & $\begin{array}{l}\text { Fish and invertebrates } \\
\text { Marine mammals } \\
\text { Seabirds (diving) } \\
\text { Sea turtles }\end{array}$ & $\begin{array}{l}\text { Fish and invertebrates } \\
\text { Marine mammals } \\
\text { Seabirds (diving) } \\
\text { Sea turtles }\end{array}$ & $\begin{array}{l}\text { Fish and invertebrates } \\
\text { Marine mammals } \\
\text { Seabirds (diving) } \\
\text { Sea turtles }\end{array}$ & & \\
\hline
\end{tabular}


Table 5.4. Monitoring distribution and habitat use with tags. Receptors shown in green indicate that the use of the instrument to monitoring that receptor is feasible; those shown in red most likely cannot be monitored using the instrument indicated. Shaded columns represent combinations of instruments and platforms that do not represent a reasonable combination.

\begin{tabular}{|c|c|c|c|c|c|c|c|}
\hline & $\begin{array}{l}\text { Aerial (tag } \\
\text { detection) }\end{array}$ & $\begin{array}{l}\text { UAV (tag } \\
\text { detection) }\end{array}$ & $\begin{array}{l}\text { Vessel (tag } \\
\text { detection) }\end{array}$ & $\begin{array}{l}\text { AUV (tag } \\
\text { detection) }\end{array}$ & $\begin{array}{l}\text { Fixed (tag } \\
\text { detection) }\end{array}$ & $\begin{array}{l}\text { ARGOS (tag } \\
\text { detection) }\end{array}$ & $\begin{array}{c}\text { Animal-Borne Tags and } \\
\text { Loggers }\end{array}$ \\
\hline Positives & $\begin{array}{l}\text { Synoptic data (fast } \\
\text { search of a large } \\
\text { area) } \\
\text { Large spatial range } \\
\text { Ease of access to } \\
\text { remote areas }\end{array}$ & $\begin{array}{l}\text { Same }+ \text { reduced } \\
\text { risk relative to } \\
\text { manned study }\end{array}$ & $\begin{array}{l}\text { Focal follows } \\
\text { possible } \\
\text { Short-term, fine- } \\
\text { scale patterns of } \\
\text { behavior }\end{array}$ & $\begin{array}{l}\text { Synoptic } \\
\text { searches of } \\
\text { medium to large } \\
\text { areas } \\
\text { Easy to access } \\
\text { remote areas } \\
\text { Large spatial } \\
\text { range }\end{array}$ & $\begin{array}{l}\text { Data collected in } \\
\text { all metocean } \\
\text { conditions } \\
\text { Focal follows are } \\
\text { possible } \\
\text { Short-term, fine- } \\
\text { scale patterns of } \\
\text { behavior }\end{array}$ & $\begin{array}{l}\text { Data collected in } \\
\text { all metocean } \\
\text { conditions } \\
\text { No need for } \\
\text { instrument } \\
\text { recovery }\end{array}$ & $\begin{array}{l}\text { Data collected in all } \\
\text { metocean conditions } \\
\text { High spatial and temporal } \\
\text { resolution possible }\end{array}$ \\
\hline Negatives & $\begin{array}{l}\text { Animal needs to } \\
\text { be near surface } \\
\text { Low probability of } \\
\text { encounter } \\
\text { Low resolution } \\
\text { Aircraft costs } \\
\text { High human risk }\end{array}$ & $\begin{array}{l}\text { Same as aerial } \\
\text { except costs and } \\
\text { human risks }+ \\
\text { FAA permitting }\end{array}$ & $\begin{array}{l}\text { Low probability } \\
\text { of encounter } \\
\text { Vessel costs }\end{array}$ & $\begin{array}{l}\text { Same as vessel }+ \\
\text { Low spatial } \\
\text { resolution }\end{array}$ & Same as AUV & $\begin{array}{l}\text { Low probability } \\
\text { of encounter } \\
\text { Low spatial and } \\
\text { temporal } \\
\text { resolution }\end{array}$ & $\begin{array}{l}\text { Labor-intensive to attach } \\
\text { tags } \\
\text { Requires instrument } \\
\text { recovery } \\
\text { Relatively few } \\
\text { individuals sampled } \\
\text { Some species cannot be } \\
\text { tagged for biological } \\
\text { reasons or regulatory } \\
\text { reasons }\end{array}$ \\
\hline Needs & $\begin{array}{l}\text { Automated } \\
\text { receiving and } \\
\text { locating systems }\end{array}$ & $\begin{array}{l}\text { Highly compact } \\
\text { automated } \\
\text { receiving and } \\
\text { locating systems }\end{array}$ & $\begin{array}{l}\text { Automated } \\
\text { receiving and } \\
\text { locating systems }\end{array}$ & $\begin{array}{l}\text { Ability to } \\
\text { download data } \\
\text { remotely (incl. at } \\
\text { sea nodes) at low } \\
\text { cost }\end{array}$ & $\begin{array}{l}\text { Automated } \\
\text { receiving and } \\
\text { locating system } \\
\text { cost reduction }\end{array}$ & $\begin{array}{l}\text { Remote } \\
\text { transmission of } \\
\text { large data } \\
\text { volumes over } \\
\text { satellite uplinks }\end{array}$ & $\begin{array}{l}\text { Tag cost reduction } \\
\text { Remote transmission of } \\
\text { large data volumes } \\
\text { Improved battery life and } \\
\text { signal strength } \\
\text { Long-term tag attachment }\end{array}$ \\
\hline $\begin{array}{l}\text { General } \\
\text { Applicability }\end{array}$ & $\begin{array}{l}\text { Fish and } \\
\text { invertebrates } \\
\text { Marine mammals } \\
\text { Seabirds } \\
\text { Sea turtles }\end{array}$ & $\begin{array}{l}\text { Fish and } \\
\text { invertebrates } \\
\text { Marine mammals } \\
\text { Seabirds } \\
\text { Sea turtles }\end{array}$ & $\begin{array}{l}\text { Fish and } \\
\text { invertebrates } \\
\text { Marine mammals } \\
\text { Seabirds } \\
\text { Sea turtles }\end{array}$ & $\begin{array}{l}\text { Fish and } \\
\text { invertebrates } \\
\text { Marine mammals } \\
\text { Seabirds } \\
\text { Sea turtles }\end{array}$ & $\begin{array}{l}\text { Fish and } \\
\text { invertebrates } \\
\text { Marine mammals } \\
\text { Seabirds } \\
\text { Sea turtles }\end{array}$ & $\begin{array}{l}\text { Fish and } \\
\text { invertebrates } \\
\text { Marine mammals } \\
\text { Seabirds } \\
\text { Sea turtles }\end{array}$ & $\begin{array}{l}\text { Fish and invertebrates } \\
\text { Marine mammals } \\
\text { Seabirds } \\
\text { Sea turtles }\end{array}$ \\
\hline
\end{tabular}


Table 5.5. Monitoring distribution and habitat use with optical cameras. Receptors shown in green indicate that the use of the instrument to monitoring that receptor is feasible; those shown in red most likely cannot be monitored using the instrument indicated. Shaded columns represent combinations of instruments and platforms that do not represent a reasonable combination.

\begin{tabular}{|c|c|c|c|c|c|c|c|}
\hline & Aerial & UAV & Vessel & AUV & Fixed & ARGOS & $\begin{array}{c}\text { Animal-Borne } \\
\text { Loggers }\end{array}$ \\
\hline Positives & $\begin{array}{l}\text { Removes observer bias } \\
\text { and produces archival } \\
\text { record } \\
\text { Fish: Good for large } \\
\text { species and schools } \\
\text { Marine Mammals and } \\
\text { Seabirds: Species } \\
\text { identification, distribution, } \\
\text { and size } \\
\text { Marine Mammals and } \\
\text { Seabirds: Cheaper than } \\
\text { observers from fixed } \\
\text { location }\end{array}$ & $\begin{array}{l}\text { Same as aerial }+ \\
\text { Reduced risk and } \\
\text { expense relative } \\
\text { to manned } \\
\text { surveys }\end{array}$ & $\begin{array}{l}\text { Species } \\
\text { identification, } \\
\text { distribution, and } \\
\text { size } \\
\text { Fish: Variety of } \\
\text { deployment } \\
\text { options (trawls, } \\
\text { drop, sleds) }\end{array}$ & $\begin{array}{l}\text { Species } \\
\text { identification, } \\
\text { distribution, and } \\
\text { size }\end{array}$ & $\begin{array}{l}\text { Same as AUV + } \\
\text { Continuous } \\
\text { sampling }\end{array}$ & & $\begin{array}{l}\text { Accurate } \\
\text { identifications of } \\
\text { habitats used or } \\
\text { interaction with } \\
\text { device }\end{array}$ \\
\hline Negatives & $\begin{array}{l}\text { Data volume for post- } \\
\text { processing } \\
\text { Limited post-processing } \\
\text { algorithms } \\
\text { Limited spatiotemporal } \\
\text { coverage (metocean } \\
\text { conditions and available } \\
\text { light) } \\
\text { Fish: Limited number of } \\
\text { species that could be } \\
\text { identified } \\
\text { Marine Mammals and } \\
\text { Seabirds: Limited ability } \\
\text { to identify smaller species }\end{array}$ & Same as aerial & $\begin{array}{l}\text { Limited field of } \\
\text { view } \\
\text { Fish: Avoidance } \\
\text { behavior with } \\
\text { lighting, gear, and } \\
\text { noise } \\
\text { Fish: Problems } \\
\text { deploying in high } \\
\text { flow areas } \\
\text { Fish: Range } \\
\text { limited by } \\
\text { turbidity and } \\
\text { ambient light } \\
\text { Marine } \\
\text { Mammals: } \\
\text { Expense of } \\
\text { infrared cameras }\end{array}$ & $\begin{array}{l}\text { Avoidance } \\
\text { behavior with } \\
\text { lighting and noise } \\
\text { Problems } \\
\text { deploying in } \\
\text { high-flow areas } \\
\text { Range limited by } \\
\text { turbidity and } \\
\text { ambient light }\end{array}$ & $\begin{array}{l}\text { Range limited by } \\
\text { turbidity and } \\
\text { ambient light } \\
\text { Limited spatial } \\
\text { coverage } \\
\text { Seabirds: Low } \\
\text { probability of } \\
\text { encounter }\end{array}$ & & $\begin{array}{l}\text { Must recover for } \\
\text { data recovery with } \\
\text { current } \\
\text { technology. Short } \\
\text { battery life for } \\
\text { micro cameras } \\
\text { (e.g., bird-borne) }\end{array}$ \\
\hline
\end{tabular}


Table 5.5. (contd)

\begin{tabular}{|c|c|c|c|c|c|c|c|}
\hline & Aerial & UAV & Vessel & AUV & Fixed & ARGOS & $\begin{array}{c}\text { Animal-Borne } \\
\text { Loggers }\end{array}$ \\
\hline Needs & $\begin{array}{l}\text { Automated data } \\
\text { processing } \\
\text { Higher resolution, and } \\
\text { larger fields of view } \\
\text { Glare reduction beyond } \\
\text { polarization } \\
\text { Seabirds: Better ability to } \\
\text { determine flight height }\end{array}$ & Same as aerial & $\begin{array}{l}\text { Automated data } \\
\text { processing } \\
\text { Better ability to } \\
\text { control field of } \\
\text { view } \\
\text { Validation of } \\
\text { species } \\
\text { identification }\end{array}$ & Same as vessel & $\begin{array}{l}\text { Same as vessel + } \\
\text { Higher } \\
\text { resolution, and } \\
\text { larger fields of } \\
\text { view }\end{array}$ & & $\begin{array}{l}\text { Further } \\
\text { miniaturization, } \\
\text { longer battery life, } \\
\text { remote download }\end{array}$ \\
\hline $\begin{array}{l}\text { General } \\
\text { Applicability }\end{array}$ & $\begin{array}{l}\text { Fish and invertebrates } \\
\text { (shallow water and } \\
\text { intertidal) } \\
\text { Marine mammals } \\
\text { Seabirds } \\
\text { Sea turtles }\end{array}$ & $\begin{array}{l}\text { Fish and } \\
\text { invertebrates } \\
\text { (shallow water } \\
\text { and intertidal) } \\
\text { Marine mammals } \\
\text { Seabirds } \\
\text { Sea turtles }\end{array}$ & $\begin{array}{l}\text { Fish and } \\
\text { invertebrates } \\
\text { Marine mammals } \\
\text { (surface) } \\
\text { Seabirds (surface) } \\
\text { Sea turtles } \\
\text { (surface) }\end{array}$ & $\begin{array}{l}\text { Fish and } \\
\text { invertebrates } \\
\text { Marine mammals } \\
\text { Seabirds (diving) } \\
\text { Sea turtles }\end{array}$ & $\begin{array}{l}\text { Fish and } \\
\text { invertebrates } \\
\text { Marine mammals } \\
\text { Seabirds (diving) } \\
\text { Sea turtles }\end{array}$ & & $\begin{array}{l}\text { Fish and } \\
\text { invertebrates } \\
\text { Marine mammals } \\
\text { Seabirds } \\
\text { Sea turtles }\end{array}$ \\
\hline
\end{tabular}


Table 5.6. Monitoring distribution and habitat use with human observers. Receptors shown in green indicate that the use of the instrument to monitoring that receptor is feasible; those shown in red most likely cannot be monitored using the instrument indicated. Shaded columns represent combinations of instruments and platforms that do not represent a reasonable combination.

\begin{tabular}{|c|c|c|c|c|c|c|c|}
\hline & Aerial & UAV & Vessel & AUV & Fixed & ARGOS & $\begin{array}{l}\text { Animal- } \\
\text { Borne } \\
\text { Loggers }\end{array}$ \\
\hline Positives & $\begin{array}{l}\text { Real-time species } \\
\text { identification }\end{array}$ & & $\begin{array}{l}\text { Real-time species } \\
\text { identification } \\
\text { High spatial resolution } \\
\text { Ability to collect synoptic } \\
\text { data }\end{array}$ & & $\begin{array}{l}\text { Real-time species } \\
\text { identification } \\
\text { High spatial and temporal } \\
\text { resolution } \\
\text { Inexpensive }\end{array}$ & & \\
\hline Negatives & $\begin{array}{l}\text { Availability of trained } \\
\text { observers } \\
\text { Safety risks for low-elevation } \\
\text { flight } \\
\text { Observer bias } \\
\text { No archival record } \\
\text { Limited spatiotemporal } \\
\text { coverage (metocean } \\
\text { conditions and available } \\
\text { light) } \\
\text { Fish: Limited to } \\
\text { identification of large species } \\
\text { or schools of fish }\end{array}$ & & $\begin{array}{l}\text { Availability of trained } \\
\text { observers } \\
\text { Safety risks for low-elevation } \\
\text { flight } \\
\text { Observer bias } \\
\text { No archival record } \\
\text { Limited spatiotemporal } \\
\text { coverage (metocean } \\
\text { conditions and available light) }\end{array}$ & & $\begin{array}{l}\text { Availability of trained } \\
\text { observers } \\
\text { Observer bias } \\
\text { No archival record } \\
\text { Labor-intensive for limited } \\
\text { observations in low-density } \\
\text { areas } \\
\text { Limited by metocean } \\
\text { conditions and available light }\end{array}$ & & \\
\hline Needs & $\begin{array}{l}\text { Training programs for } \\
\text { observers, including QA } \\
\text { routines }\end{array}$ & & $\begin{array}{l}\text { Training programs for } \\
\text { observers, including QA } \\
\text { routines }\end{array}$ & & $\begin{array}{l}\text { Training programs for } \\
\text { observers, including QA } \\
\text { routines }\end{array}$ & & \\
\hline $\begin{array}{l}\text { General } \\
\text { Applicability }\end{array}$ & $\begin{array}{l}\text { Fish and invertebrates } \\
\text { Marine mammals } \\
\text { Seabirds } \\
\text { Sea turtles }\end{array}$ & & $\begin{array}{l}\text { Fish and invertebrates } \\
\text { Marine mammals } \\
\text { Seabirds } \\
\text { Sea turtles }\end{array}$ & & $\begin{array}{l}\text { Fish and invertebrates } \\
\text { Marine mammals } \\
\text { Seabirds } \\
\text { Sea turtles }\end{array}$ & & \\
\hline
\end{tabular}

$\mathrm{QA}=$ quality assurance 
Table 5.7. Monitoring of distribution and habitat use with passive acoustics. Receptors shown in green indicate that the use of the instrument to monitoring that receptor is feasible; those shown in red most likely cannot be monitored using the instrument indicated. Shaded columns represent combinations of instruments and platforms that do not represent a reasonable combination.

\begin{tabular}{|c|c|c|c|c|c|c|c|}
\hline & Aerial & UAV & Vessel & AUV & Fixed & ARGOS & $\begin{array}{l}\text { Animal- } \\
\text { Borne } \\
\text { Loggers }\end{array}$ \\
\hline Positives & $\begin{array}{l}\text { Potential to drop passive } \\
\text { acoustic buoys from } \\
\text { planes for localization } \\
\text { and tracking }\end{array}$ & & $\begin{array}{l}\text { Distribution and } \\
\text { behavior for vocalizing } \\
\text { species } \\
\text { For drifting vessel, } \\
\text { limited disturbance } \\
\text { Can be combined with } \\
\text { human observers to } \\
\text { validate }\end{array}$ & $\begin{array}{l}\text { Distribution and } \\
\text { behavior for vocalizing } \\
\text { species } \\
\text { Continuous sampling }\end{array}$ & $\begin{array}{l}\text { Same as AUV + } \\
\text { High spatial resolution } \\
\text { Low cost }\end{array}$ & & \\
\hline Negatives & Limited range & & $\begin{array}{l}\text { Limited ability to } \\
\text { characterize abundance } \\
\text { Not all marine mammal } \\
\text { vocalize }\end{array}$ & $\begin{array}{l}\text { Same }+ \text { Low spatial } \\
\text { resolution }\end{array}$ & Same as AUV & & \\
\hline Needs & $\begin{array}{l}\text { Low cost buoys with } \\
\text { satellite or GSM uplinks }\end{array}$ & & & $\begin{array}{l}\text { Automated data } \\
\text { processing }\end{array}$ & Same as AUV & & \\
\hline $\begin{array}{l}\text { General } \\
\text { Applicability }\end{array}$ & $\begin{array}{l}\text { Fish and invertebrates } \\
\text { Marine mammals } \\
\text { Seabirds } \\
\text { Sea turtles }\end{array}$ & & $\begin{array}{l}\text { Fish and invertebrates } \\
\text { Marine mammals } \\
\text { Seabirds } \\
\text { Sea turtles }\end{array}$ & $\begin{array}{l}\text { Fish and invertebrates } \\
\text { Marine mammals } \\
\text { Seabirds } \\
\text { Sea turtles }\end{array}$ & $\begin{array}{l}\text { Fish and invertebrates } \\
\text { Marine mammals } \\
\text { Seabirds } \\
\text { Sea turtles }\end{array}$ & & \\
\hline
\end{tabular}


Table 5.8. Monitoring distribution and habitat use with trawls. Receptors shown in green indicate that the use of the instrument to monitoring that receptor is feasible; those shown in red most likely cannot be monitored using the instrument indicated. Shaded columns represent combinations of instruments and platforms that do not represent a reasonable combination.

\begin{tabular}{|c|c|c|c|c|c|c|c|}
\hline & Aerial & UAV & Vessel & AUV & Fixed & ARGOS & $\begin{array}{l}\text { Animal- } \\
\text { borne } \\
\text { Loggers }\end{array}$ \\
\hline Positives & & & $\begin{array}{l}\text { Species identification morphometrics and demographics } \\
\text { High spatial resolution } \\
\text { Synoptic environmental data }\end{array}$ & & & & \\
\hline Negatives & & & $\begin{array}{l}\text { Labor-intensive } \\
\text { Limited by metocean conditions } \\
\text { Bias associated with avoidance of fishing gear }\end{array}$ & & & & \\
\hline Needs & & & Fishing gear with minimal avoidance to prevent bias & & & & \\
\hline $\begin{array}{l}\text { General } \\
\text { Applicability }\end{array}$ & & & $\begin{array}{l}\text { Fish and invertebrates } \\
\text { Marine mammals } \\
\text { Seabirds } \\
\text { Sea turtles }\end{array}$ & & & & \\
\hline
\end{tabular}


Table 5.9. Monitoring distribution and habitat use with LiDAR. Receptors shown in green indicate that the use of the instrument to monitoring that receptor is feasible; those shown in red most likely cannot be monitored using the instrument indicated. Shaded columns represent combinations of instruments and platforms that do not represent a reasonable combination.

\begin{tabular}{|c|c|c|c|c|c|c|c|}
\hline & Aerial & UAV & Vessel & AUV & Fixed (surface platform) & ARGOS & $\begin{array}{l}\text { Animal- } \\
\text { borne } \\
\text { Loggers }\end{array}$ \\
\hline Positives & $\begin{array}{l}\text { Fine spatial resolution, } \\
\text { including vertical distribution } \\
\text { within water column } \\
\text { Operation in both day and } \\
\text { night }\end{array}$ & $\begin{array}{l}\text { Same as aerial } \\
+ \text { Low risk sampling relative } \\
\text { to manned surveys }\end{array}$ & & & $\begin{array}{l}\text { Same as UAV + } \\
\text { Continuous sampling }\end{array}$ & & \\
\hline Negatives & $\begin{array}{l}\text { Depth limited to upper } 10 \mathrm{~m} \\
\text { and is limited by turbidity } \\
\text { Cannot identify species } \\
\text { directly } \\
\text { Restricted wavelength to } \\
\text { prevent harm to animals } \\
\text { Fish and Seabirds: Only } \\
\text { detectable in high density } \\
\text { schools or flocks }\end{array}$ & Same as aerial & & & Same as aerial & & \\
\hline Needs & $\begin{array}{l}\text { Improved vertical sampling } \\
\text { range } \\
\text { Techniques for indirect } \\
\text { species identification }\end{array}$ & Same as aerial & & & Same as aerial & & \\
\hline
\end{tabular}


Table 5.10. Monitoring distribution and habit use with radar. Receptors shown in green indicate that the use of the instrument to monitoring that receptor is feasible; those shown in red most likely cannot be monitored using the instrument indicated. Shaded columns represent combinations of instruments and platforms that do not represent a reasonable combination.

\begin{tabular}{|c|c|c|c|c|c|c|c|}
\hline & Aerial & UAV & Vessel & AUV & Fixed & ARGOS & $\begin{array}{l}\text { Animal- } \\
\text { borne } \\
\text { Loggers }\end{array}$ \\
\hline Positives & & & $\begin{array}{l}\text { Day and night sampling } \\
\text { Large spatial coverage } \\
\text { Access to remote areas }\end{array}$ & & $\begin{array}{l}\text { Day and night sampling } \\
\text { Large spatial coverage }\end{array}$ & & \\
\hline Negatives & & & $\begin{array}{l}\text { Limited ability to characterize abundance } \\
\text { Identification limited to broad categories } \\
\text { (not species-specific) } \\
\text { Difficult to implement - specialty } \\
\text { applications }\end{array}$ & & $\begin{array}{l}\text { Limited ability to characterize abundance } \\
\text { Identification limited to broad categories } \\
\text { (not species-specific) }\end{array}$ & & \\
\hline Needs & & & $\begin{array}{l}\text { Automated data processing, including } \\
\text { target detection }\end{array}$ & & $\begin{array}{l}\text { Automated data processing, including } \\
\text { target detection }\end{array}$ & & \\
\hline $\begin{array}{l}\text { General } \\
\text { Applicability }\end{array}$ & & & $\begin{array}{l}\text { Fish and invertebrates } \\
\text { Marine mammals } \\
\text { Seabirds } \\
\text { Sea turtles }\end{array}$ & & $\begin{array}{l}\text { Fish and invertebrates } \\
\text { Marine mammals } \\
\text { Seabirds } \\
\text { Sea turtles }\end{array}$ & & \\
\hline
\end{tabular}




\subsubsection{Fish and Invertebrates}

Data needs for fish and invertebrates include measuring changes in density distributions (e.g., using metrics such as residence time or occupancy), near real-time monitoring to enable mitigation measures to be implemented for MEC array operation, and species identification.

Several approaches to meeting these needs were discussed. In general, individual instruments were deemed unlikely to provide all of the necessary data, rather packages integrating multiple types of active acoustic measurements or active acoustic and optical measurements will likely be required. Characterization of distribution and habitat use with such packages is dependent upon the development of quantitative metrics (direct or derived) and significant advances in automated data processing. For observations around WEC arrays, active acoustic packages would need to be incorporated into AUVs or other, small platforms. Because of the energetics of tidal environments, this approach would not be suitable for TECs and distributed, fixed (cabled or autonomous) active acoustic systems would be required.

The group noted that any methods used to observe fish and invertebrates in the United States would need to comply with the regulatory constraints imposed by the Marine Mammal Protection Act and Endangered Species Act.

\subsubsection{Marine Mammals}

The most commonly applied approach for evaluating marine mammal distribution and habitat use around MRE sites is the deployment of human observers, either on vessels or from shore stations. While effective on a site-specific basis, this approach has several key weaknesses. First, standardization across sites is difficult to achieve, because each observer has varying levels of capability that can bias observations. This is not a new problem in marine mammal monitoring, but will complicate comparisons between different projects. Second, as deployments scale up, the group felt that there would never be enough qualified human observers to support traditional approaches to marine mammal monitoring. Consequently, the group felt that there was a need to move toward more automated observation that would still be able to provide information about species-specific abundance and use of MRE sites. It was noted that in the United Kingdom, species identification is currently less important than characterizing abundance and habitat use for taxonomic families of marine mammals.

Data needs for monitoring marine mammal distribution and habitat use around MRE sites include those data necessary to assess avoidance, attraction, and behavior. This requires 3D, temporally resolved distribution information.

Passive acoustic monitoring can provide some of this information. However, there is no global database to validate detections in a way that provides confidence in the identification of geographically distinct marine mammal populations. Passive acoustic monitoring will also be limited by masking from ambient noise sources and differences in vocalization rates for different taxonomic orders of marine mammal (e.g., cetaceans versus pinnipeds). Software to automatically recognize the diversity of marine mammal dialects will require further baseline data and coordinated algorithm development. In addition, the deployment of tracking arrays at MRE sites is non-trivial owing to the energetic wave and current climates. 
For automated monitoring, optical systems (e.g., computer vision) and radar might be coupled with passive acoustic systems to meet data needs. All of the technology is presently available and affordable, but has not been integrated in a way that would allow standardized deployment at MRE sites. Further, significant development would be necessary to automate processing.

The group also noted that aerial surveys and animal-borne tags could be powerful tools for monitoring. In particular, aerial surveys could be used for evaluating marine mammal distribution over large areas, but may not be cost-effective for the spatial-temporal range and resolution required for studies around pilot-scale MEC deployments. Low-cost, long-range UAVs would improve the feasibility of aerial surveys to study marine mammals. Similarly, animal-borne tags have been used to good effect in the United Kingdom to study species distribution and habitat use around MRE projects. However, tag cost is high and tags would need to capable of multi-month data collection owing the difficulties in tag attachment. Tags that incorporate PAM exist, but are marginal in terms of longevity. Overlaps between active tag transmission frequencies and marine mammal hearing obviate the use of actively transmitting tags for observing most marine mammals.

The group felt that it was unlikely that split-beam or multi-beam active acoustics would be used to study marine mammals, given the permitting difficulty and moral questions associated with source levels that can cause temporary or permanent hearing loss for marine mammals at close range.

\subsubsection{Seabirds}

Data needed to evaluate seabird distribution and habitat use are similar to marine mammals and sea turtles, including the need to understand spatial use patterns in 3D space. Optical observations are of primary interest for species identification and are currently achieved using vessel-based observers (which raises human safety concerns in some wave and tidal environments). Radar has also been used for species identification in some locations, such as identifying marbled murrelets in British Columbia (Canada), but has not been cost-effective in comparison to alternatives at locations in the United Kingdom. Computerized recognition programs show promise for post-processing taxonomic identification.

Tagging seabirds with tracking devices may offer opportunities for improved information about their distribution and habitat use. Recognizing the difficulty inherent in any tagging activity, smaller tags and tracking devices are needed (in the 3- to 4-g range) for smaller seabirds of concern, such as marbled murrelets, storm petrels, and common murres. For MRE applications, such tags would ideally include both satellite tracking and dive loggers that allow remote downloading of all tag data, in order reduce the need to recapture individual seabirds to access tag data.

Vessel-based radar deployments have also been used to observe small birds in inland waters (e.g., marbled murrelets) in specialty applications. Such deployments are rare, but can allow observations in remote areas. Passive acoustics are unlikely to be effective for monitoring, because few birds vocalize while at sea. LiDAR is unlikely to be used extensively to monitor seabird distribution and use given that the LiDAR beam is unlikely to detect birds except in high densities, when other tools may be more effective. 


\subsubsection{Sea Turtles}

Evaluating sea turtle distribution and habitat use around MRE sites requires information about their 3D distribution as a function of time. Distribution and use is likely to be seasonal and dependent on location, conditions, and migration intervals. Up to 5 years of monitoring might be required to capture high- and low-nesting years, post-nesting movements, re-migration intervals, and inter-annual environmental variability. These complexities are further compounded by variations in how sea turtles make use of the water column and behave as they age. Species identification will be required and individual identification may be necessary for monitoring turtles in areas with high-density rookeries with a high potential for seasonal interactions with MECs.

Given these complexities, there are several technology gaps in monitoring capabilities for sea turtles. The size, weight, and cost of available tracking tags are problematic. Tags, particular those attached to young sea turtles, must be low cost to achieve a statistically relevant sample size in the face of natural mortality and tag loss with animal growth. At the same time, hatchling tags would need to weigh only $0.2 \mathrm{~g}$, whereas the smallest GPS satellite tags weigh $5 \mathrm{~g}$ and are not suitable for the marine environment. Aerial surveys can be used for species identification, but higher-resolution optics would be required to monitor smaller turtles from aerial platforms. There is also a lack of trained observers capable of species and individual identification from survey data. This gap could be addressed by data collection with longrange UAVs, including some automated data processing for target detection, such as "scoot pattern" recognition software.

Radar and passive acoustics are unlikely to be used to monitor sea turtles, and infrared imaging from above the water surface is unlikely to be effective.

\subsubsection{Sensor Package Integration}

Recognizing the expense of deploying monitoring platforms in MRE environments, there is a clear need to integrate technologies for monitoring distribution and habitat use. This requires answering two questions: 1) what instruments should be incorporated into the package and 2) from what platform should an integrated package be deployed? In some cases, this "integration" may be merely the ability of different autonomous packages to make observations with time synchronization to correlate the various observations. For example, marine mammal monitoring using a combination of radar, aerial optics, and passive acoustics cannot, by definition, be co-located into a single package, but would need to have acceptable time synchronization to be useful.

For co-located sensors, the biggest concern is having one sensor interfere with the operation of another. However, there is great advantage in having co-located sensors that can trigger another sensor. For example, passive acoustics could trigger an underwater optical camera, obviating the need for the optical camera system to operate continuously. Such packages should also include environmental sensors (e.g., wave climate, temperature) to obtain covariate data for interpreting animal observations. While overlapping electronic frequencies for active acoustic observations of fish and passive acoustic observations of marine mammals pose a risk of interference, such sensors can be integrated on a duty cycle with an active pulse followed by a period of passive listening. This could provide valuable covariate data about predator-prey distributions that would be unavailable if either sensor were used in isolation. 


\subsubsection{Priority Gaps and Solutions}

The broad range in the size of receptors, scales at which patterns change for some receptors, and the array of potential survey methodologies, preclude making recommendations of specific survey techniques for characterizing species distributions and habitat use. Rather, researchers and developers need access to a toolbox of methodologies suitable for various combinations of receptor groups, locations, questions, and spatial-temporal scales. The group agreed that the onus of determining the population distribution at the regional level should be on governments, while the site-based onus should be on developers. In many cases, the path forward requires development of tools, both hardware (e.g., autonomous vehicles) and software (e.g., automated detection in real time and for post-processing).

\subsubsection{Autonomous Vehicle Development}

Both unmanned aerial vehicles and autonomous underwater vehicles could enable substantial improvements in monitoring species distribution and habitat use. In particular, UAVs could help to reduce the cost and safety risks associated with manned aerial surveys to the extent that statistically relevant temporal resolution could be achieved. However, effective use of autonomous vehicle platforms requires more accurate positioning and increased versatility in instrumentation payloads. This includes broader support for optical and acoustic monitoring technologies that include some degree of automated onboard processing to overcome storage limitations and allow longer deployments.

\subsubsection{Animal-Borne Tag Development}

Broad-scale distribution and habitat use studies would benefit from the ability to track individual animals over time scales on the order of months to years. In some cases, the technology exists, but in others reductions in weight and cost, in conjunction with increases in longevity, are needed. This would obviously require further development of individual tag technologies, but would also be facilitated by coordinated procurement strategies, such as establishing equipment pools for the MRE community.

\subsubsection{Sensor Integration}

At present, it is difficult to integrate sensors to achieve the objectives of distribution and habitat use studies. For example, there are no autonomous platforms that can automatically synchronize and index the output from multiple active and passive acoustic sensors. Technologies and protocols that can facilitate this integration are desirable, whether as simple as clock synchronization or as complicated as instrument-to-instrument hand-off for animal tracking. Because most sensors in an integrated package would be developed by different companies, a central "brain" would likely be required to achieve tight integration, but would be simplified by common communication protocols.

\subsubsection{Automated Data Processing}

In almost all cases, instrumentation deployed to study animal distribution and habitat use is likely to produce vast quantities of data. At a minimum, software capable of post-processing data with minimal human intervention is required to conduct these surveys in a cost-effective manner. For data collection using autonomous platforms, onboard processing is needed to circumvent the limitations of onboard storage. 


\subsection{Sound Produced by Marine Renewable Energy Converters}

\begin{tabular}{ll}
\hline Participant & Affiliation \\
\hline Brian Polagye (Chair) & University of Washington \\
Ben Wilson & Scottish Association for Marine Science \\
Chris Bassett & University of Washington \\
Courtney Smith & U.S. Department of Energy \\
Erick Johnson & University of Montana \\
Joe Haxel & Oregon State University \\
Keith Kirkendall & NOAA Northwest Region \\
Nathan Johnson & Ocean Renewable Power Company \\
Peter Dahl & University of Washington \\
Peter Stein & Scientific Solutions, Inc. \\
Tom Carlson & Pacific Northwest National Laboratory \\
\hline
\end{tabular}

\section{Questions Addressed:}

- What approaches to measuring sound from marine energy converters are most likely to be successful?

- What constitutes an adequate characterization of a marine energy converter sound source?

- What would be the elements of a standard for sound measurements of marine energy converters?

\subsubsection{Introduction}

Measurements of underwater sound around MECs are generally conducted to either 1) develop an ambient noise budget that provides context for the sound produced by a MEC or 2) characterize MEC sound. The most appropriate technology for an underwater sound measurement depends on the specific study objectives. Breakout group discussions focused on hydrophones, which are sensitive to fluctuations in acoustic pressure fluctuations and are most commonly used to measure underwater sound. Some discussion was given to accelerometers mounted on MECs as a direct measurement of the source vibration, which may allow easy monitoring of changes in source output.

The characterization of sound from MECs is a complex problem and could be costly to address, particularly given the limited definition of measurement sample sizes and availability of equipment pools for spatially resolved measurements. Discussions primarily considered the characterization of sound produced by a single MEC or a small array of MECs. The group did not achieve consensus on the best way to scale measurements of a single MEC to predict the sound from a larger MEC array.

\subsubsection{Definition of Ambient Noise}

Ambient noise is defined as all sound that is not associated with the MEC (i.e., both natural and anthropogenic sources). It is recommended that ambient noise be assessed using a 10-minute sampling period to achieve high statistical confidence in resulting acoustic spectra. Acoustic spectra from preinstallation measurements should be presented on a percentile basis with "typical" ambient noise conditions defined as the 50th percentile spectra. 


\subsubsection{Temporal Variability}

In practice, the sound produced by MECs may change over time scales on the order of a second (e.g., TEC response to turbulent inflow, WEC response to wind waves). However, shorter bursts of sound are not sustained and longer-term averages are needed to achieve statistical confidence in the resulting acoustic spectra. This trade-off is further considered in the context of both MEC and ambient noise measurements.

\subsubsection{Measurement Accuracy}

MECs represent "non-cooperative" sources. That is to say, these are sources of sound that are varying in a manner beyond the control of an operator (unlike a calibrated tonal source). The group's consensus is that distinguishing between ambient noise and converter sound with accuracy better than $\pm 10 \mathrm{~dB}$ (broadband) will be challenging to achieve. This is compounded by the likelihood that frequencies less than $100 \mathrm{~Hz}$ are likely to be the most energetic, thereby driving broadband levels, but will have higher uncertainty. Calibration uncertainty at frequencies above $1 \mathrm{kHz}$ are likely to be $\pm 3 \mathrm{~dB}$ and can be confirmed in the field by pistonphones, but calibrations at frequencies less than $100 \mathrm{~Hz}$ are difficult and infrequently performed. Consequently, while high-frequency sounds from MECs may be characterized with accuracy, broadband sound levels are likely to have wide uncertainty.

Because of these uncertainties, the current regulatory thresholds for "broadband" sound exposure in the United States are problematic. In theory, broadband sound is an integral measure of acoustic pressure over all frequencies greater than $0 \mathrm{~Hz}$. Presently, the National Oceanic and Atmospheric Administration's National Marine Fisheries Service (NOAA NMFS 2013) defines $120 \mathrm{~dB}$ re $1 \mu \mathrm{Pa}$ (broadband) as the threshold for behavioral disturbance of marine mammals by continuous, nonimpulsive noise sources and $180 \mathrm{~dB}$ re $1 \mu \mathrm{Pa}$ (broadband) as the threshold for acoustic injury of marine mammals. ${ }^{1}$ Consequently, there are significant regulatory differences between a reported broadbandreceived level of $119 \mathrm{~dB}$ and $121 \mathrm{~dB}$, even if the underlying accuracy of both estimates is no better than $\pm 10 \mathrm{~dB}$. The group felt that the regulatory community should be given additional flexibility to interpret acoustic measurements near these thresholds because accuracy on the order of $\pm 3 \mathrm{~dB}$ is technologically possible across multiple frequency bands, but likely to be unrealistically difficult to achieve in practice.

Those measurements that have been made of MEC sound suggest that MECs produce sound at frequencies below $10 \mathrm{kHz}$, and the highest intensities are likely to be associated with the lowest frequencies (i.e., fundamental rotation rate for TEC or wave period for a WEC). However, as summarized in Table 5.11, characterizing sound at frequencies below $100 \mathrm{~Hz}$ is difficult and only relevant to a subset of fish and marine mammals. Because of the potential for even underwater noise experts to overlook the challenges associated with low-frequency measurements, acoustic characterizations of both MEC sound and ambient noise at frequencies below $100 \mathrm{~Hz}$ will be less certain than characterizations at higher frequencies. Correspondingly, reported "broadband" noise that includes frequencies below $100 \mathrm{~Hz}$ will also have higher inherent uncertainty.

\footnotetext{
${ }^{1}$ Excepting pinnipeds, for which the threshold for acoustic injury is $190 \mathrm{~dB}$ re $1 \mu \mathrm{Pa}$ (broadband).
} 
Table 5.11. Sound measurement difficulty and regulatory interest.

\begin{tabular}{llccc}
\hline \multicolumn{5}{c}{ Regulatory Interest } \\
\hline $\begin{array}{c}\text { Frequency } \\
\text { Decade }\end{array}$ & $\begin{array}{c}\text { Measurement } \\
\text { Difficulty }\end{array}$ & Europe & $\begin{array}{c}\text { United States } \\
\text { (Marine Mammals) }\end{array}$ & $\begin{array}{c}\text { United States } \\
\text { (Fish) }\end{array}$ \\
\hline $1-10 \mathrm{~Hz}$ & Extremely hard & & & $\mathrm{X}$ \\
$10-100 \mathrm{~Hz}$ & Hard & & $\mathrm{X}$ & $\mathrm{X}$ \\
$100-1000 \mathrm{~Hz}$ & Moderate & $\mathrm{X}$ & $\mathrm{X}$ & $\mathrm{X}$ \\
$>1000 \mathrm{~Hz}$ & Routine & $\mathrm{X}$ & $\mathrm{X}$ & $\mathrm{X}$ \\
\hline
\end{tabular}

Accurate measurements of low-frequency acoustic pressure and particle velocity may be possible with either vector sensors or geophones. The high-frequency cut-off for these instruments is likely to be a few hundred hertz and, in conjunction with hydrophones, could provide a complete and accurate characterization of broadband sound levels. However, neither technology is mature, particularly in the context of the deployment environments for MECs. For example, vector sensors may be more sensitive to flow noise than hydrophones, but may also be more amenable to flow-noise mitigation through flow shielding (further discussion under Priority Gaps [Section 5.3.5]). Both vector sensors and geophones would likely need to be deployed within one water depth of a WEC or TEC, which could present logistical challenges. Further, methods for simultaneous calibration of hydrophones and vector sensors or geophones would need to be developed. If improved measurement accuracy at frequencies below $100 \mathrm{~Hz}$ or an understanding of acoustic particle velocity is required, the group felt that it would be helpful to establish a timeline for technology readiness. However, the group also recognized that until some preliminary measurements are obtained with either vector sensors or geophones, it would be difficult to establish their relative importance.

\subsubsection{Measurements of Sound from Tidal Energy Converters}

Table 5.12 describes the considerations for measurements of TEC sound.

The primary challenge to distinguishing TEC sound from ambient noise is the non-propagating interference from flow noise. For fixed hydrophones, flow noise is likely to substantially mask TEC sound at frequencies below a few hundred hertz, depending on the stage of the tide. Drifting hydrophone measurements are, therefore, recommended, though fixed measurements could be useful if adequate flow shields could be developed.

Measurements of TEC sound should be undertaken with metocean conditions as close to a Beaufort Sea State of " 0 " as possible for a particular site to reduce the potential for significant flow noise caused by wave orbital velocity. Similarly, measurements should be obtained while vessel traffic is at a minimum to avoid masking of TEC sound by another anthropogenic source. Measurements should span a range of flow conditions from slack water up to strong currents $(>2 \mathrm{~m} / \mathrm{s})$. If possible, measurements of TEC sound should be obtained for different converter operating states at the same velocity (e.g., braked, free wheel, and standard operation) to evaluate the influence of operating state on sound characteristics.

While a 10-minute average of radiated sound is preferred to achieve high levels of statistical certainty in reported acoustic spectra, this is not likely to be achievable for a drifter moving through an area ensonified by a TEC. Spectra should be reported for the longest averaging period over which sound 
pressure levels in one-third octave bands do not display a significant trend in time. Depending on the specific TEC being characterized, sound output may vary on turbulent time scales $O(1 \mathrm{~s})$, but these cannot be resolved with useful certainty, particularly at lower frequencies.

Table 5.12. Measurements of sound from tidal energy converters (differences from WECs in italics).

\begin{tabular}{|c|c|c|c|c|}
\hline $\begin{array}{l}\text { Measurement } \\
\text { Consideration }\end{array}$ & $\begin{array}{c}\text { Desired } \\
\text { Accuracy }\end{array}$ & $\begin{array}{l}\text { Measurement } \\
\text { Approaches }\end{array}$ & Challenges & Development Needs \\
\hline $\begin{array}{l}\text { Acoustic pressure } \\
\text { measurement to } \\
\text { distinguish TEC } \\
\text { sound from ambient } \\
\text { noise }\end{array}$ & $\begin{array}{l}\text { - } 3 \mathrm{~dB} \\
\text { - } 10 \mathrm{~dB} \\
\text { above } \\
\text { ambient }^{(\mathrm{a})}\end{array}$ & Hydrophones & $\begin{array}{l}\text { - Temporal and } \\
\text { spatial variability in } \\
\text { ambient noise and } \\
\text { TEC sound } \\
\text { - Accuracy at } \\
\text { frequencies less } \\
\text { than a few hundred } \\
\text { hertz }\end{array}$ & $\begin{array}{l}\text { Improved } \\
\text { protocols/standards for } \\
\text { calibration, } \\
\text { measurement, and } \\
\text { processing }\end{array}$ \\
\hline $\begin{array}{l}\text { Characterizing } \\
\text { temporal variability } \\
\text { of TEC sound and } \\
\text { ambient noise at a } \\
\text { point in space }\end{array}$ & $\begin{array}{l}10 \text {-minute } \\
\text { avg. of } \\
\text { radiated sound }\end{array}$ & $\begin{array}{l}\text { - Fixed } \\
\text { hydrophones } \\
\text { - Accelerometers } \\
\text { (long-term source } \\
\text { variability) }\end{array}$ & $\begin{array}{l}\text { - Flow noise during } \\
\text { strong currents } \\
\text { - Logistics and cost } \\
\text { of deployment/ } \\
\text { retrieval }\end{array}$ & $\begin{array}{l}\text { - Flow shields } \\
\text { combined with multi- } \\
\text { element arrays (very } \\
\text { difficult to mitigate } \\
\text { flow noise during } \\
\text { strongest currents) } \\
\text { - Equipment pools }\end{array}$ \\
\hline $\begin{array}{l}\text { Characterizing } \\
\text { spatial variability of } \\
\text { TEC sound and } \\
\text { ambient noise at an } \\
\text { instant in time }\end{array}$ & $\begin{array}{l}\text { On the order } \\
\text { of } 10 \mathrm{~m}\end{array}$ & $\begin{array}{l}\text { Drifting } \\
\text { hydrophones w/ } \\
\text { GPS tracking }\end{array}$ & $\begin{array}{l}\text { - Convolution of } \\
\text { time and space } \\
\text { - Logistics and cost } \\
\text { of deployment / } \\
\text { retrieval }\end{array}$ & - Equipment pools \\
\hline $\begin{array}{l}\text { Acoustic particle } \\
\text { velocity } \\
\text { measurement to } \\
\text { distinguishing TEC } \\
\text { sound from ambient } \\
\text { noise }\end{array}$ & $\begin{array}{l}\text { - } 3 \mathrm{~dB} \\
\text { - } 10 \mathrm{~dB} \text { above } \\
\text { ambient }^{(\mathrm{a})}\end{array}$ & $\begin{array}{l}\text { Acoustic vector } \\
\text { sensors }\end{array}$ & $\begin{array}{l}\text { Limited } \\
\text { deployment } \\
\text { experience (in any } \\
\text { field environment) } \\
\text { - Potential } \\
\text { interference from } \\
\text { flow noise }\end{array}$ & $\begin{array}{l}\text { General maturation of } \\
\text { technology through } \\
\text { deployment and } \\
\text { assessment, with } \\
\text { objective to bring to } \\
\text { field readiness for MHK } \\
\text { in the future }\end{array}$ \\
\hline
\end{tabular}

(a) At frequencies less than a few hundred hertz, accuracy may be lower.

In evaluating spatial patterns, source directivity may be less relevant than transmission loss uncertainty, particularly if there are significant temporal variations in propagation losses. The group did not achieve consensus on whether variations in sound speed profiles were likely to be significant at tidal energy sites because of the degree of mixing associated with energetic currents. Outside of an array, the accuracy of transmission-loss estimates are likely to be more important than source directivity, because the combination of multiple sources is unlikely to have strong directivity. Within an array, directivity may be more important for estimating marine mammal and fish responses to sound. However, if, as for some wind turbines, directivity variations are on the order of $\pm 6 \mathrm{~dB}$, these may not be detectable, particularly at lower frequencies. 


\subsubsection{Measurements of Sound from Wave Energy Converters}

Table 5.13 describes the considerations for measurements of WEC sound.

The primary challenge to distinguishing WEC sound from ambient noise is propagating interference from local sound sources, such as breaking waves. The group consensus is that the simplest solution for minimizing masking associated with surface noise is to obtain measurements from fixed hydrophones deployed at depth. Multiple fixed hydrophones could be used to obtain spatially resolved measurements of WEC sound. However, it is possible that surface drifters that have measures to suppress the vertical velocity of the hydrophone element and/or have hydrophones equipped with flow shields could be viable, albeit primarily in non-breaking wave environments. It was noted that drifters may be the only option for sound characterization in situations where the deployment of an additional mooring is precluded (either by regulation or the risk of potential interference with the WEC mooring). The idea of benchmarking fixed and drifting measurements under breaking and non-breaking wave climates was discussed, but this was deemed unlikely to be productive given the number of possible explanations for differences between a fixed, bottom measurement and drifting, surface measurement around a WEC.

Table 5.13. Measurements of sound from wave energy converters (differences from TECs in italics).

\begin{tabular}{|c|c|c|c|c|}
\hline $\begin{array}{l}\text { Measurement } \\
\text { Consideration }\end{array}$ & $\begin{array}{l}\text { Desired } \\
\text { Accuracy }\end{array}$ & $\begin{array}{l}\text { Measurement } \\
\text { Approaches }\end{array}$ & Challenges & Development Needs \\
\hline $\begin{array}{l}\text { Acoustic pressure } \\
\text { measurement to } \\
\text { distinguish WEC } \\
\text { sound from ambient } \\
\text { noise }\end{array}$ & $\begin{array}{l}\text { - } 3 \mathrm{~dB} \\
\text { - } 10 \mathrm{~dB} \text { above } \\
\text { ambient }^{\text {(a) }}\end{array}$ & Hydrophones & $\begin{array}{l}\text { - Temporal and } \\
\text { spatial variability in } \\
\text { ambient noise and } \\
\text { WEC sound } \\
\text { - Accuracy at } \\
\text { frequencies less than } \\
\text { a few hundred hertz }\end{array}$ & $\begin{array}{l}\text { Improved } \\
\text { protocols/standards for } \\
\text { calibration, } \\
\text { measurement, and } \\
\text { processing }\end{array}$ \\
\hline $\begin{array}{l}\text { Characterizing } \\
\text { temporal variability } \\
\text { of WEC sound and } \\
\text { ambient noise at a } \\
\text { point in space }\end{array}$ & $\begin{array}{l}\text { 10-minute } \\
\text { avg. of } \\
\text { radiated sound }\end{array}$ & $\begin{array}{l}\text { - Fixed } \\
\text { hydrophones } \\
\text { - Accelerometers } \\
\text { (long-term source } \\
\text { variability) }\end{array}$ & $\begin{array}{l}\text { - Flow noise during } \\
\text { strong currents } \\
\text { - Logistics and cost of } \\
\text { deployment/retrieva } \\
1\end{array}$ & $\begin{array}{l}\text { - Flow shields (if in } \\
\text { shallow, nearshore } \\
\text { areas) } \\
\text { - Equipment pools }\end{array}$ \\
\hline $\begin{array}{l}\text { Characterizing } \\
\text { spatial variability of } \\
\text { WEC sound and } \\
\text { ambient noise at an } \\
\text { instant in time }\end{array}$ & $10 \mathrm{~s}$ of $\mathrm{m}$ & $\begin{array}{l}\text { - Fixed } \\
\text { hydrophones (all } \\
\text { operating } \\
\text { conditions) } \\
\text { - Drifting } \\
\text { hydrophones (low } \\
\text { orbital velocity } \\
\text { conditions) for } \\
\text { reconnaissance) }\end{array}$ & $\begin{array}{l}\text { - Potential flow noise } \\
\text { (orbital velocity, } \\
\text { vertical motion) } \\
\text { - Difficult to deploy in } \\
\text { close proximity } \\
\text { (mooring conflicts) } \\
\text { - Logistics and cost of } \\
\text { deployment/retrieval }\end{array}$ & $\begin{array}{l}\text { - Flow shields (shallow, } \\
\text { nearshore areas or } \\
\text { drifting } \\
\text { measurements) } \\
\text { - Equipment pools }\end{array}$ \\
\hline $\begin{array}{l}\text { Acoustic particle } \\
\text { velocity } \\
\text { measurement to } \\
\text { distinguishing TEC } \\
\text { sound from ambient } \\
\text { noise }\end{array}$ & $\begin{array}{l}\text { - } 3 \mathrm{~dB} \\
\text { - } 10 \mathrm{~dB} \text { above } \\
\text { ambient }^{(\mathrm{a})}\end{array}$ & $\begin{array}{l}\text { Acoustic vector } \\
\text { sensors }\end{array}$ & $\begin{array}{l}\text { - Limited deployment } \\
\text { experience (in any } \\
\text { field environment) } \\
\text { - Potential } \\
\text { interference from } \\
\text { flow noise (but less } \\
\text { than for TECs) }\end{array}$ & $\begin{array}{l}\text { General maturation of } \\
\text { technology through } \\
\text { deployment and } \\
\text { assessment, with } \\
\text { objective to bring to } \\
\text { field readiness for MHK } \\
\text { in the future }\end{array}$ \\
\hline
\end{tabular}

(a) At frequencies less than a few hundred hertz, accuracy may be lower. 
The group consensus is that characterizing temporal variations in WEC sound is best achieved through fixed hydrophone deployments. A 5- to 10-minute averaging period for radiated sound is recommended, although the group noted that time scales on the order of wave group velocity are likely to be important (i.e., averaging period should span an integer number of these scales to avoid bias) and additional measurements of sound from wave converters are needed to further specify this averaging period. Low-frequency sound is likely to be important and it may be difficult to differentiate sound from the converter itself and sound from its mooring. Converter sound is likely to be produced primarily from rotating components and temporally vary with incident wave period.

Measurements of WEC sound should be undertaken during weak, steady currents to minimize the risk of interference from flow noise. Similarly, measurements should be obtained while vessel traffic is at a minimum to avoid masking of WEC sound by another anthropogenic source. Measurements should span a range of wave conditions from a Beaufort Sea State of "0" to maximum operating state. If possible, measurements of WEC sound should be obtained for different converter operating states at the same velocity (e.g., tuned, de-tuned) to evaluate the influence of operating state on sound characteristics.

\subsubsection{Elements of an Acoustic Characterization Standard}

A standard for acoustic characterization should provide a minimum level of specifications to enable relevant comparisons of sound between different MECs operating at different locations. Given the number of similarities noted between TEC and WEC characterization a single standard is likely appropriate, with deviations for the particular classes of converter noted, as needed.

The frequency range over which sound is characterized should range from $20 \mathrm{~Hz}$ to $20 \mathrm{kHz}$. While the low-frequency propagation cut-off is depth dependent, it is unlikely that frequencies lower than $20 \mathrm{~Hz}$ sound will propagate in water depths where MECs will be deployed. At frequencies higher than $20 \mathrm{kHz}$, sound will attenuate rapidly due to absorption. The standard should include an explanation of how to identify artifacts and errors at frequencies less than $100 \mathrm{~Hz}$.

The standard should describe the minimum performance standards for the measurement tool (e.g., self noise, dynamic range, sensitivity) and describe or reference existing calibration procedures.

The standard should provide specific guidance about appropriate techniques for measurement of ambient noise and MEC sound. This should include criteria for the temporal and spatial stationarity of measurements (recognizing that this is likely to be, at best, quasi-stationarity). Ambient noise should be characterized within one water depth of the MEC or within one channel width of the MEC (whichever is smaller). Specific guidance for drifting, fixed, and hybrid measurements of MECs should be provided. Given the likely spatial variability in MEC sound, the standard should specify where, in 3D space, a sound measurement system should be deployed relative to the MEC.

Reporting should include site conditions, such as the general characteristics of the sediment that is present (particularly if it is likely that wave orbital velocity or currents are likely to mobilize this sediment). Metocean conditions and vessel traffic should be monitored during measurements and described. Acoustic measurements should be presented in the form of narrowband spectra, one-third octave bands, and hearing-weighted (e.g., M-weighting or boxcar filtering) for different classes of marine mammals (e.g., cetaceans, pinnipeds). A standard format for measured sound and metadata should be established, such that re-analysis can be readily conducted by other parties. 


\subsubsection{Priority Gaps and Solutions}

\subsubsection{Measurements in High Flow Environments}

Flow noise is a barrier to fixed hydrophone measurements for both WECs and TECs; flow shields capable of suppressing this non-propagating interference in both wave and tidal environments are needed. Exploratory research on marine hydrokinetic (MHK)-specific flow shields is recommended, given the benefits of a standardized solution, such as a cage or dome compatible with multiple hydrophones. There are some parallels to naval expertise in flow-noise suppression, but differences in the range of velocities, allowable form factors, and allowable costs point toward a need for an MHK-specific solution. While the intensity of flow noise is daunting in high-current conditions, there would be a high return on investment if the exploratory research bears promising results. If flow shields are successfully developed, calibration procedures would need to incorporate these shields, co that calibrations could be undertaken at high-flow test facilities. Such facilities are rare, but do exist.

\subsubsection{Standardized Measurements and Reporting for Use by the Broader Research Community}

Standardized approaches to the measurement and reporting of MEC sound do not exist. International standards, with the elements described in Section 5.3.4, should be developed. In doing so, it should be acknowledged that, regardless of standardization, characterizing non-cooperative acoustic sources will entail significant uncertainty.

\subsubsection{Low-Cost Surface Drifters}

Simultaneous deployments of a large number of surface drifters equipped with hydrophones and GPS loggers could help to characterize spatial variability in MEC sound. However, for reasons of cost, no single research group is likely to have more than a handful of identical drifters. Strategies for reducing the cost of large-scale surface drifter deployments should be pursued. These include reducing drifter fabrication costs (including hydrophones) from $\sim \$ 25 \mathrm{~K}$ to $\sim \$ 5 \mathrm{~K}$, engaging in competitive procurement strategies, and developing shared equipment pools. An equipment pool of approximately 50 drifters would likely meet the needs of the global acoustic community engaged in characterization of MEC sound and its effects on receptors in the marine environment.

\subsubsection{Role of Accelerometers}

While not capable of providing a measurement of acoustic pressure or particle velocity, accelerometers could be a "canary in the coal mine" to monitor long-term changes in MEC sound production. If distributed over the MEC and its support structure, accelerometers could be a costeffective tool for identifying sources of sound production. Prior to their use, modal testing should be conducted to characterize the frequency response of a MEC for forcing at a particular frequency. While accelerometers intended to monitor variations in sound production would likely operate at higher sampling rates than those intended to detect impacts (e.g., fish, marine mammals, ice, or debris), the sampling rates may be compatible with structural health monitoring. Wider quantitative use of accelerometers might be able to leverage experience gained from wind-energy development. 



\subsection{Common Themes}

Common themes noted across the marine energy community during the workshop breakout sessions included the need for cost-effective risk evaluation as part of well-focused monitoring; processing and optimization of large volumes of data; integration of instrumentation for deployment and operation as a single package; platforms and supporting technologies that help realize the full potential of instrumentation; and collaboration between developers, researchers, and regulators. Each of these themes is discussed in the following sections.

\subsection{Evaluating Risk}

Carrying out risk-based assessments before designing monitoring programs and assigning appropriate instrumentation packages for the highest risk interactions will help to create cost-effective data collection that will allow marine energy developers to site and permit devices without jeopardizing their financing and forward momentum. Risk-based assessments will also assist regulators in mapping potential highrisk interactions around marine energy devices to the applicable regulation/statute, thereby enabling efficient and supportable permitting guidance and monitoring requirements. With a stepwise application of risk-based assessment, defensible monitoring strategies, and high-quality data collection and analysis, the marine energy community will be able to distinguish between interactions that do not constitute an elevated risk to marine animals and those for which further avoidance or mitigation measures are needed. In this manner, there may be a pathway to "retire" certain specific environmental questions from consideration for future MRE projects with risk profiles similar to existing projects. To date, there is no means of determining how much data collection and analysis is enough to allow this "retirement" to occur. Risks associated with individual MECs will need to be substantially resolved before larger arrays can be deployed. Successive increases in array size are likely to present new risks and monitoring challenges, but given the difficulties associated with near-converter monitoring, comprehensive monitoring of every converter in an array is unlikely to be feasible.

\section{2 "Data Mortgages"}

Observations of MRE projects are likely to produce large volumes of data within a short time period. If pre- or post-processing can winnow these data streams down to their essential elements, data volume need not present a significant challenge, provided that regulatory agencies are willing to accept the deletion of raw data over relatively short horizons. Such practices occur for any instrument that preprocesses data, such as cetacean click detectors of fish-tag receivers. However, if real-time processing is unavailable or regulatory agencies require the archiving of all raw data for future re-processing, "data mortgages" can be very challenging, particularly for high-resolution optical or active acoustic imagery. A "data mortgage" occurs when data are archived with the intent of undergoing future review, postprocessing occurs in less than real time, or post-processing relies on a processing technique that is not yet developed.

Examples of existing software packages that can process active acoustic data from split-beam echosounders in real time or close to real time include NewTracer and VisualAcquisition from BioSonics, Inc. (United States), Echoview from Myriax (Tasmania), and Sonar5 from Lindem Data (Norway). 
Similarly, PAMGuard (open source) can process passive acoustic data in near real time. Tools are not yet available for real-time post-processing of multi-beam acoustic, optical, or radar imagery.

Data mortgages should be avoided when possible, but may be inevitable in the collection of comprehensive data sets to validate triggering routines, such as hand-offs between different instruments or detections of collision between marine animals and MECs. These validation data sets will, however, require large-scale storage solutions and high-bandwidth communications infrastructure to connect the sensor to the large-scale storage solution. For example, a stereo camera arrangement involving a pair of 16-bit, black-and-white, 2-megapixel cameras would generate over 100 terabytes of uncompressed video in a fortnight. Further, a validation data set might include an array of such camera systems, in conjunction with active sonars and passive acoustic arrays, such that petabyte-level storage might be required to archive all data. This specific example demonstrates the challenges associated with data management, data communications infrastructure, and why a continuous monitoring strategy may only be possible with robust pre- or post-processing that obviates the need to archive the vast majority of raw sensor data. In some cases, it may be more cost-effective to address an environmental concern by "mining" existing data mortgages in a manner that advances software tools for post-processing, than it is to collect additional data.

\subsection{Integrated Instrumentation}

Integrated instrumentation packages entail the use of one sensor to trigger a second sensor; the handoff achieved to the second sensor may be an effective way to reduce the risk of data mortgages. As an example, a passive acoustic array might localize a marine mammal vocalization at a range of several hundred meters. The coarse bearing information could then be used to aim a split-beam echosounder at the target and track its trajectory. Once the target is close enough to the MEC, an optical or acoustic camera could then be activated to classify the target. This information could then be correlated with accelerometer data from the MEC structure to determine if a collision occurred.

This process would require several specific research and development tasks to be brought to fruition. For example, passive acoustic triggering for classification and coarse localization would have to occur within a few seconds in the outer layer of the triggering system. It may be possible to "nudge" opensource software such as PAMGuard to meet this processing specification. Similarly, the hand-off from the passive to active systems would require a framework for inter-instrumentation communication that does not currently exist.

If successfully implemented, such systems could greatly reduce data bandwidth, despite having multiple sensors operating continuously, as follows:

- The passive acoustic array would only archive wave forms classified as originating from a marine mammal and bearing information about the animal to the source, not the raw data stream from the hydrophone array.

- The split-beam active sonar would only archive data while tracking a target and, ultimately, perhaps only the target track. 
- The acoustic or optical camera would only archive data when instructed to by the split-beam tracking information.

- The accelerometer data stream could be processed in near real time and only potential collision events archived for subsequent analysis.

This type of integration is within the reach of the MRE community, but would require a focused, multi-year development effort.

\subsection{Platforms and Supporting Technologies}

Platforms to deploy instrumentation, particularly for studies of distribution and habitat use, are a limiting consideration for several types of instrumentation. This is a standing challenge for the study of high-energy oceanographic sites, even in the absence of MECs. Unmanned aerial vehicles and AUVs may be potentially powerful platforms, but are prohibitively expensive at present.

The ability to simultaneously deploy multiple, low-cost packages to achieve a desired spatial resolution for species distribution and habitat use studies was, in general, deemed preferable to more expensive "one-off" packages that need to be deployed repeatedly to achieve similar spatial resolution.

In a number of cases, distributed cabled instrumentation packages have been suggested to facilitate observations of nearfield interactions, as well as species distribution and habitat use. For example, a cabled split-beam echosounder on a bottom-mounted platform could be equipped with a pan-and-tilt actuator to increase the spatial coverage by a single sensor. The difficulty associated with deploying arrays of cabled instrumentation nodes in energetic wave and tidal environments is likely to be comparable to the difficulty of deploying arrays of marine energy converters. The benefits of deploying distributed cabled packages needs to be balanced against the cost realities of instrumentation deployment and survivability.

In contrast, there are a number of benefits to installing sensors on the MEC itself, including the potential to tie in to the power and communications link between the MEC and shore infrastructure. Such installations may not, however, provide the requisite stand-off distance for an observation. For example, to achieve significant spatial coverage of a MEC, optical or active acoustic sensors require a stand-off distance inversely proportional to their field of view. Depending on array density and sensor range, it may be possible to achieve the requisite stand-off distance by using a sensor package mounted on one MEC to observe another.

In addition to addressing high-priority issues for the marine energy industry, MECs could potentially, serve as general-purpose ocean observing platforms. This could provide a number of long-term data streams, such as water quality, that are currently outside of the priority areas for the MRE research and development community, but could eventually be of value to the industry. In integrating any sensor package with a MEC it is important to ensure that electrical power of sufficiently high quality is available and that electrical noise from the MEC does not interfere with communications between a shore station and the sensor package. Fiber-optic communication links may mitigate the latter risk. 


\subsection{Collaborations between Developers and Researchers}

Regulatory considerations provide a powerful incentive for the MRE industry to address short-term environmental questions. Greater incentives are, however, required to encourage developers and researchers to work together to address long-term environmental questions. Such incentives should include open access to data and publications, but also acknowledge the costs associated with exchange of information between parties and the time required to build trusted relationships between parties.

One concept to facilitate collaborations between researchers and industry would be the development of a standardized "science port" on MECs. This would reduce the "one-off" engineering costs associated with customized integration of monitoring packages with converters and reduce the engineering uncertainty the industry currently faces when making a decision about whether a particular instrument should be incorporated into a converter. This type of interface has been considered for offshore wind, but would need to balance specific considerations for WECs and TECs, such as the cost-benefit of being able to swap instrumentation without recovering the entire converter. At present, this arrangement requires expensive wet-mate connectors, but the development of non-contact power and data transfer technologies could be transformative.

Moving away from custom integration of instruments with specific converters to a converter-agnostic science port architecture would also reduce the risk of methods and instrumentation being tied to "legacy" WECs and TECs. Converter designs are undergoing rapid evolutions and systems designed to integrate with the structure of the current-generation of converters may be incompatible with the next.

While improved coordination and collaboration between the research and developer communities is desirable, when pursuing such improvement, clear lines need to be drawn to avoid a public perception of conflict of interest. Failing to do so may result in a public perception that environmental studies funded by developers are subjectively biased and of limited value (regardless of the cost to implement them). 


\subsection{Recommended Near-Term Next Steps}

Several breakout groups expressed a desire to establish a standard set of metrics and methodologies for monitoring MRE projects. This would improve the comparability of results between projects and clarify monitoring needs and costs for industry. Efforts to establish standards for acoustic monitoring of WECs and TECs are being advanced within IEC Technical Committee 114, but are at an early stage of development. No comparable standards for monitoring nearfield or species distribution and habitat use have been proposed. A key step toward standards might be the establishment of best practices for monitoring in the nearfield and further around MECs. The present level of scientific uncertainty may necessitate a targeted, international workshop to lay the groundwork for the eventual emergence of common practices.

Most workshop participants developed a new understanding as the result of the workshop, highlighting important opportunities for international knowledge exchange when connections are made outside of researcher's geographic regions. Such collaborations are difficult to maintain without specific funding. Coordination between different international funding agencies that can sustain and grow international collaborations through the exchange of personnel between institutions and industry are recommended.

Presently, there are no international conferences dedicated to environmental research around MECs. The first Environmental Interactions of Marine Renewable Energy Technologies (EIMR) meeting in 2012 was noted as a welcome exception to this and mechanisms to support international researcher involvement in the second EIMR meeting planned for 2014 are recommended. This venue could also support an organizational meeting for the development of international standards for environmental monitoring of MECs. 



\subsection{Conclusions}

This workshop identified several high-priority gaps and solutions related to instrumentation. While some instrumentation needs are site-specific or specific to a particular tidal or wave conversion technology, the majority of needs identified by the working groups cut across the entire MRE sector. Consequently, coordinated development efforts are likely to pay dividends for the entire industry. In recognition of limited resources, these efforts should be focused, in the near term, on addressing the environmental effects of highest potential significance and regulatory uncertainty. Such advances are likely to accelerate the permitting process for MRE projects on a global scale and lay the groundwork for environmental research and development for commercial arrays.

There is a need for automated pre- and post-processing of data streams from instrumentation. Currently, continuous monitoring using high-resolution optical or acoustic instrumentation results in data streams that are too large to be feasibly archived within the resources available for pilot-scale and earlycommercial demonstrations. However, it may be impossible to obtain observations of relatively rare, but important, events without continuous observations. Algorithms that enable processing of data streams in near real time to retain only data needed to address the most pressing environmental concerns is desirable to avoid unwieldy "data mortgages." A particularly high priority in this area is automated post-processing of optical and acoustic imagery.

Even for single marine energy converters, continuously observing the entirety of the converter and supporting infrastructure (foundation, cable) is difficult. Optical and acoustic imaging systems all have limited fields of view and achieving continuous, full spatial coverage of MECs may require a significant amount of equipment and supporting infrastructure, depending on the range and resolution required to address the monitoring hypothesis. However, this type of monitoring may not be necessary if the probability of negative interactions is judged to be acceptably small. This depends on assessment outcomes and stakeholder concerns. Risk assessment may allow regulatory communities to responsibly "retire risk" in some areas.

Instrumentation deployment at MRE sites is costly and long-term instrument survivability faces challenges similar to MEC survivability. Addressing this gap will require collaboration between the environmental research and development communities to create feasible methods for deploying instrumentation packages integrated with the MECs. To reduce cost, such integration should be standardized to the extent possible, while recognizing that site-specific requirements will continue to influence environmental studies and some flexibility/adaptability will be required.

Instrumentation and data-processing software should be integrated to leverage the relative strengths of different sensors without the burden of data streams from continuous monitoring. The basic instrumentation to support most monitoring needs for MRE projects exists, but packaging and deploying these instruments in an integrated manner to achieve monitoring objectives continues to be costly and beyond the general capabilities of the community. Algorithms for automatic pre- and post-processing of data can play a critical role in enabling triggers that "hand off" monitoring responsibilities between instruments (e.g., a single-beam sonar triggering the activation of an optical camera system).

The discussions in this workshop demonstrate the power and challenges of data collection in support of MRE projects. In the United Kingdom, where more MECs have been deployed than anywhere in the 
world, the availability of data has led to changes in monitoring strategies. Adaptive management is a critical part of this process, because, until some data are collected, it is difficult to judge the effectiveness of a monitoring strategy. Similarly, definitions of the "nearfield" are likely to change as single marine energy converters are scaled up to larger arrays. The extrapolation of monitoring results from pilot-scale deployments needs to be considered in order to assess risk and to design monitoring methods for arrayscale studies.

In the collection of environmental data related to MRE deployments, the audience for these data must be considered. Environmental regulators will often be able to respond more easily to intuitive imagery of receptors interacting with MECs than more scientifically robust data, such as post-processed results from arrays of single-beam echosounders. Instrumentation selection needs to account for both the scientific aims of environmental research and its potential to make an impact on the emergence of a sustainable MRE industry. 


\subsection{References}

Boehlert G and A Gill. 2010. Environmental and ecological effects of ocean renewable energy development: A current synthesis. Oceanography 23(2):68-81.

Boom BJ, PX Huang, C Spampinato, S Palazzo, J He, C Beyan, E Beauxis-Aussalet, J van Ossenbruggen, G Nadarajan, JY Chen-Burger, D Giordano, L Hardman, F-P Lin, and RB Fisher. 2012. Long-term underwater camera surveillance for monitoring and analysis of fish populations. In Proceedings of the International Workshop on Visual Observation and Analysis of Animal and Insect Behavior (VAIB). In conjunction with International Conference on Pattern Recognition 2012, Tsukuba, Japan.

Cada G, J Ahlgrimm, M Bahleda, T Bigford, S Damiani Stavrakas, D Hall, R Moursund, and M Sale. 2007. Potential impacts of hydrokinetic and wave energy conversion technologies on aquatic environments. Fisheries 32(4):174-181.

Copping A, K Blake, L Hanna, T Carlson, J Ward, C Brandt, J Elster, R Jepsen, K Metzinger, M Jones, J Brandenberger, G Gill, B Watson, and M Watkins. 2012. Evaluating Effects of Stressors from Marine and Hydrokinetic Energy. PNNL-SA-21885, Pacific Northwest National Laboratory, Seattle, Washington.

Dähne M, U Verfuß, A Brandecker, U Siebert, and H Benke. 2013. Methodology and results of calibration of tonal click detectors for small odontocetes (C-PODs). The Journal of the Acoustical Society of America 134:2514.

Endangered Species Act of 1973, as amended. 16 USC $§ 1531$ et seq.

Graber J, J Thomson, B Polagye, and A Jessup. 2011. Land-based infrared imagery for marine mammal detection. Proceedings of SPIE Photonics + Optics, August 20-25, San Diego, California.

Huang PX, JB Boom, and RB Fisher. 2013. Underwater live fish recognition using a balance-guaranteed optimized tree. In Computer Vision-ACCV 2012, 422-433, Springer, Berlin.

Isaacman L and G Daborn. 2011. Pathways of Effects for Offshore Renewable Energy in Canada. Fisheries and Oceans Canada, Acadia Centre for Estuarine Research Publication No. 102, Acadia University, Wolfville, NS, Canada.

Jacobson P, S Amaral, T Castro-Santos, D Giza, A Haro, G Hecker, B McMahon, N Perkins, and N Pioppi. 2012. Environmental Effects of Hydrokinetic Turbines on Fish: Desktop and Laboratory Flume Studies. Electric Power Research Institute, Palo Alto, California.

Macaulay J, D Gillespie, S Northridge, and J Gordon. 2013. Porpoises and tidal turbines, fine scale tracking using passive acoustics to assess and mitigate collision risk. The 6th International Workshop on Detection, Classification, Localization, and Density Estimation of Marine Mammals Using Passive Acoustics, June 12-15, University of St. Andrews, Fife, Scotland.

Marine Mammal Protection Act of 1972, as amended. 16 USC 1361. 
Marine Scotland. 2012. Marine Energy. Accessed May 11, 2012 from

http://www.scotland.gov.uk/Topics/marine/marineenergy

Matai J, R Kastner, GR Cutter, Jr., and DA Demer. 2012. Automated techniques for detection and recognition of fishes using computer vision algorithms. K Williams, C Rooper, and J Harms (eds), NOAA Technical Memorandum NMFS-F/SPO-121, report of the National Marine Fisheries Service Automated Image Processing Workshop, Seattle, Washington, September 4-7, 2010. NOAA NMFS, Seattle, Washington.

McMichael GA, MB Eppard, TJ Carlson, JA Carter, BD Ebberts, RS Brown, M Weiland, GR Ploskey, RA Harnish, and ZD Deng. 2010. The juvenile salmon acoustic telemetry system: a new tool. Fisheries 35(1):9-22.

NOAA NMFS (National Oceanic and Atmospheric Administration National Marine Fisheries Service). 2013. Guidance for Assessing the Effects of Anthropogenic Sound on Marine Mammals. Under development. Available at: http://www.nmfs.noaa.gov/pr/acoustics/guidelines.htm

Normandeau Associates. 2009. An Estimation of Survival and Injury of Fish Passed through the Hydro Green Energy Hydrokinetic System, and a Characterization of Fish Entrainment Potential at the Mississippi Lock and Dam No. 2 Hydroelectric Projects. Manchester, New Hampshire.

Petrell RJ, X Shi, RK Ward, A Naiberg, and CR Savage. 1997. Determining fish size and swimming speed in cages and tanks using simple video techniques. Aquacultural Engineering 16(1):63-84.

Polagye B, B Van Cleve, A Copping, and K Kirkendall (eds). 2011. Environmental effects of tidal energy development. NOAA Technical Memorandum F/SPO-116, U.S. Department of Commerce, Seattle, Washington.

Schusterman R, D Kastak, D Levenson, C Reichmuth, B Southall. 2000. Why pinnipeds don't echolocate. The Journal of the Acoustical Society of America 107:2256-2264.

Sousa-Lima RS, T Norris, J Oswald, D Fernandes. 2013. A Review and Inventory of Fixed Autonomous Recorders for Passive Acoustic Monitoring of Marine Mammals. Aquatic Mammals 39(1):23-53. DOI: 10.1578/AM.39.1.2013.

Southall B, A Bowles, W Ellison, J Finneran, R Gentry, C Greene Jr., D Kastak, D Ketten, J Miller, P Nachtigall, W Richardson, J Thomas, P Tyack. 2007. Marine Mammal Noise Exposure Criteria: Initial Scientific Recommendations. Aquatic Mammals 33:411-522.

Viehman HA. 2012. Fish in a Tidally Dynamic Region in Maine: Hydroacoustic Assessments in Relation to Tidal Power Development. Master's Thesis, The University of Maine, Orono, Maine.

Wilson B, S Benjamins, and J Elliott. 2013. Using drifting passive echolocation loggers to study harbour porpoises in tidal-stream habitats. Endangered Species Research 22:125-143. 


\section{Appendix A}

\section{Workshop Participant List and Affiliations}





\section{Appendix A}

\section{Workshop Participant List and Affiliations}

\begin{tabular}{|c|c|c|c|}
\hline Name & Affiliation & Needs and Gaps Breakout & Capabilities Breakout \\
\hline Andrea Copping & $\begin{array}{l}\text { Pacific Northwest } \\
\text { National Laboratory }\end{array}$ & Nearfield & Passive \\
\hline Anna Redden & Acadia University & Distribution & Passive \\
\hline Ben Wilson & $\begin{array}{l}\text { Scottish Association for } \\
\text { Marine Science }\end{array}$ & Sound & Passive \\
\hline Beth Mackey & Royal Haskoning DHV & Nearfield & Active \\
\hline Brian Polagye & University of Washington & Sound & Optical \\
\hline Bryan Apell & Kleinschmidt & Nearfield & Active \\
\hline Chris Bassett & University of Washington & Sound & Passive \\
\hline Courtney Smith & $\begin{array}{l}\text { U.S. Department of } \\
\text { Energy }\end{array}$ & Sound & Passive \\
\hline Erick Johnson & University of Montana & Sound & Passive \\
\hline Gayle Zydlewski & University of Maine & Nearfield & Active \\
\hline Greg Sanders & $\begin{array}{l}\text { Bureau of Ocean Energy } \\
\text { Management }\end{array}$ & Nearfield & Passive \\
\hline Gretchen Steiger & Cascadia Research & Nearfield & Optical \\
\hline Hoyt Battey & $\begin{array}{l}\text { U.S. Department of } \\
\text { Energy }\end{array}$ & Nearfield & Optical \\
\hline Ian Hutchison & Aquatera & Distribution & Optical \\
\hline Jeff Condiotty & Kongsberg Mesotech & Nearfield & Active \\
\hline Jesse Roberts & $\begin{array}{l}\text { Sandia National } \\
\text { Laboratories }\end{array}$ & Nearfield & Optical \\
\hline Jim Boutiller & $\begin{array}{l}\text { DFO Canada Pacific } \\
\text { Biological Station }\end{array}$ & Distribution & Optical \\
\hline Jim Dawson & BioSonics, Inc. & Nearfield & Active \\
\hline Jocelyn Brown-Saracino & $\begin{array}{l}\text { New West } \\
\text { Technologies/US } \\
\text { Department of Energy }\end{array}$ & Distribution & Active \\
\hline Joe Haxel & Oregon State University & Sound & Passive \\
\hline John Horne & University of Washington & Distribution & Active \\
\hline Kate Mansfield & $\begin{array}{l}\text { Florida International } \\
\text { University }\end{array}$ & Distribution & Optical \\
\hline Keith Kirkendall & NOAA Northwest Region & Sound & Active \\
\hline Manuel Castellote & $\begin{array}{l}\text { National Marine Mammal } \\
\text { Laboratory, Alaska } \\
\text { Fisheries Science Center, } \\
\text { NMFS/NOAA. }\end{array}$ & Distribution & Passive \\
\hline Mel Broadhurst & Alderney Wildlife Trust & Nearfield & Optical \\
\hline Nathan Johnson & $\begin{array}{l}\text { Ocean Renewable Power } \\
\text { Company }\end{array}$ & Sound & Passive \\
\hline
\end{tabular}




\begin{tabular}{llll}
\hline Name & Affiliation & Needs and Gaps Breakout & Capabilities Breakout \\
\hline Paul Bell & National Oceanography & Distribution & Active \\
& Centre & & \\
Paul Thompson & University of Aberdeen & Distribution & Passive \\
Peter Dahl & University of Washington & Sound & Passive \\
Peter Stein & Scientific Solutions, Inc. & Sound & Active \\
Rob Suryan & Oregon State University & Distribution & Optical \\
Rodrigo Hucke G. & Universidad Austral de & Distribution & Optical \\
Sharon Kramer & Chile & & \\
Sharon Nieukirk & H.T. Harvey \& Associates & Distribution & Optical \\
Simon Geerlofs & Oregon State University & Nearfield & Passive \\
& Pacific Northwest & Distribution & Active \\
Tom Carlson & National Laboratory & & \\
& Pacific Northwest & Sound & Active \\
\hline
\end{tabular}


Appendix B

\section{Workshop Evaluation Responses}





\section{Appendix B}

\section{Workshop Evaluation Responses}

Self-identified affiliations and professional emphasis are shown in Figure B.1 and Figure B.2.

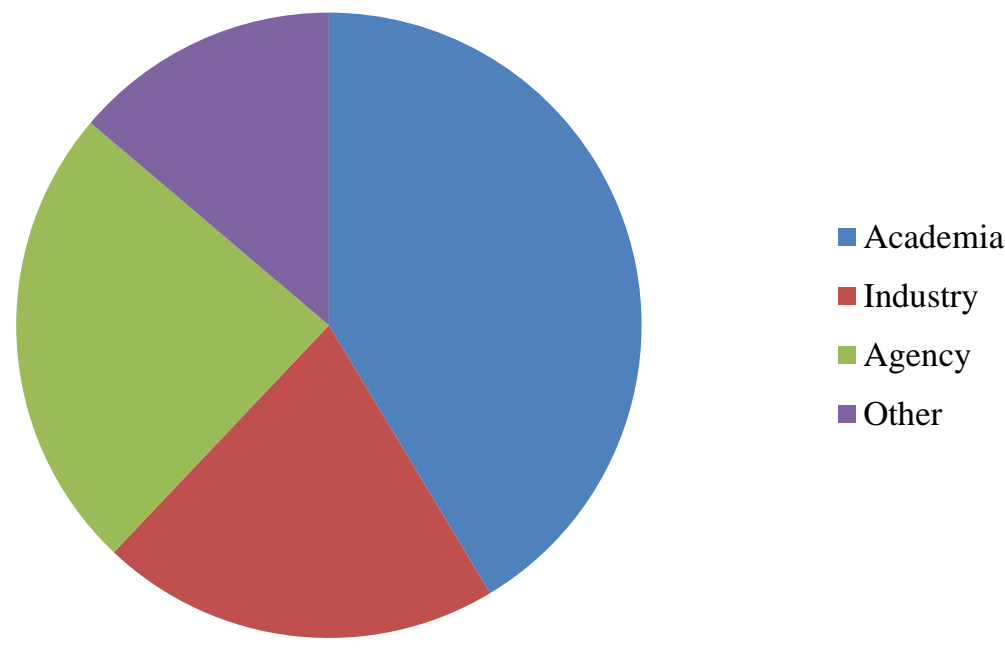

Figure B.1. Workshop participant self-identified affiliation.

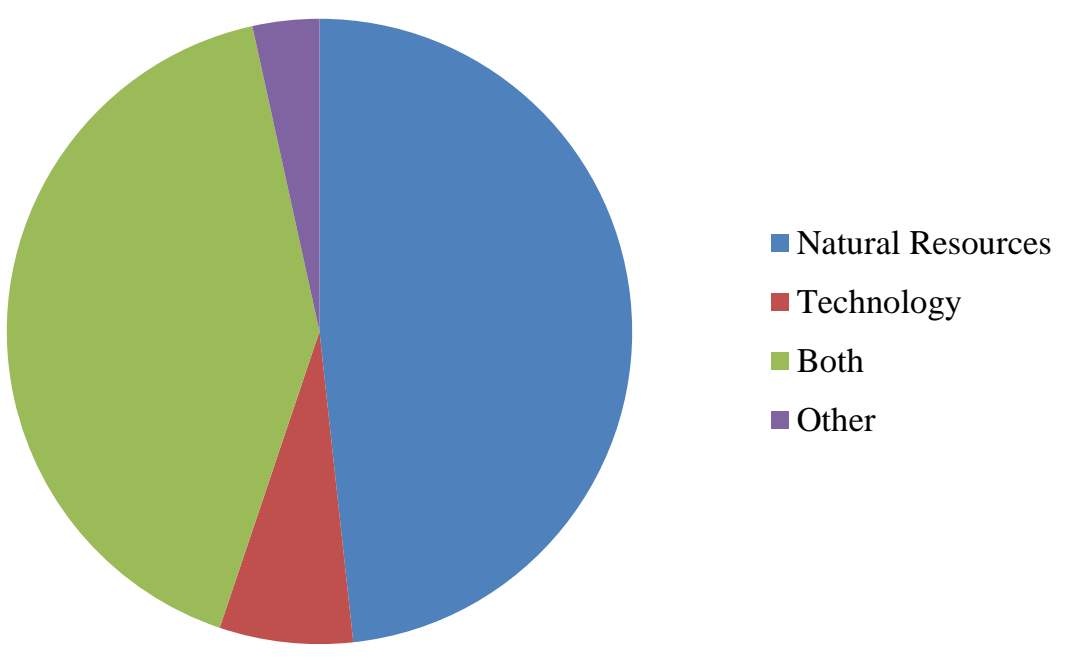

Figure B.2. Workshop participant self-identified professional emphasis.

Figure B.3 through Figure B.9 show quantitative evaluations of workshop outcomes by the participants. The vast majority of participants found the workshop to be appropriately structured and beneficial. 


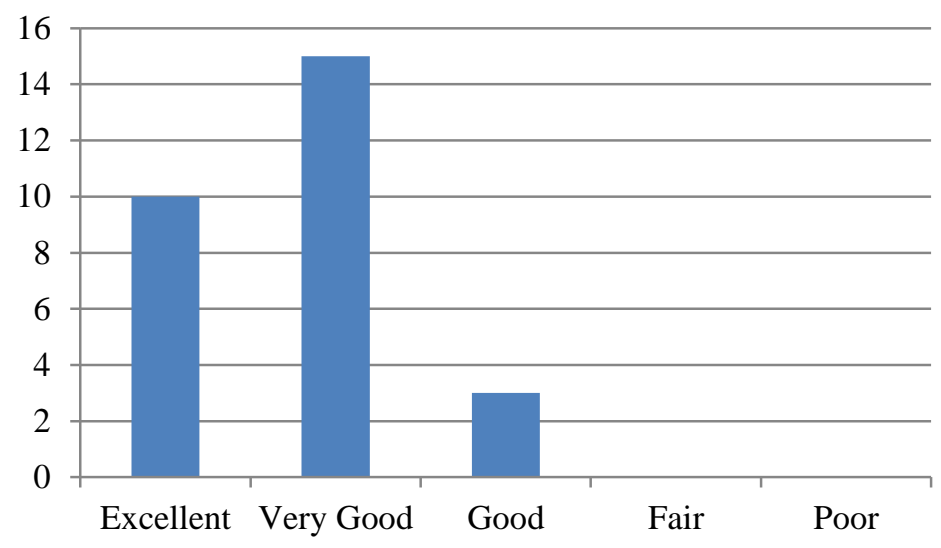

Figure B.3. Evaluation of workshop quality - "How would you rate the overall quality of the workshop?"

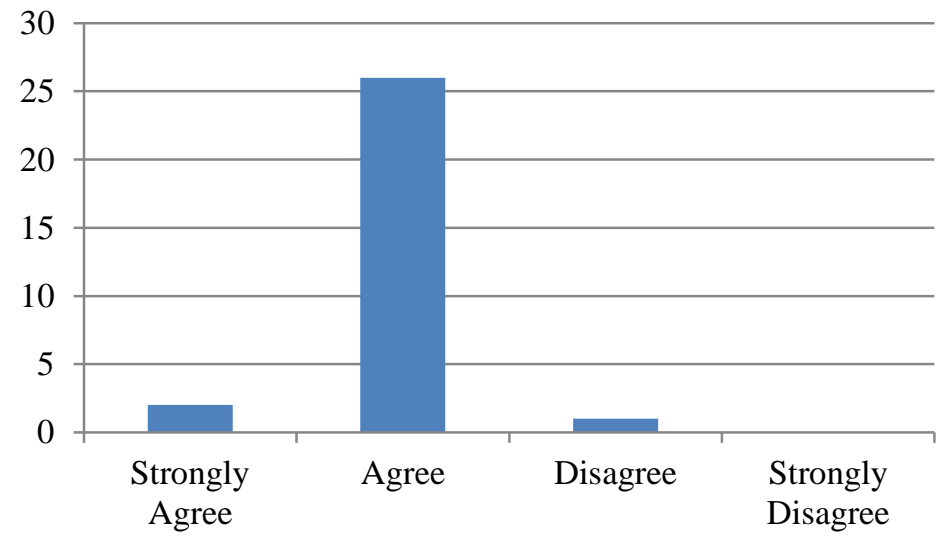

Figure B.4. Evaluation of workshop goals - "Were goals clear?"

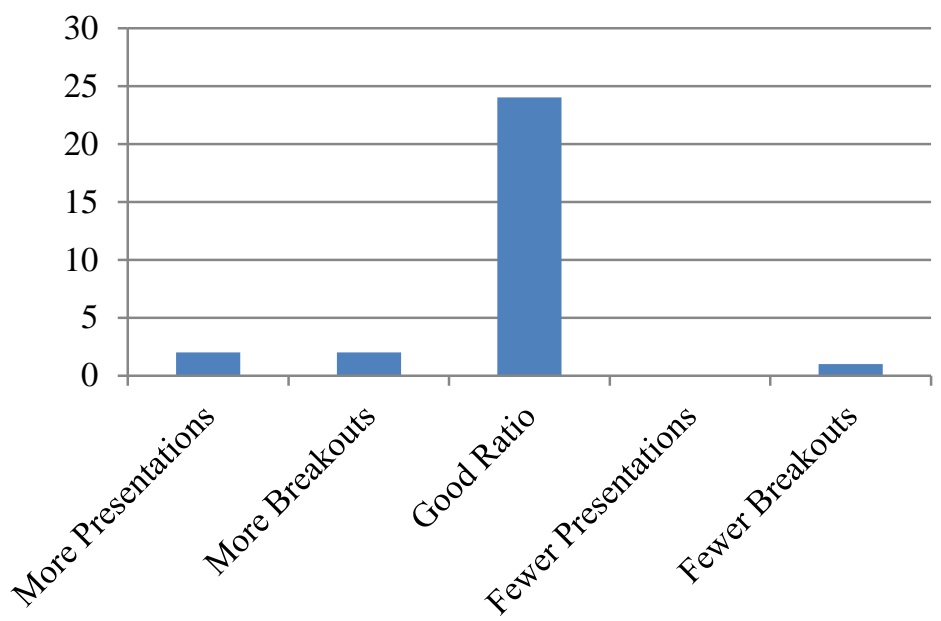

Figure B.5. Evaluation of time allocation - "How did you feel about the balance of time between presentations and breakout groups?" 


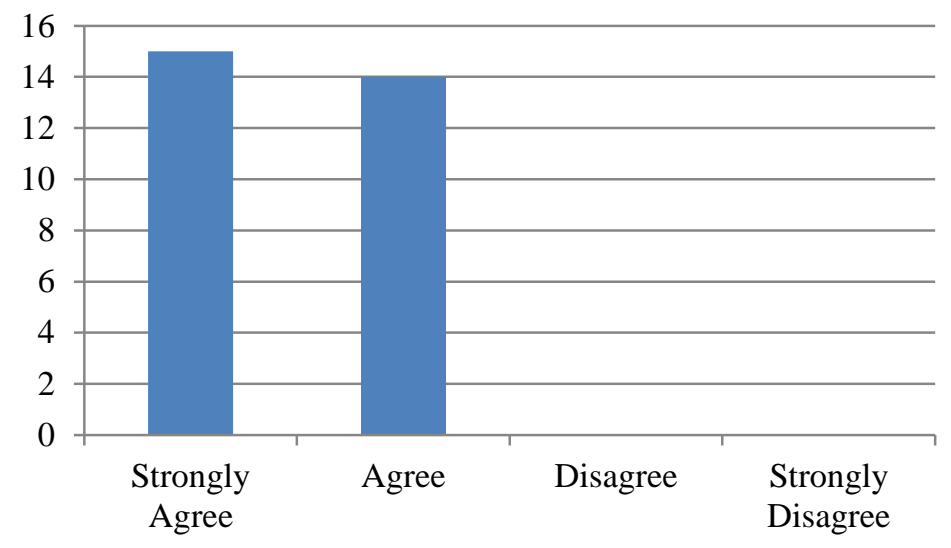

Figure B.6. Evaluation of information sharing - "Did the workshop design facilitate exchange of expertise among participants?"

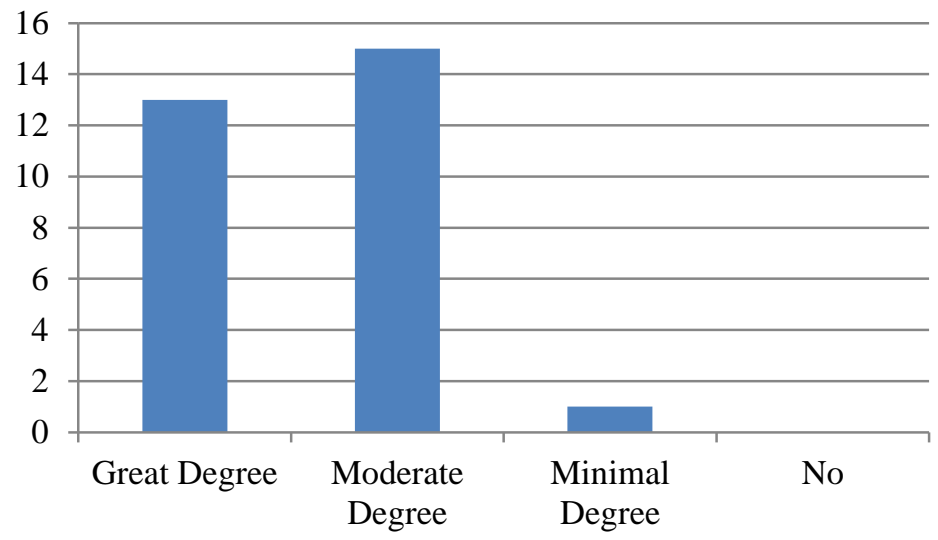

Figure B.7. Evaluation of workshop benefits - "Did the workshop improve your understanding of instrumentation needs, capabilities, and gaps?"

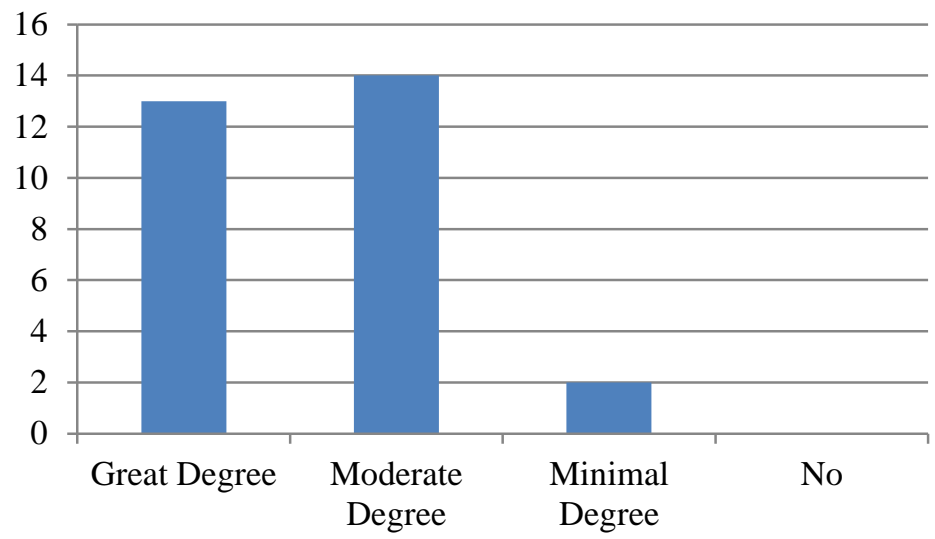

Figure B.8. Evaluation of workshop learning - "Did the workshop provide you with new viewpoints and insights?" 


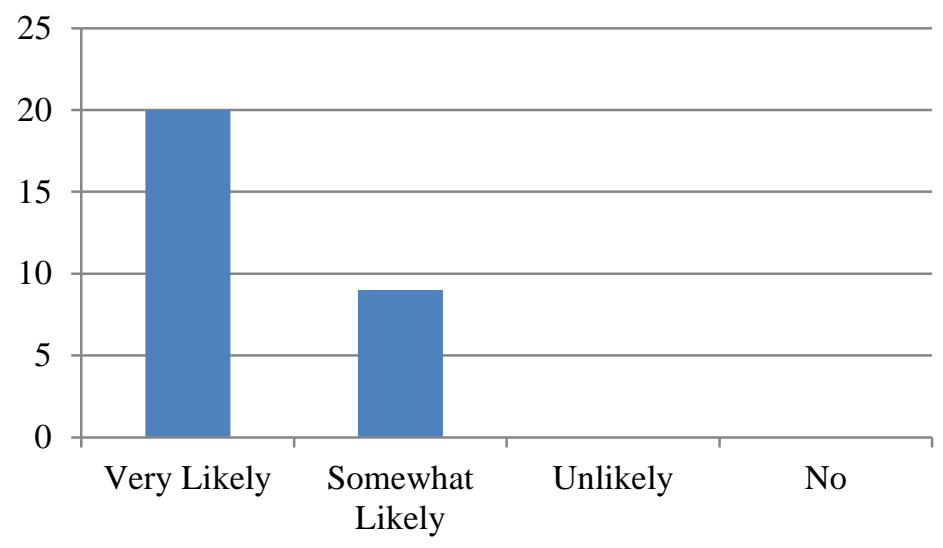

Figure B.9. Evaluation of applicability - "What is the likelihood that you would apply the information from this workshop to marine renewable energy projects?"

Workshop participants found the following to be most valuable:

- level of expertise represented by participants

- networking and interaction across sectors and geographies

- interdisciplinary approach.

Some workshop participants felt that filling out breakout session matrices was not particularly valuable, but many participants felt that every aspect of the workshop was valuable.

Recommendations for improvement in a similar, future workshop included the following:

- longer workshop

- narrower scope or additional bounding discussions

- more instrumentation developer participation, including hands on demonstrations.

Several participants commented on the high quality of logistics and level of organization associated with the workshop. 



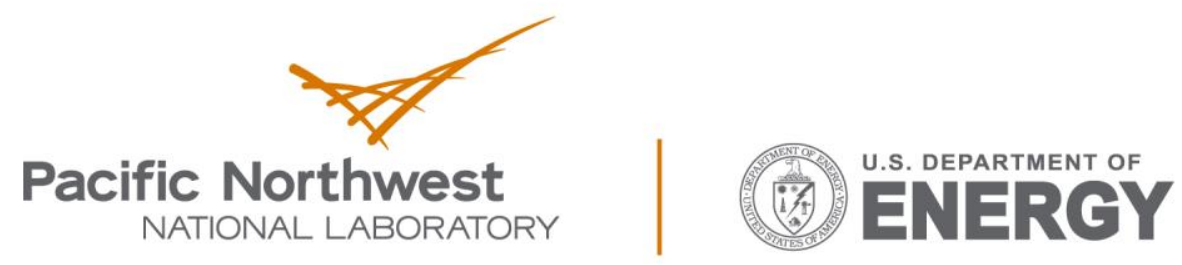

Proudly Operated by Battelle Since 1965

902 Battelle Boulevard

P.O. Box 999

Richland, WA 99352

1-888-375-PNNL (7665)

www.pnnl.gov 